

\section{PAPERS}

\section{Guest Editors: Marcus Richards, Ingrid Schoon}

197-200 Cognitive capital in the British birth cohorts: an introduction Marcus Richards, lan Deary

201-208 Setting the scene Gillian Sutherland

209-222 Family hardship and children's development: the early years Ingrid Schoon, Steven Hope, Andy Ross, Kathryn Duckworth

223-240 Progress and attainment during primary school: the roles of literacy, numeracy and self-regulation Kathryn Duckworth, Ingrid Schoon

241-258 Childhood cognitive ability and adult academic attainment: evidence from three British cohort studies Ingrid Schoon
259-280 Family income, education and cognitive ability in the next generation: exploring income gradients in education and test scores for current cohorts of youth Paul Gregg, Lindsey Macmillan

281-296 Health returns to cognitive capital in the British 1946 birth cohort

Marcus Richards, Alison Stephen, Gita Mishra

297-304 Cognitive capital: the case for a construct John Bynner and Michael Wadsworth

\section{NOTES, COMIMENTS AND DEBATE}

305-309 Historical note: early years of the 1946 British birth cohort

David Blane

310-311 Response to Historical note: early years of the 1946 British birth cohort Michael Wadsworth

\section{2-314 NEWS, EVENTS AND RESOURCES}

Longitudinal and Life Course Studies: Editorial Board

Executive Editor

John Bynner, Longview and Institute of Education, UK

\section{Health Sciences}

Section Editor

Michael Wadsworth, Longview, \& University

College, London, UK

Associate Editor

David Blane, Imperial College Medical School, UK

Social and Economic Sciences

Section Editor

Robert Erikson, University of Stockholm, Sweden

Associate Editors

Paul Gregg, University of Bristol, UK

John Hobcraft, University of York, UK

Karl Ulrich Mayer, Yale University, USA

Statistical Sciences and Methodology

Section Editor

Harvey Goldstein, University of Bristol, UK

Associate Editor

Bianca de Stavola, London School of Hygiene and Tropical Medicine, UK

Development and Behavioural Sciences

Section Editor

Barbara Maughan, Inst. of Psychiatry, Kings

College, UK

Associate Editor

Lars Bergman, University of Stockholm, Sweden

\section{Members}

Mel Bartley, University College London, UK; Paul Boyle, University of St. Andrews, UK; Nick Buck, University of Essex, UK; Richard Burkhauser, Cornell University, USA; Jane Costello, Duke University, USA; Tim Croudace, University of Cambridge, UK; George Davey-Smith, University of Bristol, UK; Lorraine Dearden, Institute for Fiscal Studies, UK; lan Deary, University of Edinburgh, UK; Glen Elder, University of North Carolina, USA; Peter Elias, University of Warwick, UK; Leon Feinstein, Cabinet Office, UK; Antony Fielding, University of Birmingham, UK; Andy Furlong, University of Glasgow, UK; Frank Furstenberg, University of Pennsylvania, USA; John Gray, University of Cambridge, UK; Rebecca Hardy, University College London, UK; Walter Heinz, University of Bremen, Germany; Marjo-Ritta Jarvelin, Imperial College London, UK; Heather Joshi, Institute of Education, UK; Kathleen Kiernan, University of York, UK; Harvey Krahn, University of Alberta; Di Kuh, University College London, UK; Carli Lessof, National Centre for Social Research, UK; Dean Lillard, Cornell University, USA; Jean Martin, University of Oxford, UK; Steve Machin, London School of Economics, UK; Robert Michael, University of Chicago, USA; Sir Michael Marmot, University College, London; Scott Montgomery, Karolinska University Hospital, Sweden; Jeylan Mortimer, University of Minnesota, USA; Brian Nolan, University College Dublin, Ireland; Lindsay Paterson, University of Edinburgh, UK; lan Plewis, University of Manchester, UK; Chris Power, Institute of Child Health, UK; David Raffe, University of Edinburgh, UK; Steve Reder, University of Portland, USA; Marcus Richards, Medical Research Council, UK; Amanda Sacker, University of Essex, UK; Ingrid Schoon, Institute of Education, UK; John Schulenberg, University of Michigan, USA; Jackie Scott, University of Cambridge, UK; Rainer Silbereisen, University of Jena, Germany; Chris Skinner, University of Southampton, UK; Heike Solga, Social Science Research Centre, Germany; Fiona Steele, University of Bristol, UK; Alice Sullivan, Institute of Education, UK; Kathy Sylva, University of Oxford, UK; Gert Wagner, German Institute for Economic Research, Germany; Chris Whelan, Economic \& Social Research Institute, Ireland; Richard Wiggins, Institute of Education, UK; Dieter Wolke, University of Warwick, UK

Published by Longview90 Mansfield Road, London, NW3 2HX Tel: 02074820788 Email: info@longviewuk.com www longviewuk.com 


\title{
Cognitive capital in the British birth cohorts: an introduction
}

\author{
Marcus Richards ${ }^{1}$ and lan Deary ${ }^{2}$ \\ ${ }^{1}$ MRC Unit for Lifelong Health and Ageing \\ ${ }^{2}$ University of Edinburgh, Centre for Cognitive Ageing and Cognitive Epidemiology, Department of Psychology \\ m.richards@nshd.mrc.ac.uk
}

(Received May 2010 Revised June 2010)

In 1903 Alfred Binet published L'Etude experimentale de l'intelligence (Experimental Study of Intelligence), following the aim of the French government to distinguish children who were not motivated to learn, from those whose capacity to do so was limited and who may require special education. Working with Théodore Simon, a physician, he developed tests of motor function, memory, and various aspects of verbal ability, such as naming, repetition, vocabulary and comprehension. With these graded measures, Binet and Simon instituted an approach that would become formalised into the concept of Intelligence Quotient (IQ), where a child's 'mental age' was estimated from performance in relation to that typical for a given chronological age. Thus began the practice of intelligence testing in children. Around the same time, a more theoreticallyoriented approach to capturing cognitive ability as a general capacity was being developed by Charles Spearman in London (Deary 2000; Deary, Lawn and Bartholomew 2008).

This first special issue of Longitudinal and Life Course Studies is based on a series of seminars on the determinants and consequences of childhood cognitive ability, referred to as cognitive capital in a comprehensive series of British population-based cohorts. The seminar series was funded by the Nuffield Foundation, and took place at their headquarters in London during 2007.

http://www.longviewuk.com/pages/children.shtml

The studies in this special issue are mainly oriented around the four British birth cohorts, which all recruited as survey members, those children across the country who were born within days of each other, so that any emerging developmental differences could not be attributable to differences in chronological age, or to changes over time in the environment. These cohorts were also designed to be as closely representative of the source national population as possible. The oldest cohort is that developed by the Medical Research Council National Survey of Health and Development (NSHD), also known by its year of birth as the British 1946 cohort (Wadsworth et al 2006, 2010). This was originally established to investigate the cost of childbirth and the quality of associated care in the immediate post-war years, when birth rates were continuing to fall, and at a time when serious health and social problems, as highlighted in the Beveridge report of 1942, precipitated the development of the modern welfare state. The NSHD was followed in time by the larger National Child Development Study and the British Cohort Study, respectively known as the British 1958 and 1970 birth cohorts. Finally, the youngest of the British birth cohorts is the eponymously named Millennium Cohort Study (for details of the three latter cohorts see the Centre for Longitudinal Studies website at

\section{http://www.cls.ioe.ac.uk}

Three other British cohorts drawn upon by the seminar participants should be mentioned here. One is the Avon Longitudinal Study of Parents and Children (ALSPAC) http://www.bristol.ac.uk/alspac). This originally consisted of mothers living in the old Avon (Bristol and Bath) area of south-west England, enrolled during pregnancy in 1991 and 1992, and of course their offspring. The other two cohorts are 
the multi-purpose and multi-aged British Household Panel Survey (BHPS):-

http://www.iser.essex.ac.uk/survey/bhps

and the government-based Longitudinal Study of Young People in England (LSYPE):-

https://ilsype.gide.net/workspaces/public/wiki/LSYPE also known as Next Steps.

So these are the resources; why the term cognitive 'capital'? This was defined during the seminar series as an "accumulating asset that can be drawn upon to create and to take advantage of opportunities and to sustain well-being, in response to environmental challenge and stress". Like its financial counterpart, cognitive capital can be endowed through inheritance; as O'Donovan and Owen (2009) note, "with its role in human adaptability and survival it would be remarkable if traits that result from variation in brain function were not influenced in part by genes". We should note, however, that the heritability of general cognitive ability is at its lowest in early life, at approximately $30 \%$ in very young childhood, increasing to as much as $70-80 \%$ in older adults (Deary et al 2009). This means, of course, that cognition is at its most malleable in infancy and childhood, being influenced by a vast range of factors, including nutrition, parental nurturing, material home conditions, the built environment, and schooling (Richards et al in press), though a portion of this influence can be attributed to parental genetic selection into the environment. Aspects of this malleability are the subject of the first of the empirical papers in this special edition (Schoon et al 2010). Like financial capital cognition is unequally distributed, particularly with respect to social position, a point to which we will return below. It can accrue over the life course (Richards and Deary 2005; Hatch et al 2007), with contributions via education, work, and healthy and stimulating lifestyle; and with returns by way of life chances, skills, wealth, health, and quality of life. It can also be drawn against in times of emergency, such as disease or trauma of the brain; this is the related if somewhat different concept of cognitive 'reserve' (Stern 2002; Richards and Deary 2005), another metaphor from economics. But, like a financial reserve, cognition can itself be depreciated, in the sense of impairment through a poor early start, chronic social disadvantage (Lynch et al 1997), self-harmful behaviours, and poor health (Richards and Deary 2005).
We do not attempt to summarise the history of the measurement of cognitive abilities in this Introduction. For this, the interested reader is referred to summaries provided elsewhere (Cooper 2010; Deary 2001a, b). Studies in this special edition do not address the detailed structure of intelligence, as variously represented by Spearman (1927), Thorndike (1927), Guilford (1967), Cattell (1971), Sternberg (1985) and Carroll (1993). Nor do they address the stage-based developmental 'genetic epistemology' of Piaget (Piaget and Inhelder 1973), or other models of cognitive skills that are qualitatively different to the psychometric tradition. This is appropriate in the context of the British birth cohorts, where cognitive ability was first measured in 1954 when children of the 1946 cohort were aged eight years, by four simple graded tests of vocabulary, pronunciation, comprehension, and analysis of non-verbal material devised by the National Foundation for Educational Research (NFER). James Douglas, who founded the 1946 cohort, was interested in educational returns to cognitive capital thus measured, and was influenced by the Scottish Mental Surveys (Deary, Whalley and Starr 2009). He found that those with test scores in anything but the highest range, were far less likely to enter selective secondary education if they were from manual occupational class households, than if they were from more professional households (Douglas 1964). This was referred to as the 'wastage of ability', as had already been highlighted in the Crowther Report (1959), and is returned to in detail by Schoon in this special issue of LLCS. This turned out to be the first of many policy-relevant and policy-influencing findings based on the measurement of cognitive capital in these cohorts.

The lives of British cohort members span almost the entire sweep of the post-war years, from 1946 through to the millennium; and at the time of writing a new national cohort is being commissioned for 2012. This span encompasses the formation of the post-Beveridge welfare state, as noted, including the National Health Service; the expansion of educational opportunity; the expansion then contraction of occupational mobility and the growth of income inequality; and changes in family structure, social participation, and gender roles (Ferri, Bynner, and Wadsworth 2003). To begin the special issue, this context is set by the historian Gillian Sutherland, who reviews these important structural changes, with a particular 
emphasis on educational policy. This is then followed by five research papers, proceeding along the life course, on the determinants and consequences of cognitive capital.

First, Schoon, Hope, Ross and Duckworth examine the effects of parental socio-economic conditions on the development of cognitive capital in infants, represented as everyday learning (for example, knowledge of colours, letters, numbers and objects). Drawing on the Millennium Cohort Study, they show that the negative effects of material hardship on cognitive development are partially mediated by maternal distress, and the impact this has on the quality of parenting; although mediating effects of the latter are stronger in regard to behavioural outcomes. Then, moving into primary education, Duckworth and Schoon examine continuity and change in Key Stage assessments of literacy and numeracy in ALSPAC. They find a high degree of continuity in attainment, but also some evidence of 'escaping' and 'dropping down' from expected trajectories, with measures of attention problems as a particularly important predictor in this respect. The narrative then shifts to the consequences of cognitive capital beginning with Schoon, who examines educational attainment in the 1946, 1958 and 1970 cohorts. She finds a fairly consistent level of association over these cohorts between parental socio-economic status and the highest level of educational qualification achieved, but a diminishing predictive power of cognitive capital - suggesting that it is the less able children of socially advantaged backgrounds who have benefitted the most from the expansion of educational opportunity. Linking the first and last of these papers, Gregg and Macmillan present evidence that such inequalities may be levelling off in those born in the 1980s and 1990s (using ALSPAC, BHPS and LSYPE), at least in regard to cognitive capital and to educational attainment by the minimum school leaving age. However, these authors caution that the picture may be different for higher education, and that the impact of changes at both these levels of educational attainment on future occupational mobility and earnings are difficult to anticipate.
Where most of these papers have implications for wealth, the final empirical paper, by Richards, Stephen and Mishra, investigates returns to childhood cognitive capital in an area of equal concern - health. Using the 1946 cohort they test associations between childhood cognition and adult cardiovascular disease risk, adding several missing pieces of the British adult birth cohort jigsaw in this respect. The question of health in relation to prior cognitive ability is a complex one; its antecedents are in the medical sociology of health in relation to education, but where education may best represent social pathways to health, cognition may provide a more sensitive marker of underlying biological processes, including those programmed in early life. Consistent with most other studies in the birth cohorts, these authors find that links between childhood cognitive capital and risk of cardiovascular disease are largely mediated by education; that is, cognitive development may be a necessary link in the life course chain to health, but it is not a sufficient one. There are interesting qualifications to this, of course, in this study and elsewhere.

In conclusion, the series of papers in this special edition highlights one of the most fascinating aspects of the British birth cohort studies: that these are in effect natural experiments, where changes in social structures, whether resulting from the implementation of policy or from shifts in cultural norms, alter the weight and relative balance of components that we think of as building blocks of the life course - early circumstances, cognitive development, schooling, progress or otherwise in the labour market, social roles, lifestyle, health and function, and quality of life. Such changes strongly apply in Britain, but other changes can also be tracked around the world. Cognitive ability conceptualised as capital helps to bring this alive, since factors that influence the accumulation of this particular form of wealth, and the purchasing power of the wealth itself, are, to borrow an image from Gillian Sutherland, a shifting kaleidoscope. If this special edition helps to maintain the impetus of this kind of research, then that in itself is an achievement. 


\section{Acknowledgements}

Marcus Richards is funded by the UK Medical Research Council (MRC). Ian Deary receives funding from the cross-Council Lifelong Health and Wellbeing Initiative (Biotechnology and Biological Sciences Research Council, Engineering and Physical Sciences Research Council, Economic and Social Research Council and MRC).

\section{References}

Carroll JB. (1993) Human cognitive abilities: a survey of factor analytic studies. Cambridge University Press, Cambridge, UK.

Cattell RB. (1971) Abilities: their structure, growth and action. Houghton Mifflin, Boston.

Cooper C. (2010) Individual differences and personality. ${ }^{\text {rd }}$ edition. Hodder, London.

Crowther Report. (1959) A report of the Central Advisory Council for Education. Her Majesty's Stationery Office, London.

Deary IJ. (2000) Looking down on human intelligence. From psychometrics to the brain. Oxford University Press, Oxford.

Deary IJ. (2001a) Intelligence: a very short introduction. Oxford University Press, Oxford.

Deary IJ (2001b) Human intelligence differences: a recent history. Trends in Cognitive Sciences, 5, 127-130.

Deary IJ, Lawn M and Bartholomew DJ. (2008) A conversation between Charles Spearman, Godfrey Thompson, and Edward L. Thorndike: the International Examinations Enquiry. History of Psychology, 11, 122-142.

Deary IJ, Johnson W and Houlihan LM. (2009) Genetic foundations of human intelligence. Human Genetics, $126,215-232$.

Deary IJ, Whalley UJ and Starr JM. (2009) A Lifetime of Intelligence: follow-up studies of the Scottish Mental Surveys of 1932 and 1947. American Psychological Association, Washington, DC.

Douglas JWB. (1964) The home and the school. Macgibbon and Kee, London.

Duckworth K and Schoon I. (2010) Progress and attainment during primary school: the roles of literacy, numeracy and self-regulation. Longitudinal and Life Course Studies, 1, 223-240

Ferri E, Bynner J and Wadsworth MEJ. (2003) Changing Britain, changing lives: three generations at the turn of the century. Institute of Education, London.

Hatch SL, Feinstein L, Link B, Wadsworth MEJ and Richards M. (2007) The continuing benefits of education: adult education and midlife cognitive ability in the British 1946 birth cohort. Journal of Gerontology Series B, 62, S404-S414.

Gregg P and Macmillan L. (2010) Family income, education and cognitive ability in the next generation: exploring income gradients in education and test scores for current cohorts of youth. Longitudinal and Life Course Studies, 1,261-282.

Guilford JP. (1967) The nature of human intelligence. McGraw-Hill, New York.

Lynch JW, Kaplan GA and Shema SJ. (1997) Cumulative impact of sustained economic hardship on physical cognitive, psychological and social functioning. New England Journal of Medicine, 337, 1889-1895.

O'Donovan MC and Owen MJ. (2009) Genetics and the brain: many pathways to enlightenment. Human Genetics, 126, 1-2 (editorial).

Piaget J and Inhelder B. (1973) Memory and intelligence. Basic Books, New York.

Richards $M$ and Deary IJ. (2005) A life course approach to cognitive reserve: a model for cognitive aging and development? Annals of Neurology, 58, 617-622.

Richards M, Stephen A and Mishra G. (2010) Health returns to cognitive capital in the British 1946 birth cohort. Longitudinal and Life Course Studies, 1, 283-298.

Richards M, Hatch SL and Kuh D. (in press). Early life, mental development, and mental aging. Journal of Gerontology Series $B$.

Schoon I. (2010) Childhood cognitive ability and adult educational attainment: evidence from three British birth cohorts. Longitudinal and Life Course Studies, 1, 241-260.

Schoon I, Hope S, Ross,A and Duckworth K. (2010) Family hardship and children's development: the early years. Longitudinal and Life Course Studies, 1, 209-222.

Spearman C. (1927) The abilities of man. Macmillan, London.

Stern Y. (2002) What is cognitive reserve? Theory and research application of the reserve concept. International Journal of the Neuropsychology Society, 8, 448-460.

Sternberg RJ. (1985) Beyond IQ: A Triarchic Theory of Intelligence. Cambridge University Press, Cambridge.

Sutherland G. (2010) Setting the scene. Longitudinal and Life Course Studies, 1, 201-208.

Thorndike EL. (1927) Measurement of intelligence. Bureau of Publications, Teacher's College, Columbia University, New York.

Wadsworth MEJ, Kuh D, Richards M and Hardy R. (2006) Cohort profile: the 1946 National Birth Cohort (MRC National Survey of Health and Development). International Journal of Epidemiology, 35, 49-54.

Wadsworth, MEJ. (2010) The origins and innovatory nature of the 1946 British national birth cohort study. Longitudinal and Life Course Studies, 1, 121-136. 


\title{
Setting the scene
}

\author{
Gillian Sutherland \\ Newnham College, University of Cambridge \\ gs10012@cam.ac.uk
}

(Received April 2010 Revised June 2010)

This is the historian as Greek chorus. Or, to switch metaphors, this is a brief, highly schematic sketch of the social and political context within which these studies have been conducted over the last half-century or so. The period in the United Kingdom since the end of the Second World War has seen major changes in social and economic structures and in health and education policies and practices. They have had and are having impacts which take time to emerge and are often difficult if not impossible to quantify or in any sense measure, yet cannot be left out of account. All the historian can do is to remind authors and readers of these long-run shifts. Perhaps the greatest use of this overview is the suggestions for additional reading which the references represent.

A first caveat must be to note the articificiality of generalising about 'Britain'. The regimes in Scotland and in Northern Ireland should be distinguished from those in England and Wales. The financial and economic structures of Northern Ireland continued to have colonial dimensions for much of the period. Three central decades, from the beginning of the 1970 s to the end of the 1990s, were marked by sectarian strife and the renewal of the 'dirty war'. It was only at the end of the 1990s that selective secondary schooling and the continuance of the 11+ examination began seriously to be called into question.

Scotland presents a very sharp contrast. Its educational structures had been distinctive throughout the nineteenth and twentieth centuries (Sutherland 1990) and patterns of mobility were more 'open' and less 'structured' than elsewhere in the United Kingdom (Hope 1984). Around Godfrey Thomson and the Scottish Council for Research into Education, a cluster of research workers and specialists had already begun to form in the decade immediately preceding the Second World War. The Scottish Mental Surveys of 1932 and 1947 were the pioneer large-scale studies. Ian Deary, Lawrence Whalley, John Starr and the groups they lead, have already built on these surveys and developed longitudinal studies from their baselines (Deary et al 2004). This overview, however, is confined to England and Wales. Although the cohort studies include Scotland and most recently Northern Ireland, the different histories and financial and economic structures severely limit the use of even the broad generalizations attempted here. Moreover since devolution in 1998-9, Wales has begun to diverge from England more and more. Within England, a North-South divide continues to have reality in some aspects of life, showing up, for example, in different patterns of mortality in older age groups (Le Grand and Vizard 1998). London, too, has a distinctive character and problems all its own (White 2001). These are qualifications which may need to be born in mind particularly when generalizing from ALSPAC (Avon Longitudinal Study of Parents and Children) data.

In one respect at least, the period immediately following 1945 offered the children in England and Wales an uncommon unity of experience. As far as nutrition was concerned, the society came closer to providing a level playing field for its young than it ever had before - or has since. Food rationing, which had been in existence since the beginning of the War, did not finally disappear till 1954 (Clarke 1996; Hennessy 2006). Meanwhile the 1944 Education Act had made it a duty of Local Education Authorities (LEAs) to provide school milk and meals (Gosden 1976). School milk was made free in 1946, to complement the introduction of family allowances.

Historians have found the death rate of infants under one year per thousand live births a reliable if rough guide to family living standards: between 1938 and 1965 it fell more or less steadily, from 53 to 19 (Mitchell and Jones 1971). By the early 1970s, 
the School Medical Service could comment in its valedictory report that the 'nutrition of children has greatly improved'; there was, however, a warning sign of another kind: 'some children are now malnourished from excess of food, especially carbohydrate foods' (Chief Medical Officer 1975). Free milk for children over seven had been withdrawn in 1971-2 and the subsidy to school meals sharply reduced. The battle lines are now drawn differently, concerned more with dietary value than absolute levels of provision, but school meals and what they might contribute to the nutrition of children continue to be a contested area.

Mention of family living standards broadens the discussion into a consideration of inequalities of income and the incidence of poverty, whether defined in absolute or in relative terms. In the broadest terms, there appears to have been a gentle but persistent decline in such inequality until the end of the 1970s, which had begun to show itself as early as the beginning of the 1920s. Thereafter the pattern changed and inequality increased again through the 1980 s and into the 1990s (Feinstein 1996; Jenkins 1996; Hills Report 2010). To sharpen the focus once more to look at the experience of children, governments since 1997 have succeeded only in flattening the trend. A 2006 survey for the Institute for Fiscal Studies showed $3.6 \mathrm{~m}$ children still living in families taking home less than $60 \%$ of average income - the official poverty line. In this respect Britain ranked fifth from bottom in Europe (Brewer et al 2006; Brewer et al 2009); and as one of the leading economic analysts of patterns of educational provision concludes, 'There remains a striking link between child poverty and school performance.' (Glennerster 1998).

The importance of these patterns is acknowledged by a number of contributors. Schoon, Ross, Hope and Duckworth make the point that a serious housing deficit was almost certainly a counter-weight to the positive impacts of rationing and school-feeding in the early years of the period. These authors write of the 'corrosive effect' of family hardship and conclude that the case for the eradication of child poverty remains strong (Schoon et al 2010; see also Hills 1998).

It is difficult to get far in discussion of inequality and poverty without some consideration of social class and mobility. Over the twentieth century as a whole the structures of social class, and thus the parameters for any measurement of mobility, have been affected by the absolute shrinkage of occupations requiring manual labour and the expansion of white-collar employment and the socalled 'service class'. As Halsey has commented, while the social structure at the beginning of the twentieth century was pyramidal in shape, by its last quarter it looked much more like a light-bulb (Halsey 1995). From mid-century, far more women also worked, for far more of their adult life. By $2000,69 \%$ of working-age women were in employment - only $10 \%$ less than the proportion for men of working age. Far more of these women were working part-time $-43 \%$, compared to $8 \%$ of the men (Gales and Marks 1974; EOC 2001). However, a small proportion of women found their way into high-status occupations, opening up a widening gap between themselves and their sisters on the periphery of the labour market (Dex et al 1996). There are some signs, too, that a similar gap is emerging between male unskilled and professional/managerial workers (Brewer et al 2009). The emergence of the small group of high status women employees also complicates the measurement of social mobility, in which women have seldom if ever been treated as independent actors: for so long, the key trajectory has been that between father's occupation and husband's occupation (Heath and Payne 1999).

Factoring in such variables has presented contributors with difficulties. Gregg and Macmillan go furthest in their acknowledgement that social class in the second half of the twentieth century is not a stable or unproblematic variable. They note the work commissioned by Alan Milburn, including the Hills Report, the consensus that the UK has a low level of mobility, rivalled only by the USA, and that inter-generational mobility has declined over the period under consideration. Their finding that the gradient of educational attainment at age 16 by family background, has lessened between generations born in the 1970s and those born in the 1980 s and early 1990s, thus appears to move counter to this. They note, however, the changes in the measurement of attainment, and the recurring question as to whether improvements in measured attainments reflect changes in real attainment. They are also hampered in establishing robust measures of social class, having to fall back at times on the crude proxy of free school meals (Schoon et al 2010). These authors are persistently and 
properly worried about the extent to which the patterns they discern are gendered. There is also the likelihood that gender and social class interact with each other, to produce a whole which is larger than the sum of the parts. Schoon in this issue has begun an engagement with this problem, by combining father's occupation with mother's level of education, in her measurement of Parental Social Status (SES). But much more might be done.

Such major socio-economic shifts form the backdrop against which health and education policies and practices must be set. The creation of the National Health Service (NHS) in 1948 could be said to contribute to more equal experience for both children and adults. For children, some groundwork had already been laid by the School Medical Service, first created in 1908. And there were many health professionals working with children, including the then Chief Medical Officer, Henry Yellowlees, who lamented the dissolution of this service with its particular expertise in 1974 (Chief Medical Officer 1975). The interface between paediatric and adult health care services remains a difficult one in which to find oneself, as either patient or parent.

However to acknowledge that the creation of the NHS marks a major change, is not to suggest that there was from then onwards either consistency of policy or of patterns of investment. The swings and roundabouts of successive policy and governmental changes over the first fifty years have been brilliantly, if polemically, analysed by Charles Webster, official historian of its creation (Webster 1998). More prosaically, the fluctuations in investment and in some measures of outcomes over the final quarter-century, have been charted, suggesting that 'Although spending on the NHS has risen more than demographic need factors alone would warrant, spending on the NHS (at least in volume terms) has risen significantly less than personal income, and public expectations, buoyed by technological advance, have not been fulfilled.' (Le Grand and Vizard 1998).

Changes in educational spending, structural provision and policies are amongst the factors having the most immediate impact on children and young people growing up. In the period since the Second World War, these exhibit a high degree of turbulence, and indicate a recurrent slowness amongst policy-makers to appreciate the importance of demographic shifts and their capacity to subvert the best-laid plans (Glennerster 1998).

Turbulence was less obvious in the third quarter of the twentieth century than it subsequently became. In the first three post-war decades, educational spending had been growing in real terms, by about $4 \%$ per annum. The period immediately following the end of the Second World War saw LEAs working to develop plans for 'secondary education for all', as required by the 1944 Education Act. Several gave some consideration to the common or comprehensive school option; but in the end, all but one, Anglesey, opted for selection at 11+. Some expansion of provision had already been begun by some authorities after 1936, in preparation for the raising of the school leaving age to 15 , on 1 September 1939 - in the event, postponed until after the War. A much larger expansion got underway in the late 40s and early 50s; and for many this has been seen as the golden age of school building (Saint 1987). However the expansion of the elite-track, selective secondary schools, most often known as grammar schools, proved insufficient to keep pace with the post-war baby boom. The supply of children grew even faster than the supply of grammar school places; and the cohort born 1943-52 were to find their chances of getting to grammar schools less good than those of the cohort born 1933-42 had been (Halsey et al 1980; Sanderson 1987). A challenge to selection at $11+$ gathered pace through the 1950s; and in 1965 Circular 10/65 invited LEAs to re-consider. Ironically, many of the schemes for comprehensive schools developed in response to this, did not take their final form till 1970-74, when Margaret Thatcher was Secretary of State for Education. It was also Thatcher and the Heath Government who raised the school-leaving age to 16 in 1972.

The break in the upward trend of spending came in the middle 1970s, hardly unconnected with broader economic problems and an increasing questioning across parties of existing provision. Between 1975-6 and 1988-9, the share of Gross Domestic Product (GDP) allocated to publiclyfunded education, fell from $6.5 \%$ to $4.7 \%$. In the 1990 s, there was some recovery to just above $5 \%$, where it has bumped along (Johnson 2004). The bleakness of this picture can be qualified by a rise in private spending on education; by the changing distribution of the resources that were available; 
and by a fall in the child population. However what emerges has been characterised as a picture of 'a quite extraordinary plateau in the volume of resources available to education for two decades, with a dip in the 1980s', a pattern unlike that in any other developed country in the period. (Glennerster 1998).

As has been noted, a fall in the child population 1975-85 gave primary and secondary schools some protection from the worst consequences of such resource pressure; the main sufferers, as we shall see, were those developing aspirations for some higher education. Maintained primary and secondary schools, however, had other pressures to deal with. Although the comprehensive model of secondary schooling spread, selection never disappeared entirely. Over 150 selective grammar schools remained, and remain, with the largest cluster in Kent, which has retained grammar schools and secondary modern schools throughout the entire period. In addition, the final decade of the twentieth century saw a return to selection at $11+$ more generally. The 1988 Education Act allowed the creation of grant-maintained schools, now 'foundation' schools. Voluntary-aided denominational schools, in which the Governing Body controls admissions, have begun to expand. Academies, each of which has a separate agreement with central government on its admissions policy, were first devised as a means of replacing 'failing' inner city schools.' Since the 2007 election however, they are beginning to be perceived by politicians as a more general tool. Symptomatic of the changed attitude towards academies has been the authorisation of a mixed academy in Hackney, sponsored by the Skinners' Company and HSBC, due to open in September 2010, replacing the Skinners' Girls School; although amongst the factors also playing a part here appear to be the problems of governmental structures for education in London since the abolition of the Inner London Education Authority (ILEA) at the end of the 1980s.

In the last quarter of the century, intense activity in modifying the structures of governance of schools was matched by intense activity on the curriculum front. The Education Act of 1988 introduced a National Curriculum for maintained primary and secondary schools, a move which commanded a fair degree of support. What proved much more controversial was the development of a national framework for its assessment, with externally prescribed and moderated tests at ages 7, 11 and 14, Key Stages One, Two and Three. The $16+$ examinations, the General Certificate of Education (GCE), were simultaneously being reshaped into the General Certificate of Secondary Education (GCSE), intended to be accessible to a much wider ability range and containing a significant amount of course work. The modularisation of A Levels in 2000 was to some degree a logical corollary of this. However a situation in which there has been tinkering with curriculum and examination requirements on an annual basis, and what has amounted to a governmental obsession with assessment, has generated dissension, fatigue - and teaching to the test. As several contributors recognise, this climate may serious affect the robustness of their findings on attainment levels (Duckworth and Schoon 2010; Gregg and Macmillan 2010).

For almost the first three quarters of the twentieth century, entry at age $11+$ to the elite track of a selective secondary school was the crucial gateway to upward mobility and to access to those expanding 'service class' occupations. Entry to the even more elite track of higher education was confined to so few during this period that it mattered less. In 1938 fewer than $2 \%$ of the $18+$ age group entered university; by 1961 this proportion had crept up to just over $4 \%$. In the last quarter of the century, however, the picture began to change and the crucial gateway to shift away from 11+ towards the ages of 16-19. The spread of comprehensive schools made some contribution to this, as did the raising of the school-leaving age to 16. Least well understood but undoubtedly important, were shifts in the aspirations of young people.

The provision of places in higher education was only intermittently responsive. In the late fifties and through the sixties, existing universities had begun a modest expansion and several new universities were founded. Anthony Crosland, the Secretary of State who had promulgated Circular 10/65, also attempted to diversify the provision of higher education, encouraging the creation of polytechnics, intended to offer a larger component of practical and applied work and with a closer relationship to the local and regional communities within which they were situated. In parallel went some enhancement of the status of teacher training 
colleges. By 1970 not quite $14 \%$ of the relevant age group were in some form of higher education.

The financial down-turn which began in the mid-1970s bit hard, however. By 1980, the proportion of the relevant age group in higher education had actually fallen, to $12.8 \%$; and it did not begin to rise again until the second half of the eighties. The second half of the seventies and the eighties were especially lean times for the older universities, as, despite pressure of numbers, budgets were cut and unit costs forced down by government. Other institutions of higher education suffered relatively less because - and this undoubtedly was one of their attractions - they were cheaper. In 1992 the formal position was transformed by the re-designation of almost all polytechnics as universities.

The combined effect of this, a reversal of policy on student numbers and some slight financial easement, meant that by 1994, John Major's Conservative government could boast that $30 \%$ of the age group was in higher education. From 1997 on, it was the declared objective of the Labour government to achieve entry to higher education for $50 \%$ of the age group; although economic recession since 2007 has prompted a major reconsideration. Such ambitions are not quite 'higher education for all'. But just as the secondary schools developed in the years after 1944 did not enjoy parity of esteem one with another, however loudly 'secondary education for all' was proclaimed, so it would be difficult to contend that all universities enjoy parity of esteem. What analysis of the student bodies there has been, suggests that students from social classes $D$ and $E$, and part-time and mature students, are heavily clustered in post1992 institutions; although the absolute shrinkage of the manual working class in the population as a whole has done something to modify the dominance of upper and upper middle class students among university entrants (Oxford Review of Education 1993; Glennerster 1998). Overall, too, expansion combined with declining resources, has brought a greater variability in degree quality and its perceived status in the last quarter of the century and beyond, than was the case earlier.

For those less likely to achieve advanced or higher educational qualifications, skills and vocational training eased transition into the labour force; these also underwent important changes during the relevant years of the adult British birth cohorts. The gold standard had been represented by apprenticeships for skilled manual workers. These were traditionally employer-based, but they came increasingly under central government control with the successive impacts of the 1964 Industrial Training Act, the Youth Opportunity Programme (YOP) of 1978 and the Youth Training Scheme (YTS) of 1983. These last two aimed at universal provision of training for those not in fulltime education or employment, but were widely perceived as little more than an alternative to unemployment (Dolton 1993). Such perceptions gained in strength and indeed in reality as governments moved away from a commitment to full employment as a policy goal in the fourth quarter of the century (Johnson 1991; O'Mahony 2004).

The second half of the twentieth century has thus seen major changes in the economic and social structure of the society and major shifts in policies, practices and investment in both health and education. The studies which follow in this issue of LLCS, have made determined efforts to grapple with these, as they locate their analyses. We should not, however, underestimate the problems of dealing with a context like a kaleidoscope, the patterns rearranged at each shake.

Finally, the kaleidoscopic patterns include the complex relationships between scholarly analysis and the perceptions and actions of policy-makers, which those scholars wishing to influence policy, neglect at their peril. While specialist work on the measurement of performance has continued to develop in sophistication, understanding and perceptions of this among the public at large and among policy-makers, has remained remarkably crude and almost static. Alison Wolf has in sharply polemical fashion drawn attention to the crudity of most policy-makers' notions of the relationship between education and economic growth (Wolf 2002, 2004). A similar polemic might be developed about policy-makers' understanding of work on the structures of the mind, cognitive skills and cognitive attainments. Two snapshots might illustrate this, one from the 1930s, the other from the end of the 1980s. The 1930s snapshot is taken from the discussions of the International Examinations Inquiry meetings, which were, exceptionally, recorded and transcribed verbatim. Centre stage were Spearman, Godfrey Thomson and EL Thorndike, giving in effect a 'psychometric master- 
class', exploring their own thinking about the processes involved and how far they differed from each other. Thomson in particular reflected on policy implications, of special interest to a mixed international audience of practitioners. The sophistication was immense - but there is a yawning gulf between this and the use of and powers attributed to group verbal reasoning tests in that decade and indeed in the ones that follow (Deary et al 2008; Sutherland 1984).

The 1980s snapshot - or perhaps it is a jerky bit of newsreel - concerns the fortunes of TEGAT, the report of the Task Group headed by Paul Black, on Assessment and Testing, commissioned by Kenneth Baker, as Secretary of State for Education, and submitted in December 1987. Baker and Thatcher had determined not only on the institution of a national curriculum but also of national testing. Black and his group had made a deliberate decision to try to respond in as sophisticated a fashion as possible, perhaps 'to educate our masters'. At the time, the late and much-missed Desmond Nuttall suggested that this was a mis-conceived strategy. Dealing with an administration which took the view that anyone who had been to school knew about education, he argued that the Group might have done better to go for minimalism, for a handful of very simple tests, which politicians could recognise. As English - if not Welsh or Scottish - primary and secondary schools still cope with the hybrid outcomes of the TEGAT report, who is to say that Nuttall was wrong?

To this, one might add the operation of something which at times looks like a 'law of unintended consequences' in dealing with large, complex and long-term pieces of social engineering - which health and education policies undoubtedly are. As Howard Glennerster, the analyst of the economics of education in the last quarter of the twentieth century, has commented, 'The results of the educational changes of the 1980s and 1990s will take a long time to come to harvest, for good or ill, just as did the changes of the 1960s and 1970s.' In March 2010 Nicholas Timmins, public policy editor of the Financial Times, analysed the mechanisms in play in the reduction of waiting times in the NHS, and offered the next government, whoever they might be, some advice: 'Whitehall is littered with policy failures. But it also has a fair number of unsung successes. Go back and examine them. Forget your prejudices, and learn from the experience.' (Timmins 2010). Perhaps history has its uses after all.

\section{References}

Brewer M, Goodman A, Shaw J and Sibieta L. (2006) Poverty and Inequality in Britain: 2006. IFS Commentary, London. http://hussonet.free.fr/povuk7.pdf

Brewer M, Muriel A and Wren-Lewis L. (2009) More unequal - but why? IFS Observation London. http://www.ifs.org.uk/publications/4713

Campbell J. (2000) Margaret Thatcher, volume 1, The Grocer's Daughter. p 228. Cape, London.

Chief Medical Officer. (1975) The School Health Service 1908-1974, Report of the Chief Medical Officer of the Department of Education and Science. pp 30, 1-3. HMSO.

Clarke P. (1996) Hope and Glory. Britain 1900-1990 pp 209-210. Allen Lane, Penguin, London.

Deary IJ, Whiteman MC, Starr JM, Whalley LJ and Fox HC. (2004) The impact of childhood intelligence on later life: following up the Scottish Mental Surveys of 1932 and 1947. Journal of Personality and Social Psychology, 86, 130-147.

Deary IJ, Lawn M and Bartholomew DJ. (2008) A conversation between Charles Spearman, Godfrey Thomson and Edward L. Thorndike: the International Examinations Inquiry meetings 1931-38. History of Psychology, 11 (2008), 122-142.

Dex S, Joshi H and Macran S. (1996) A widening gulf among Britain's mothers. Oxford Review of Economic Policy, 12, 65-75.

Dolton P. (1993) The economics of youth training in Britain. Economic Journal, 193, 1261-1278.

Duckworth $\mathrm{K}$ and Schoon I. (2010) Progress and attainment during primary school. Longitudinal and Life Course Studies 1, 223-240.

EOC: Equal Opportunities Commission. (2001) Facts about Women and Men in Great Britain. http://www.unece.org/stats/gender/publications/UK/Facts about W\&M GB 2006.pdf

Feinstein C. (1996) The Equalizing of Wealth in Britain since the Second World War. Oxford Review of Economic Policy, 12, 96-105. 
Gales K and Marks PH. (1974) 'Twentieth century trends in the work of women in England and Wales', Journal of the Royal Statistical Society, series A, 137, 60-74.

Glennerster H. (1998) Education: Reaping the Harvest? In The State of Welfare. The Economics of Social Spending. H Glennerster and J Hills eds. $2^{\text {nd }}$ edition, p 69; $\mathrm{p}$ 63. Oxford University Press.

Gosden PHJH. (1976) Education in the Second World War. A Study in Policy and Administration. pp 206-9. Methuen, London.

Gregg P and Macmillan L. (2010) Family income and education in the next generation: exploring income gradients in education for current cohorts of youth. Longitudinal and Life Course Studies, 1,261282.

Halsey AH, Heath A and Ridge JM. (1980) Origins and Destinations. Family Class and Education in Modern Britain. pp 45-47. Oxford University Press, Oxford.

Halsey AH. (1995) Change in British Society. From 1900 to the present day. $4^{\text {th }}$ edition. pp 29-56. Oxford University Press, Oxford.

Heath A and Payne C. (1999) Twentieth Century Trends in Social Mobility in Britain, Centre for Research into Elections and Social Trends, Working Paper No.70.

Hennessy P. (2006) Having It So Good. Britain in the Fifties. pp 9-11. Allen Lane, Penguin, London.

Hills J. (1998) Housing: A Decent Home within the Reach of Every Family? In H Glennerster and J Hills eds. The State of Welfare. The Economics of Social Spending $2^{\text {nd }}$ edition, Oxford University Press, Oxford.

Hills Report. (2010) An Anatomy of Economic Inequality in the UK: Report of the National Equality Panel. HMSO. http://www.equalities.gov.uk/pdf/NEP\%20Report\%20bookmarkedfinal.pdf

Hope K. (1984) As Others See Us. Schooling and Social Mobility in Scotland and the United States. Cambridge University Press, Cambridge.

Jenkins SP. (1996) Recent Trends in the UK Income Distribution: What Happened and Why? Oxford Review of Economic Policy, 12, 29-46.

Johnson C. (1991) The Economy under Mrs Thatcher. pp 235-49. Penguin, London.

Johnson P. (2004) Education policy in England. Oxford Review of Economic Policy, 20, 173-197.

Le Grand J and Vizard P. (1998) The National Health Service: Crisis, Change or Continuity? In H Glennerster and J Hills eds. The State of Welfare. The Economics of Social Spending $2^{\text {nd }}$ edition. pp 111-12. Oxford University Press, Oxford.

Mitchell BR and Jones HG. (1971) Second Abstract of British Historical Statistics. p.24. Cambridge University Press, Cambridge.

O'Mahony M. (2004) Employment, education and human capital. In R Floud and P Johnson eds. The Cambridge Economic History of Modern Britain, volume iii, Structural Change and Growth, 19392000. p. 114. Cambridge University Press, Cambridge.

Oxford Review of Education. (1993) 'Access to Higher Education', special issue.

Saint A. (1987) Towards a Social Architecture. The Role of School Building in Post-War England. Yale University Press, New Haven and London.

Sanderson M. (1987) Educational Opportunity and Social Change. Faber, London.

Schoon I, Hope S, Ross A and Duckworth K. (2010) Family hardship and children's development: the early years. Longitudinal and Life Course Studies, 1, pp 209-222.

Sutherland G. (1984) Ability, Merit and Measurement. Mental Testing and English Education 1880-1940. Oxford University Press, Oxford.

Sutherland G. (1990) Education. In FML Thompson ed. The Cambridge Social History of Britain 1750-1950. (vol. 3). Cambridge University Press, Cambridge.

Timmins N. (2010) Road to Recovery. Financial Times Magazine 13/14 March. London

Webster C. (1998) The National Health Service. A Political History. Oxford University Press, Oxford.

White J. (2001) London in the Twentieth Century. A City and its People. (paperback edition 2008). Viking, London.

Wolf A. (2002) Does Education Matter? Myths about Education and Economic Growth. Penguin, London.

Wolf A. (2004) Education and Economic Performance: Simplistic Theories and their Policy Consequences. Oxford Review of Economic Policy, 20, 315-333.

\section{Endnotes}

\footnotetext{
i For a snapshot on the eve of the 2007 election, see The Guardian Thursday March 16, 2006 p 13. (In voluntarycontrolled schools LEAs set the admissions policies.)
} 


\title{
Family hardship and children's development: the early years
}

\author{
Ingrid Schoon*, Steven Hope\#, Andy Ross\#, and Kathryn Duckworth* \\ *Institute of Education, London \\ \#National Centre of Social Research \\ I.Schoon@ioe.ac.uk
}

Received May 2010 Revised June 2010)

\section{Abstract}

Examining the factors and processes shaping school readiness provides important information about how to enable young children to develop their cognitive potential and to succeed in their school careers. The aim of this paper is to assess different mediating processes through which family hardship affects children's early development, both in terms of cognitive and behavioural adjustment. Using data from the UK Millennium Cohort, we examine the associations between persistent socio-economic hardship and young children's development, and investigate the role of maternal emotional distress, mother-child interactions, and cognitive stimulation as potential mediators, in a sample of 14661 children, who were followed from birth through age 3 years. Cognitive ability was assessed by standardized tests, and child behaviour by maternal report, when the children were 3 years of age. The findings suggest that persistent family hardship was significantly associated with child developmental outcomes. The impact of hardship on cognitive and behavioural adjustment is partially mediated by the level of maternal distress, which in turn shapes the quality of parent-child interactions and the provision of a cognitively stimulating home environment. The findings suggest differential pathways in the transmission of family disadvantage, where parenting characteristics were more important in mediating the effect of hardship on behavioural adjustment, than on early cognitive development. Findings are discussed in terms of their policy implications.

Characteristics of children at school entry, provide vital clues for predicting their performance during their school careers and for later development. Moving beyond a narrow view of school readiness defined by measures of children's cognitive capacities, more holistic approaches, including indicators of socio-emotional and behavioural adjustment, have shown to be more useful indicators of early functioning (Alexander 2009; Kagan 1992; Meisels 1999), as both the possession and implementation of skills are important. The development of cognitive, behavioural, physical, and socio-emotional capacities in the early years, forms the foundation of wellbeing, learning and behaviour across the life course and is crucial in shaping later developmental adjustment (Duncan et al 2007; Heckman 2006; Marmot 2010; McLoyd 1998; Rutter 1989). Previous research has shown that differences in capabilities that exist at the beginning of school are likely to perpetuate over time (Entwistle and Alexander 1999; Feinstein and Bynner 2004; Schoon 2006). Indeed the early years have been identified as 
a crucial window for interventions, a sensitive period for skill formation (Heckman 2006), especially regarding cognitive development (Sameroff, Seifer, Baldwin and Baldwin 1993; Schuerger and Witt 1989). Gaining a better understanding of early influences on school readiness, is thus vitally important in enabling young children to fully develop their potential. In the following, we adopt a more holistic view of school readiness, focusing on both cognitive and behavioural outcomes, and examine the role of family hardship in influencing the child's development in the first three years of life. Both academic and behavioural adjustment are understood as markers of key capabilities at school entry, enabling the child to meet the demands of schooling (Janus and Duku 2007; Lloyd and Hertzman 2009). We furthermore examine the role of parent characteristics and parent-child interactions as mediators impacting on the association between hardship and child adjustment, in order to identify potential protective mechanisms and processes enabling children to strive against the odds.

\section{Socio-economic adversity and early adjustment}

There is ample evidence of the association between family hardship and children's cognitive and behavioural development (Bradley and Corwyn 2002; Duncan and Brooks-Gunn 1997; Keating and Hertzman 1999). Relative few studies, however, have focused on early childhood (Linver, Brooks-Gunn and Kohen 2002; Kiernan and Huerta 2008; Kiernan and Mensah 2009; Robila and Krishnakumar 2006; Waldfogel and Washbrook 2010), when the effects of material hardship appear to be strongest (BrooksGunn and Duncan 1997; Korenman, Miller, and Sjaastad 1995; Plewis and Kallis 2008). There is evidence to suggest that cognitive development in the early years is malleable in response to environmental conditions. For example, in a study based on a sub-sample of the 1970 British cohort study, Feinstein (2003) showed that differences in cognitive development associated with income inequalities, emerge as early as 22 months. The gap appeared to widen as children aged, and around age 6 , children in the highest achieving group, with parents in the least privileged socio-economic group, were overtaken by children from advantaged backgrounds, who were in the low-achieving group at age 22 months. Studies drawing on data collected for the most recent UK Millennium Cohort, confirm the corrosive effects of poverty on children's cognitive development, as well as their psycho-social adjustment in early childhood (Blanden and Machin, 2010; George, Hansen, and Schoon, 2007; Kiernan and Huerta, 2008; Kiernan and Mensah 2009; Waldfogel and Washbrook 2010). Furthermore, research findings based on the British Cohort Studies, highlight that early disadvantage can have important consequences and undermine later achievements. The experience of family hardship in the early years, undermines early cognitive development and psychosocial adjustment, which in turn influences later attainments, as shown in follow-up studies of the 1958 and the1970 cohort (Bynner and Joshi 2002; Bynner, Schuller and Feinstein 2003; Feinstein 2004; Feinstein and Vignoles 2008; Schoon 2006; Schoon et al 2002).

\section{Beyond income}

Much of the research to date on poverty effects on child development has focused on the effects of income (Blanden and Gregg 2004; Blanden and Machin 2010; Waldfogel and Washbrook 2010); (see also Gregg and Macmillan in this Special Issue). This is not surprising, given that income poverty rates in the UK remain high. At the turn of the Millennium about 26 per cent of children lived in households with an equivalised houshold income below 60 per cent of the national median. Between 1998/9 and 2004, this rate fell to 21 per cent, but has increased to 23 per cent in 2009 (Hills, Sefton and Steward,2009; Maclnnes, Kenway and Parekh 2009). Given the persistence of extreme poverty even in highly developed countries, it is essential for developmental scientists to learn more about the impact of poverty and material hardship on families and children living today.

In analysing effects of poverty on children's development, one should however not forget about the families whose income is considered as 'low income' just above the threshold of the poverty line. Children in these low income families experience many of the same hardships as children in families defined as income poor, such as housing insecurity, overcrowding, lack of amenities, or dependence on state benefits to make ends meet. Consideration of 
the linked contributions of family income and material hardship has thus been recommended to gain a better understanding of the corrosive effects of family poverty on children's development (Gershoff, Aber, Raver and Lennon 2007; Plewis and Kallis 2008; Yeung, Linver and Brooks-Gunn 2002).

\section{Mediating processes}

Although the association between family hardship and child development is well documented, the ways in which the experience of socio-economic hardship influences children's development have been less well studied. Family interactions, neighbourhood processes, and child-care quality have been shown to mediate the effect of family hardship on child development, illustrating the contextualized nature of early child development (Brooks-Gunn and Duncan 1997; McLoyd 1994; McLoyd and Flanagan 1990). There is evidence of promising effects of early intervention programs, such as Sure Start in the UK, which can improve the life chances of young children (Melhuish, Belsky, Leyland, and Barnes, 2008). Indeed, there is persistent research evidence to suggest that early developmental trajectories can change over time (Feinstein 2003; Rutter 1989; Schoon 2006). It is thus vital to learn more about the factors and processes that can potentially ameliorate the negative impact of poverty on children's early development. For example, economic hardship has a differential effect on specific child outcomes, generally exhibiting a stronger effect on children's cognitive development than on behaviour (Conger and Elder 1994; Kiernan and Huerta 2008; Kiernan and Mensah 2009; Linver et al 2002; Plewis and Kallis 2008; Schoon, Cheng and Jones 2010). We thus will examine the pathways linking family hardship to cognitive and behavioural adjustment separately. The lack of understanding of how the experience of hardship influences child development, has greatly hampered the ability of policy makers to design effective interventions to improve children's development and wellbeing.

Theoretical models linking the experience of material hardship to child outcomes have focused in particular on the mediating role of family psychological stress (Conger and Elder 1994; Mistry, Biesanz, Taylor, Burchinal and Cox 2004; Yeung et al 2002), parent's investments of time or money in their children (Guo and Harris 2000), or a combination of these factors (Gershoff et al 2007; Kiernan and Mensah 2009; Linver, Brooks-Gunn and Kohen 2002; Yeung et al 2002). The family investment model asserts that income is associated with children's development, because it limits the amount of resources, including money, time, energy, and support, they have available for their children (Becker and Thomes 1986; Haveman and Wolfe 1994; Mayer 1997). It does however, not specify how economic circumstances might impact the quality of parentchild interactions. The family stress model, on the other hand, postulates that family hardship influences children's cognitive development and behaviour through parental emotional distress resulting from financial strain, which negatively influences parenting practices, which are in turn associated with poorer child outcomes (Conger, Ge, Elder, Lorenz and Simons 1994; Conger et al 1992, 1993; Elder and Caspi 1988; McLoyd 1989; McLoyd 1994). It has also been shown that parental psychological distress impacts on parent's abilities or willingness to invest in their children, suggesting the appropriateness of combining both models (Gershoff et al 2007; Kiernan and Huerta 2008; Linver et al 2002; Yeung et al 2002). However, there is also evidence to suggest that different components of the family environment may have differential effects on child outcomes. While the provision of stimulating experiences in the home environment is shown to be more strongly associated with children's cognitive development than with behavioural adjustment, parent-child relations were more strongly associated with children's behaviour (Linver et al 2002; Kiernan and Huerta 2008). It is thus important to differentiate between cognitive and emotional components of parenting, and to assess their relative impact on child adjustment.

In the following we will test the usefulness of combining the family stress and investment model to explain variations in early adjustment, by drawing on data collected for the UK Millennium Cohort. We will assess the relative sizes of associations when considering several aspects simultaneously, as well as in their separate effects. Adding to the existing few studies examining the mediating processes by which family economic hardship influences cognitive and behavioural development of young children, we will take into account the effects of persistent hardship 
and persistent maternal stress during early childhood, and their impact on school readiness and behavioural adjustment by age 3 . In addition, instead of focusing on household income (Kiernan and Mensah 2009), we take into account material resources available to the family at age 9 months and 3 years, to account for persistence of family hardship. Furthermore, we conceptually differentiate between proximal and distal processes (Bronfenbrenner 1979), following the assumption that the strongest influence on children's development are processes and interactions directly experienced by the child, such as parenting behaviour. Distal characteristics, such as family income and material hardship, impact on children insofar as they shape these proximal processes. Furthermore, we take account of a number of background, or control variables to ensure that the predicted findings were not spurious. It has been argued that economic hardship has little, or no, direct effect on children's outcomes, which are largely due to other characteristics of the parents, such as parental education (Rowe and Roger 1997). We thus control for maternal education, as well as maternal age, ethnicity, marital status at birth, total number of siblings living in the household, sex of the child, low birthweight (<2500 grams) and prematurity. Including these basic demographic characteristics in the model gives greater confidence in the links between the variables included in the model.

Following from previous research, we tested the following hypotheses: a.) family hardship is directly associated with child outcomes, although the association may vary across different outcomes, i.e. cognitive and behavioural adjustment; b.) the association between family hardship and child outcomes persists after controlling for sociodemographic characteristics of the family and biological risk factors; c.) the association between family hardship and child outcomes is mediated by i.) constructs of the family stress model; ii.) the family investment model; iii.) by the combination of both models.

\section{Method}

\section{Sample}

The study draws on data collected for the Millennium Cohort Study (MCS), a survey of 18,819 babies born between September 2000 and January
2002 into 18,553 families living in the UK (Dex and Joshi 2005). The first sweep of the Millennium Cohort Study was carried out during 2001 and 2002 when most babies were 9-months old. The sample design allowed for disproportionate representation of families living in areas of child poverty. Electoral wards based on 1998 geography were used as the sampling frame and information about child poverty was incorporated as provided in the Index of Deprivation (Noble et al 2000). Due to disproportionate sampling, special weights have to be applied in analyzing the data (Plewis, Calderwood, Hawkes, Hughes, and Joshi 2004).

Data were collected from the parents of the babies via personal interview and self-completion questionnaire, as well as direct assessment of children's cognitive abilities (Plewis et al 2004; Shepherd, Smith, Joshi and Dex 2004). The following analyses are based on 14,661 singleton babies, with data from the 9 and 36 month data collection sweeps.

\section{Measures}

\section{Focal variable: material hardship}

An index of family material hardship was created, based on five indicators assessed at both age 9 months and 3 years, including low net household income [less than $£ 10,400$ per annum, which represents the bottom quartile], receipt of income support (a means-tested benefit), access to a car or van, as well as housing-based measures including home ownership and overcrowding [more than one person per room]. The individual items were dichotomised to create a summary hardship index for each time point, with an observed range of 0 to 5 . Scale values of four and five were combined due to small numbers, and indicate severe levels of hardship, while a score of 0 indicates lack of hardship. There was a strong correlation between reported hardship at the two ages $(r=0.81)$.

\section{Mediating variables}

Maternal emotional distress was assessed when the child was 9 months and 3 years old. At age 9 months (in 2000/1) a shortened 9-item version of the Rutter Malaise Inventory (Rutter, Tizard and Whitmore 1970) was used. The Malaise Inventory is a selfcompletion measure that has been widely used as a measure of depression, anxiety and psychosomatic 
illness in general population studies (McGee, Williams and Silva 1986; Rodgers, Pickles, Power, Collishaw and Maughan 1999) as well as in investigations of high-risk groups, notably informal carers (Grant, Nolan, and Ellis 1990). The shortened scale ranges from 0 to 9 , has acceptable internal consistency (Cronbach's alpha $=.73$ ), and correlates significantly with previously diagnosed and currently treated depression.

At age 3 (in 2003/4) the 6 item Kessler psychological distress scale (K6) was used for the identification of maternal anxiety and depression. The K6 is a widely used screening instrument, which has been especially developed for use in population surveys (Kessler et al 2002). Responses are given on a four-point Likert scale and are summed to produce a uni-dimensional scale (alpha for the $\mathrm{MCS}=0.86$ ) with a range of 0 to 24 . The two measures of psychological distress are moderately correlated $(r=0.47)$.

Parent-child relationship was assessed at age 3 years using the Pianta scale (Pianta 1992), a 15 item selfadministered rating scale with responses on a 5-point Likert scale. A total score was derived, with a high score reflecting an overall positive relationship. The alpha coefficient for the Pianta scale in the MCS sample was .77 .

Cognitive stimulation at age 3 years was measured on the basis of maternal report on whether the child was read to, taught the alphabet, counting or songs, at least once a week, and whether the parents took the child on visits to the library. The five items were summed to an index of cognitive stimulation ranging from 0 to 5 .

\section{Child Outcomes at age 3}

School Readiness was assessed with the Bracken School Readiness Assessment (BSRA) which was individually administered to each child. The BSRA comprises six subtests measuring children's knowledge of colours, letters, numbers, sizes, comparisons of objects, and shapes (Bracken 2002). It is a developmentally sensitive measure of children's basic concept acquisition and receptive language skills, designed for children ages two and a half through to age seven. The BSRA has strong psychometric characteristics and good validity (Panter and Bracken 2009). In the following analysis we use age-standardised scores.

Behavioural adjustment is measured with the Strength and Difficulties Questionnaire (SDQ), a behavioural screening questionnaire for 3 to 16 years olds (Goodman 1997, 2001). It consists of 25 items, assessed via parental report, generating an overall scale score as well as scores for five subscales: conduct problems, hyperactivity, emotional symptoms, peer problems and pro-social behaviour. For the following analysis, an overall difficulties mean score for the whole sample, was computed by summing replies to the subscales indicating behaviour problems, i.e. conduct problems, hyperactivity, emotional symptoms, and peer problems.

\section{Control variables}

A number of control variables were included in the analysis to make sure that the results are not spurious:

- Mother's age at birth of child

- Mother's marital status at the birth of the child

- Mother's education (below GCSE versus GCSE and above)

- Mother's ethnicity (white versus other)

- Total number of children living in household

- Baby gender (male, female)

- Prematurity (gestation period less than 37 weeks)

- Low birthweight (less than 2500 grams)

\section{Analytic Strategy}

Structural equation modeling was used to assess the pathways linking family hardship to children's developmental outcomes at age 3 years. All analyses were carried out using the statistical package Mplus 5 (Muthén and Muthén 2007). This method allows analysis of cases with missing data under the assumption that the data are missing at random (Little and Rubin 2002). Probit regressions were used based on robust weighted least squares estimation. Because some of the dichotomised variables functioned as both independent and dependent variables in the conceptual model, the theta 
parameterization was necessary. Regression estimates convert probit estimates for ordinal dependent variables to a common metric that allows comparison with standardised linear regression estimates for the continuous variables.

In line with current practice, several criteria were used to assess the fit of the data to the model. The $\chi^{2}$ statistic is overly sensitive to model mis-specification when sample sizes are large, or the observed variables are non-normally distributed. The root mean square error of approximation (RMSEA) gives a measure of the discrepancy in fit per degrees of freedom (e.g. values less than .05 indicate a good fit). The final index of choice is the comparative fit index (CFI), indicating if the model provides significantly better explanation of the relations between variables than the null hypothesis-model with no relations between variables. Values above .95 indicate an acceptable fit (Bentler 1990).

In a first step, bivariate Pearson's correlations between variables were calculated. Table 1 shows means, standard deviations and correlations between variables under study. In the next step the authors investigated the association between family adversity and child outcomes as well as mediator effects for cognitive and behavioural adjustment separately. To decompose the relative impact of family hardship, control variables, and mediating variables, we tested separate models. Model a establishes the direct link between hardship and child outcomes. Model $b$ adds the control variables, and model c, the mediating variables. This analysis sequence allowed the examination of whether the relationship between family hardship is partially or fully mediated by the addition of the control variables and the mediators. Furthermore, different models were tested to assess whether family stress constructs, a parental investment measure (i.e. cognitive stimulation), or both, act as mediators of the relations between family hardship and child outcomes. 
Table 1: Means, Standard Deviations, and bivariate Pearson Correlations between variables included in the model

\begin{tabular}{|c|c|c|c|c|c|c|c|c|c|c|c|c|c|c|c|c|c|c|}
\hline Variables & 1 & 2 & 3 & 4 & 5 & 6 & 7 & 8 & 9 & 10 & 11 & 12 & 13 & 14 & 15 & 16 & $M$ & $S D$ \\
\hline $\begin{array}{l}\text { 1. Material } \\
\text { hardship ( } 9 \\
\text { mths) }\end{array}$ & 1.00 & & & & & & & & & & & & & & & & 1.06 & 1.38 \\
\hline $\begin{array}{l}\text { 2. Material } \\
\text { hardship } \\
\text { (36 mths) }\end{array}$ & $.81^{* *}$ & 1.00 & & & & & & & & & & & & & & & 0.96 & 1.33 \\
\hline 3. Bracken & $-.34 * *$ & $-.34 * *$ & 1.00 & & & & & & & & & & & & & & 103.69 & 16.29 \\
\hline 4. SDQ & $.31^{* *}$ & $.31 * *$ & $-.29 * *$ & 1.00 & & & & & & & & & & & & & 9.55 & 5.26 \\
\hline $\begin{array}{l}\text { 5. Malaise } \\
\text { ( } 9 \text { months) }\end{array}$ & $.18^{* *}$ & $.18^{* *}$ & $-.10 * *$ & $.28^{* *}$ & 1.00 & & & & & & & & & & & & 1.67 & 1.76 \\
\hline $\begin{array}{l}\text { 6. Kessler } \\
\text { (36 mths) }\end{array}$ & $.25^{* *}$ & $.27^{* *}$ & $-.17^{* *}$ & $.36^{* *}$ & $.47^{* *}$ & 1.00 & & & & & & & & & & & 3.54 & 3.86 \\
\hline 7. Pianta & $-.19 * *$ & $-.18 * *$ & $.17^{* *}$ & $-.61 * *$ & $-.27 * *$ & $-.37 * *$ & 1.00 & & & & & & & & & & 64.51 & 6.86 \\
\hline $\begin{array}{l}\text { 8. Cogn } \\
\text { stimulation }\end{array}$ & $-.15^{* *}$ & $-.15^{* *}$ & $.26^{* *}$ & $-.17^{* *}$ & $-.06 * *$ & $-.09 * *$ & $.11^{* *}$ & 1.00 & & & & & & & & & 3.74 & 0.99 \\
\hline $\begin{array}{l}\text { 9. Maternal } \\
\text { ethnicity }\end{array}$ & $-.18 * *$ & $-.15^{* *}$ & $.21 * *$ & $-.10 * *$ & $-.05 * *$ & $-.12 * *$ & $.02 *$ & $.13^{* *}$ & 1.00 & & & & & & & & 0.85 & 0.54 \\
\hline $\begin{array}{l}\text { 10.Maternal } \\
\text { age }\end{array}$ & $-.42 * *$ & $-.40 * *$ & $.18^{* *}$ & $-.23 * *$ & $-.08 * *$ & $-.12 * *$ & $.15^{* *}$ & $-.05 *$ & $.04 * *$ & 1.00 & & & & & & & 28.66 & 5.87 \\
\hline $\begin{array}{l}\text { 11.Maternal } \\
\text { education }\end{array}$ & $-.41 * *$ & $-.40 * *$ & $.29 * *$ & $-.24 * *$ & $-.09 * *$ & $-.15^{* *}$ & $.11^{* *}$ & $.18^{* *}$ & $.17^{* *}$ & $.18^{* *}$ & 1.00 & & & & & & 0.77 & 0.42 \\
\hline $\begin{array}{l}\text { 12. Married } \\
\text { at birth }\end{array}$ & $-.59 * *$ & $-.53 * *$ & $.17^{* *}$ & $-.18^{* *}$ & $-.09 * *$ & $-.15^{* *}$ & $.12^{* *}$ & $.06^{* *}$ & $.03 * *$ & $.29 * *$ & $.21^{* *}$ & 1.00 & & & & & 0.83 & 0.37 \\
\hline $\begin{array}{l}\text { 13. Nr of } \\
\text { children }\end{array}$ & $.13^{* *}$ & $.12^{* *}$ & $-.23 * *$ & .01 & $.06 * *$ & $.06 * *$ & $.06 * *$ & $-.14 * *$ & $-.12 * *$ & $.32 * *$ & $-.19 * *$ & $.04 * *$ & 1.00 & & & & 0.94 & 1.06 \\
\hline $\begin{array}{l}\text { 14. Birth- } \\
\text { weight low) }\end{array}$ & $.06 * *$ & $.06 * *$ & $-.07 * *$ & $.06^{* *}$ & $.04 * *$ & $.05^{* *}$ & $-.02 *$ & $.03 * *$ & $-.09 * *$ & -.01 & $-.06 * *$ & $-.03 * *$ & -.05 & 1.00 & & & 0.06 & 0.24 \\
\hline $\begin{array}{l}15 . \\
\text { Gestation } \\
\text { (premature) }\end{array}$ & $.03 *$ & $.03 * *$ & $-.04 * *$ & $.04 * *$ & $.03 *$ & $.04 * *$ & -.01 & .00 & -.01 & -.00 & -.01 & $-.02 *$ & -.01 & $.50 * *$ & 1.00 & & 0.07 & 0.25 \\
\hline $\begin{array}{l}\text { 16. Gender } \\
\text { (female) }\end{array}$ & .00 & .01 & $.12^{* *}$ & $-.10 * *$ & $-.02 *$ & -.01 & $.06 * *$ & $.07 * *$ & -.01 & .00 & .01 & .00 & .00 & $.02+$ & -.01 & 1.00 & 0.49 & 0.50 \\
\hline
\end{tabular}




\section{Results}

Figure 1 shows the structural equation model assessing the pathways linking family hardship to school readiness. The usual structural equation modeling conventions are used, depicting latent variables as a circle, and manifest variables in rectangles. The two latent variables comprise indicators of family hardship on the one hand, and maternal distress on the other, providing measures of persistent hardship and persistent distress, averaging the experiences at age 9 months and 3 years. Unique and error variance for each manifest variable and disturbance on the latent variables are included in the model (not shown in the diagram). Path estimates are given as standardised regression coefficients, that may be squared to obtain the variance shared by adjacent variables. All paths in the model were significant at the $5 \%$ level (parameter estimates divided by their standard errors), and the model provides a good fit to the data.

Figure 1. Predicting school readiness at age 3: the full model

(a. no mediators no controls, b. no mediators with controls, c. with mediators and controls)

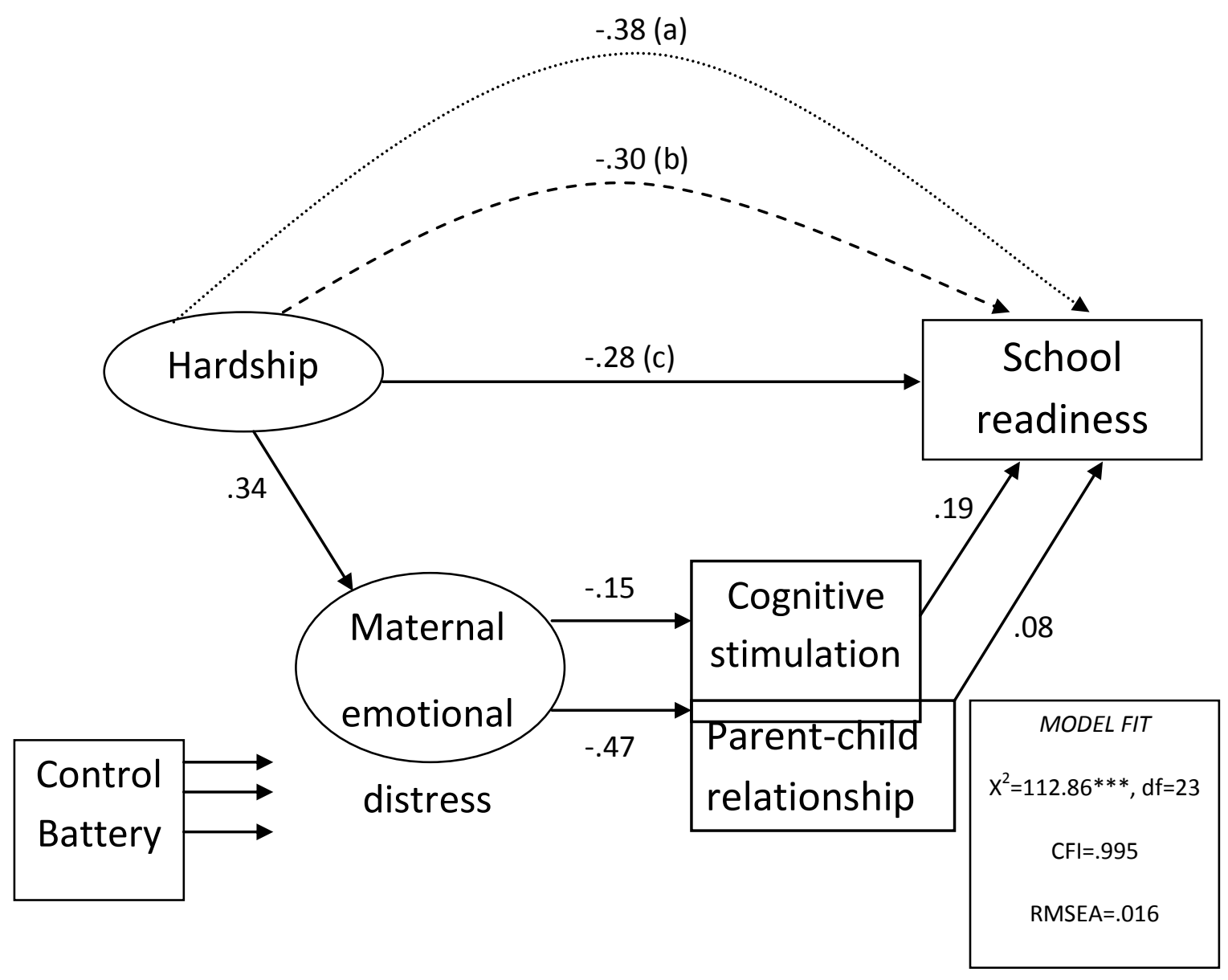


The association between family hardship and cognitive ability was statistically significant, both without ( $(=-.38)$ and with controls $(\beta=-.30)$. With controls the model explained $19 \%$ of the variance in cognitive ability. After adding the mediators, the path from family hardship to child cognitive development reduced to $\beta=-.28$, suggesting that parenting factors only partially mediate the association between poverty and cognitive development. Adding the parenting characteristics enables us to explain an additional $4 \%$ of variance in school readiness, in addition to that explained by family poverty and controls.

Figure 2. Predicting behaviour adjustment at age 3: the full model

a. no mediators no controls, b. no mediators with controls, c. with mediators and controls)

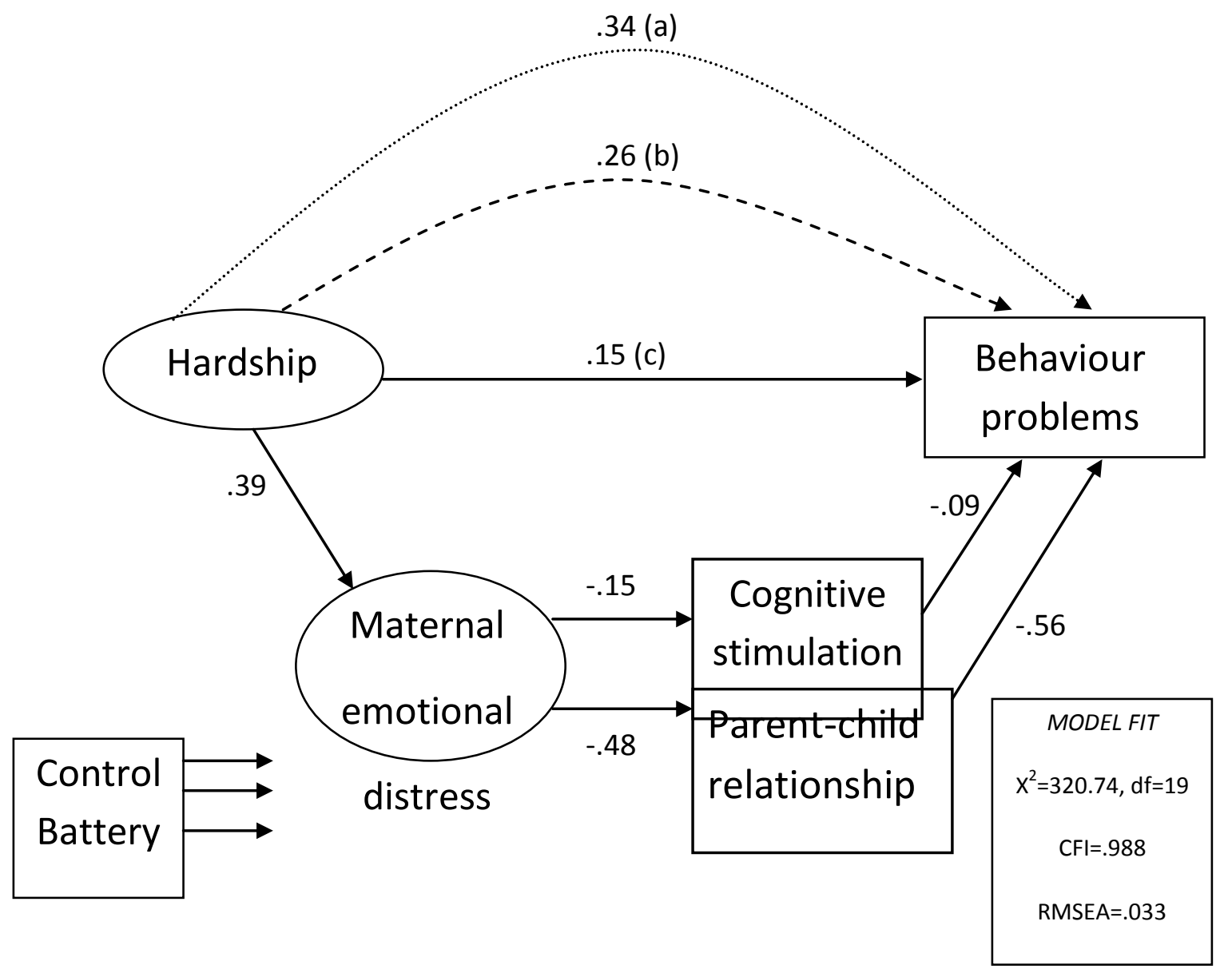

In a next step we assessed the pathways linking family hardship to behavioural adjustment (Figure 2). Family hardship was significantly associated with behaviour problems ( $\beta=-.34)$. Adding the control variables reduces the direct association to $\beta=-.26$. When the controls are included, the model explained 14 per cent of the variance in behaviour problems.
The full model, depicted in Figure 2 shows the combination of both family stress and family investment constructs. After adding all the mediators we can explain an additional 32 per cent of the variance in behavioural adjustment, and the path from family hardship to child cognitive development reduced to $\beta=-.15$. 


\section{Discussion}

The study illustrates the corrosive effect of family hardship on the cognitive development and behavioural adjustment of young children. The experience of hardship in the first three years of life undermines the formation of skills that are necessary for the child to succeed in their school careers. The study furthermore identifies the role of characteristics in the family environment as potential mediators, differentiating between the impact of constructs identified within the family stress and the family investment models. In particular, the study tests the viability of combining both models to gain a better understanding of how family hardship is associated with early developmental outcomes (see also Linver et al 2002). Constructs of both models mediated the association between family hardship and child development. However, the provision of stimulating experiences in the home appears to be more important for the cognitive development of the child, while family stress constructs emphasizing the role of maternal distress and less-involved parenting, appear to be especially important for behavioural adjustment (see also Linver et al 2002; Kiernan and Huerta 2008; Yeung, Linver, and Brooks-Gunn 2002). While parenting characteristics explained relative little of the variation in cognitive development, in addition to the influence of family hardship and the control variables, they were crucial in reducing the negative impact of family hardship on behavioural adjustment.

Furthermore, combining both models enabled us to illustrate how distal influences impact on more proximal experiences of the child, and to identify the role of persistent maternal distress as a mediating factor, linking family hardship to parenting behaviour as well as cognitive stimulation, which in turn influences children's development. Maternal depression is generally considered a risk factor for poor socio-emotional and cognitive development (Cummings and Davies 1994), although the associations between maternal depression and child outcomes are complex (Downey and Coyne 1990), and not all studies have found a relationship between maternal distress and cognitive development (Kiernan and Huerta 2008; Linver, Brooks-Gunn and Kohen 2002). Variations in severity, chronicity, and timing of depression (Campbell, Cohn and Meyers 1995), as well as heterogeneity in sampling and other potential risk factors such as low social support, can contribute to differences in child outcomes (Sameroff et al 1993). In this study, the authors accounted for persistence of maternal distress between ages 9 months and 3 years, and found that mothers exposed to persistent hardship, with reduced access to economic resources, are more likely to experience continued stress, which in turn is associated with reduced investment in their children (in terms of cognitive stimulation) as well as less involved parentchild interactions, which in turn are associated with their children's developmental outcomes. These associations were significant even after controlling for a number of background characteristics, such as mother's education, ethnicity, and marital status, as well as indictors of early biological risk, to ensure that the findings were not spurious. It should be noted that in another study also using the Millennium cohort, the association between persistent maternal distress and cognitive functioning was also apparent (Kiernan and Mensah 2009).

In interpreting the findings, a number of limitations have to be considered: the hypothesized pathways examined in the model, test specific assumptions regarding the combination of the family stress and the family investment model. The observed associations do not imply causal relationships between the factors, as there might be other explanatory processes not included in the model. For example, there might be a reciprocal relationship between the child characteristics and parenting behaviour (Bell and Chapman 1986; Rutter 2002), and parenting behaviour might change over time. Also, the role of the father in supporting positive development in the face of family hardship has not been addressed. Furthermore, while family hardship and maternal distress were assessed at two time points, measures of family investment and parent-child interactions were only available at age 3 , the same age when the outcome variables were assessed. Another limitation is that, except for the assessment of cognitive ability, all other measures were obtained via maternal report, and the inclusion of some objective or independent observational data would have helped to improve the validity of the findings. It is also likely that other mediators of the 
association between family hardship and child outcomes exist that are beyond the scope of this study, as for example characteristics of the neighbourhood, or availability of social support.

Given these limitations, the findings provide some useful insights into the pathways linking family hardship to early cognitive and behavioural functioning. The findings suggest that economic hardship has a slightly stronger association with cognitive than with behavioural development, confirming evidence from previous studies (Conger and Elder 1994; Conger et al 1994; Kiernan and Huearta 2008; Linver et al 2002, Plewis and Kallis 2008; Schoon et al 2010). The study furthermore highlights the role of maternal depression as a mediator between distal and proximal experiences, and its association with good quality parent-child interactions, as well as the provision of a stimulating home environment. Of course, not all mothers suffering from depression are affected in their ability to provide a good enough, sensitive and caring environment for their children (Cicchetti, Rogosch, and Toth 1998), yet maternal depression appears to be a risk for their children's cognitive and especially behavioural adjustment. About $17 \%$ of mothers in the Millennium Cohort reported that they were depressed when their child was 9 months old, as well as at age 3 (Kiernan and Mensah 2009). Contextual risk factors such as poverty, marital conflict, and stressful life events may exacerbate maternal depression, and consequently the child's development, suggesting the importance of being vigilant in detecting or screening for maternal depression, especially among highly disadvantaged families. The findings furthermore suggest the usefulness of disentangling the emotional and cognitive components of parenting and the home environment, to gain a better understanding of the processes shaping cognitive and behavioural development. While parenting processes are more effective in mediating the influence of poverty on behavioural adjustment, they play a relative small role in mediating the effects of family hardship on cognitive development. It is therefore not enough to develop policies targeting the improvement of parenting behaviour and parental health. What is needed is a concentrated effort to reduce or eradicate child poverty and to improve the living conditions of families with young children.

The study has shown that family hardship has a direct influence on children's developmental outcomes and plays a role in shaping maternal mental health as well as parenting behaviours. Given the long-term consequences of achievement gaps emerging early in life, the fact that this gap widens throughout the childhood years (Feinstein 2003; Schoon 2006), and that children who fall behind in early development are more likely to fall further behind at subsequent stages, renders the reduction of family hardship during the first years of life a priority (Heckman 2006; Marmot 2010). The possibility of correlated unobserved characteristics and alternative mediating processes, opens the field for further investigation into the mechanisms and processes involved in the early inter-generational transmission of disadvantage. These efforts should focus their attention to both cognitive and behavioural adjustment during the early years, as both capabilities are the foundation for later developmental adjustment, and are cross-fertilizing, as shown in Duckworth and Schoon 2010 (this issue).

\section{Acknowledgements}

The analysis and writing of this paper were supported by grants from the Nuffield Foundation and the UK Economic and Social Research Council (ESRC): L326253061, RES-594-28-0001. Data from the Cohort Studies were supplied by the ESRC Data Archive. Those who carried out the original collection of the data bear no responsibility for its further analysis and interpretation. 


\section{References}

Alexander RE. (2009) Children, their world, their education: final report and recommendations of the Cambridge primary review. Routledge, London.

Becker GS and Thomes N. (1986) Human capital and the rise and fall of families. Journal of Labour Economics, 4, S1-S139.

Bell RQ and Chapman M. (1986) Child effects in studies using experimental or brief longitudinal approaches to socialization. Developmental Psychology, 22(5), 595-603.

Blanden J and Gregg P. (2004) Family income and educational attainment: a review of approaches and evidence for Britain. Oxford Review of Economic Policy, 20, 245-236.

Blanden J and Machin S. (2010) Intergenerational inequality in early years assessments. In K Hansen, H Joshi and S Dex. eds. Children of the 21st century. The first five years (pp. 153-168). Policy Press, Bristol.

Bollen KA. (1989) Structural Equations with Latent Variables. Wiley, New York.

Bradley R, Caldwell BM, Rock SL and Ramey CT. (1989) Home environment and cognitive development in the first 3 years of life: a collaborative study involving six sites and three ethnic groups in North America. Developmental Psychology, 25, 217-235.

Bradley R and Corwyn R. (2002) Socio-economic status and child development. Annual Review of Psychology, 53, 371-399.

Bronfenbrenner U. (1979) The ecology of human development : experiments by nature and design. Harvard University Press, Cambridge, MA.

Brooks-Gunn J and Duncan GJ. (1997) The effects of poverty on children. Children and Poverty, 7(2), 55-71.

Bracken BA. (2002) Bracken school readiness assessment administration manual. The Psychological Corporation, San Antonio, Texas.

Brooks-Gunn J and Duncan GJ. (1997) The effects of poverty on children. Children and Poverty, 7(2), 55-71.

Bynner J and Joshi H. (2002) Equality and opportunity in education: evidence from the 1958 and 1970 birth cohort studies. Oxford Review of Education, 28(4), 405-425.

Bynner J, Schuller T and Feinstein S. (2003) Wider benefits of education: skills, higher education and civic engagement. Zeitschrift für Pädagogik, 49(3), 341-361.

Campbell S, Cohn J and Meyers T. (1995) Depression in first-time mothers: mother-infant interaction and depression chronicity. Developmental Psychology, 31, 349-357.

Cicchetti D, Rogosch FA, and Toth SL. (1998) Maternal depressive disorder and contextual risk: contributions to the development of attachment insecurity and behavior problems in toddlerhood. Development and Psychopathology, 10(2), 283-300.

Conger KJ and Elder GH. (1994) Families in troubled times: adapting to change in rural America $\left(1^{\text {st }}\right.$ edn.) Aldine De Gruyter, New York.

Conger R, Ge X, Elder GH, Lorenz F and Simons RL. (1994) Economic stress, coercive family process, and developmental problems of adolescents. Child Development, 65, 541-561.

Cummings E and Davies P. (1994) Maternal depression and child development. Journal of Child Psychology and Psychiatry, 35, 73-112.

Downey G and Coyne JC. (1990) Children of depressed parents - an integrative review. Psychological Bulletin, 108(1), 50-76.

Duckworth K and Schoon I. 2010 Progress and attainment during primary school: the roles of literacy, numeracy and self-regulation. Longitudinal and Life Course Studies 1, 223-240.

Duncan GJ, Dowsett CJ, Claessens A, Magnuson K, Huston AC, Klebanov P, Pagani LS, Feinstein L, Engel M, Brooks-Gunn J, Sexton H, Duckworth K and Japel C. (2007) School readiness and later achievement. Developmental Psychology, 43(6), 1428-1446.

Entwistle DR and Alexander, KL. (1999) Early schooling and social stratification. In R Pianta and M Cox. eds. The transition to kindergarten (pp. 13-38). Brookes, Baltimore.

Feinstein L. (2003) Inequality in the early cognitive development of British children in the 1970 cohort. Economica, 70, 73-98.

Feinstein L. (2004) Mobility in pupils' cognitive attainment during school life. Oxford Review of Economic Policy, 20(2), 213-229.

Feinstein L and Bynner J. (2004) Mobility in pupils' cognitive attainment during school life. Oxford Review of Economic Policy, No 20.

Feinstein L and Vignoles A. (2008) Individual differences in the pathways into and beyond higher education in the UK: a life-course approach. Journal of Social Issues, 64(1), 115-133. 
George A, Hansen K and Schoon I. (2007) Child development. In K Hansen and H Joshi eds. Millennium cohort study. second survey. A user's guide to initial findings. Institute of Education, Centre for Longitudinal Studies, London.

Gershoff ET, Aber JL, Raver CC and Lennon MC. (2007) Income is not enough: incorporating material hardship into models of income associations with parenting and child development. Child Development, 78(1), 70-95.

Guo G and Harris KM. (2000) The mechanisms mediating the effects of poverty on children's intellectual development. Demography, 37(4), 431-447.

Heckman JJ. (2006) Skill formation and the economics of investing in disadvantaged children. Science, 312, 19001912.

Hills J, Sefton T and Steward K. (2009) Towards a more equal society. Poverty, inequality and policy since 1997. Policy Press, Bristol.

Janus M and Duku E. (2007) The school entry gap: socio-economic, family, and health factors associated with children's school readiness to learn. Early education and development, 18, 375-403.

Kagan SL. (1992) Readiness past, present and future. Shaping the agenda. Young Children, 48, 48-53.

Kiernan KE and Huerta MC. (2008) Economic deprivation, maternal depression, parenting and children's cognitive and emotional development in early childhood. British Journal of Sociology, 59(4), 783-806.

Kiernan KE and Mensah FK. (2009) Poverty, maternal depression, family status and children's cognitive and behavioural development in early childhood: a longitudinal study. Journal of Social Policy, 38, 569-588.

Korenman S, Miller JE and Sjaastad JE. (1995) Long-term poverty and child development: evidence from the NLSY. Children and Youth Services Review, 17(1-2), 127-155.

Linver MR, Brooks-Gunn J and Kohen DE. (2002) Family processes as pathways from income to young children's development. Developmental Psychology, 38(5), 719-734.

Lloyd JEV and Hertzman C. (2009) From kindergarten readiness to fourth-grade assessment: longitudinal analysis with linked population data. Social Science and Medicine, 68(1), 111-123.

Maclnnes T, Kenway P and Parekh A. (2009) Monitoring poverty and social exclusion. Joseph Rowntree Foundation, York.

Marmot M. (2010) Fair society healthy lives. The Marmot review: Strategic Review of Health Inequalities in England post 2010. http://www.ucl.ac.uk/gheg/marmotreview/FairSocietyHealthyLives.

McLoyd VC. (1998) Socioeconomic disadvantage and child development. American Psychologist, 53(2), $185-204$.

Melhuish E, Belsky J, Leyland,AH and Barnes J. (2008) Effects of fully-established Sure Start local programmes on 3-year-old children and their families living in England: a quasi-experimental observational study. Lancet, 372(9650), 1641-1647.

Meisels SJ. (1999) Assessing readiness. In R Pianta and M Cox. eds. The transition to kindergarten (pp. 39-66). Brookes, Baltimore.

Mistry RS, Biesanz JC, Taylor LC, Burchinal M and Cox MJ. (2004) Family income and its relation to preschool children's adjustment for families in the NICHD study of early child care. Developmental Psychology, 40(5), 727-745.

Panter JE, and Bracken BA. (2009) Validity of the Bracken School Readiness Assessment for predicting first grade readiness. Psychology in the Schools, 46(5), 397-409.

Plewis I and Kallis C. (2008) Changing economic circumstances in childhood and their effects on subsequent educational and other outcomes. DWP Working Paper No. 49. HMSO, Norwich.

Rutter M. (1989) Pathways from childhood to adult life. Journal of Child Psychology and Psychiatry and Allied Disciplines, 30(1), 23-51.

Rutter M. (2002) The interplay of nature, nurture, and developmental influences - the challenge ahead for mental health. Archives of General Psychiatry, 59(11), 996-1000.

Sameroff AJ, Seifer R, Baldwin A and Baldwin C. (1993) Stability of intelligence from preschool to adolescence the influence of social and family risk-factors. Child Development, 64(1), 80-97.

Schoon I. (2006) Risk and resilience. Adaptations in changing times. Cambridge University Press, Cambridge.

Schoon I, Bynner J, Joshi H, Parsons S, Wiggins RD and Sacker A. (2002) The influence of context, timing, and duration of risk experiences for the passage from childhood to mid-adulthood. Child Development, 73(5), 1486-1504.

Schuerger JM and Witt AC. (1989) The temporal stability of individually tested intelligence. Journal of Clinical Psychology, 45, 294-302.

Waldfogel J and Washbrook E. (2010) Low income and early cognitive development in the UK. The Sutton Trust http://www.suttontrust.com/reports/Sutton_Trust_Cognitive_Report.pdf

Yeung WJ, Linver MR and Brooks-Gunn J. (2002) How money matters for young children's development: parental investment and family processes. Child Development, 73(6), 1861-1879. 


\title{
Progress and attainment during primary school: the roles of literacy, numeracy and self-regulation
}

\author{
Kathryn Duckworth and Ingrid Schoon \\ Institute of Education, University of London \\ K.Duckworth@ioe.ac.uk
}

(Received May 2010 Revised June 2010)

\section{Abstract}

Academic achievement is a cumulative process marked by both continuity and change over time. Research increasingly documents the critical importance of not only language and mathematical competency for academic success, but also the centrality of wider skills that enable pupils to regulate their own learning behaviours. This paper examines the balance that exists between change and stability in different domains of children's academic achievement during middle childhood and the relative importance of achievement, attention and related features of self-regulation skills for subsequent achievement. Using data from the Avon Longitudinal Study of Parents and Children, the analysis attempts to move beyond a narrow view of educational success and seeks to inform the understanding of how changes in children's developing capabilities predict educational success at the end of primary school in English and mathematics. The results demonstrate a clear pattern of continuity in attainment but also evidence of mobility both up and down the achievement distributions. In line with an increasing body of literature, the findings also show evidence of a remarkable persistence in skills related to attention as important predictors of later achievement.

\section{Introduction}

Continuity in cognitive attainments is now a well established phenomenon in developmental research (Kowleski-Jones and Duncan 1999; McCall, Applebaum and Hogarty 1973; Wilson 1983). A wealth of data shows that children's achievement test scores are strongly related to their prior cognitive functioning and attainment of basic skills in mathematics and literacy. Many studies also highlight the predictive power of achievement at the end of primary school, around age 11, for a broad range of successful outcomes in adulthood (Feinstein and Bynner 2004). However, although academic attainment is largely stable throughout childhood, children do demonstrate both shifts and fluctuations in the trajectories in the development of these skills, particularly during the early and middle schooling childhood period (Huston and Ripke 2006; Pungello et al 1996).

Cumulative evidence has also highlighted the role of broader skills and capabilities, often called "noncognitive skills" (Heckman and Rubenstein 2001), for educational success, placing a particular emphasis on the importance of attentional skills and related features of self-regulation (Duncan et al., 2007; Breslau et al., 2009). Moreover, developments in both academic and non-academic capabilities are closely intertwined with efforts to promote children's early social and emotional learning carrying positive gains to both concurrent and future attainment (Hallam, Rhamie \& Shaw, 2006; Rimm-Kaufman et al., 2007; 
Zins et al., 2004). Yet in the current era of assessment practices and standards-based accountability, schools may feel pressured to de-emphasise the development of these broader capabilities and in doing so limit the opportunity for every child to "develop at the best pace, and [ensure that] no child gets left behind" (DfES, 2006, p.1).

This paper explores the balance that exists between change and stability in different domains of children's academic achievement during primary school. The analysis seeks to inform the understanding of how changes in achievement and pupils' capabilities to regulate their own learning over the Key Stage 1 (KS1) period', predict subsequent educational success at the end of primary school in English and mathematics Key Stage 2 (KS2) tests (the National Curriculum assessments at the end of primary school). Finally, following on from the more holistic approaches to the development of children's cognitive capacities outlined in Schoon et al 2010 (thisissue), we investigate links between measures of achievement, attention and related features of selfregulatory and motivational skills. Using longitudinal data from a cohort of children born in the early 1990s, this paper considers how the different foundation stones of literacy and numeracy, attention and other features of self-regulation, such as locus of control and scholastic competence, operate to support progress and attainment once children are in formal schooling. The methodology used attempts to isolate the relative contributions of skills and capabilities developed during the early school years for later academic success, by controlling for earlier development as well as for an extensive set of prior child and family influences associated with children's achievement.

\section{Development in middle childhood}

Middle childhood roughly spans the period from 5 to 12 years of age and is marked by considerable developmental changes in many domains (Collins 1984). Consequently it has been distinguished from early childhood and adolescence along a number of dimensions, yet has received comparatively little attention relative to other developmental periods, such as infancy, early-childhood and adolescence (Huston and Ripke 2006). Moreover, the period between 5 and 7 years of age forms the first years of schooling for almost every society that provides formal education, suggesting some universal recognition that the abilities needed for such schooling emerge during this age period.

Throughout middle childhood, children become more adept at acquiring new information, consolidating, extending and integrating previously acquired knowledge, and using this information in subsequent reasoning and action. Evidence here suggests that during this period of development, children 'learn to learn', adapting previous strategies to develop new cognitive skills that enable them to think more flexibly and subtly than during the preschool years (Hiebert and Wearne 1996; Leppänen, Niemi, Aunola and Nurmi 2006; Scarborough 2001; Storch and Whitehurst 2002). As these skills become more automatic, attentional resources can be devoted to learning more complex tasks and making learning more efficient. Such evidence has contributed to the move away from discrete, qualitative stages in development, towards the recognition that individual development is a continual process, where children steadily become better and more efficient information processors as skills advance and the brain develops a greater capacity for more complicated procedures (Keating 2004; Siegler and Alibali 2004).

Given that the learning trajectories children embark on during primary school are marked by both stability and change, practitioners and policy makers need to have a clear understanding of this balance, to best support progression in learning for all children. There is therefore a need to address questions that focus on the extent to which, and in what ways, fundamental skills implicated in educational success are fixed or become crystallised, before children make the important transition to secondary school. By understanding the complex patterns of stability and change in attainment during primary school, we will be better placed to address disparities of underachievement and ensure that every child is able to achieve their full potential.

\section{Beyond a narrow view of academic achievement}

Success in school, while clearly dependent on general intelligence, foundational skills in literacy and numeracy and other cognitive processes such as memory, is also a product of broader self-regulatory 
and socio-emotional skills and individual adjustment (Duncan et al 2007; Heckman, Stixrud and Urzua 2006). Attention and related self-regulatory features of the child, such as concentration and persistence versus impatience and impulsivity, are expected to increase, or decrease, the capacity that children have for engagement in the classroom, as well as their level of sustained participation in academic activities. While less common than research on development of cognitive skills, studies investigating the associations between children's attention-related classroom behaviour and school performance, consistently suggest that the ability to control and sustain attention predicts achievement during pre-school and school years (Alexander, Entwisle and Dauber 1993; Raver, Smith-Donald, Hayes and Jones 2005). Moreover, these authors suggest that children who are engaged, interested and pay attention, not only spend more time on task, but also invest in greater quality time in this respect.

Recent research documenting the particular importance of attentional skills for subsequent academic achievement shows that, while attention problems are frequently found in conjunction with other behavioural difficulties, they are conceptually distinct from other problem behaviours, and relate to achievement outcomes in unique ways. For example, Duncan and colleagues (2007) found that the association of disruptive behaviours and emotional problems had no bearing on school performance once attention was taken into account (see also Barriga et al 2002; Breslau et al 2009). This association is true, independent of prior levels of cognitive attainment (see also McClelland, Morrison and Holmes, 2000; Yen, Konold and McDermott, 2004) and after taking into account changes in attentional skills over time (Breslau et al 2010), further indicating that children with greater and more adaptive self-regulatory skills are more likely to succeed academically. Moreover, while the contribution of learning-related behaviours is relatively small in comparison to academic ability, authors here highlight that skills such as attention, persistence, perceived control, motivation and confidence are more easily amenable through intervention (Blackwell, Trzesniewski and Dweck 2007; Diamond, Barnett, Thomas and Munroe 2007; RimmKaufmann et al 2007).

\section{Aims and Hypotheses}

The aims of this investigation were twofold: (1) to explore the degree of stability versus malleability in the development of literacy and numeracy across the Key Stage assessments; and (2) to examine the relative importance of changes in developing skills and capabilities for achievement at the end of primary school. By examining how children progress over the KS2 period using a broad set of developing capabilities, the analyses aim to unpack some of the individual differences, progression disparities and attainment gaps that can get averaged out in nationally descriptive, target-focussed-only data.

\section{Method}

\section{Data}

The study is based on data collected for the Avon Longitudinal Study of Parents and Children (ALSPAC), an ongoing population-based study designed to investigate the effects of environmental, genetic and other influences on the health and development of children (Golding, Pembrey, Jones and the ALSPAC study team, 2001). To be eligible for the study, mothers had to be resident in the former Avon Health Authority area while pregnant, with an expected date of delivery between 1st April 1991 and 31st December 1992. iii More than $80 \%$ of the known births from the geographically defined catchment area were included, resulting in a total cohort of 14,062 live births.

These data are unique amongst large sample, longitudinal birth cohort studies in the UK, in surveying children year on year, plus each child's mother and her partner(s) at short, regular intervals, prenatally and later on. The study contains a wealth of data on family background, family process, the cognitive, social and behavioural development of children, and key features of the school environment. In addition, school-level data including Local Education Authority (LEA) entry assessment scores were obtained, and administrative data from the National Pupil Database (NPD) have been merged with the ALSPAC data, providing records of individual achievement in the National Curriculum Key Stage 1 and 2 assessments. These data cover all 
relevant state schools in the four LEAs that cover this area now; Bristol, South Gloucestershire, North Somerset, and Bath and North East Somerset.

\section{Measures}

\section{Outcome measures}

Academic achievement is assessed in Year 6, the final year of primary school, when children are aged between 10 and 11 years old, in terms of Key Stage scores in English and mathematics. The English assessment is marked out of 100 and consists of three tests: a reading test, a writing test and a spelling test. Marks are also awarded for handwriting. The mathematics test is marked out of 100 and consists of three separate tests: a calculator paper, a noncalculator paper and a mental arithmetic test. Additional marks for both English and mathematics can be gained through pupils sitting extension papers, with marks added onto their individual result to minimise any possible ceiling effects. At Key Stage 2, the national target is for $85 \%$ of 11 year olds to achieve Level 4 or above in English and mathematics. In 2002/2003, the year most ALSPAC children sat their KS2 assessments, this figure was 75\% for English and 73\% for mathematics (DfES 2003).

The raw information available regarding actual marks is used to calculate 'exact' attainment levels, measured on the same scale as the National Curriculum final levels awarded. To illustrate this, consider the following example: pupils who were awarded Level 3 in English at KS2 would have achieved a mark between 24 and 43 on the English paper. The method used in this paper assigns an attainment level of 3.00 to a child who scored 24 , for instance, and 3.950 to a child who scored 42; a pupil whose score was in the middle of the two thresholds (i.e. 34) is assigned a level of 3.5 (for further details of this interpolation formula see Levačić, Jenkins, Vignoles et al 2005). The advantage of this approach is that in producing a more continuous measure of attainment, we are better able to rank pupils in terms of their achievement at each Key Stage. Further, it controls for the year the pupil took their KS2 assessments and the variations in cut scores each year. In the regression analysis it also enables an approximation of the amount of 'monthly progress' made. $^{\text {iv }}$

\section{Key Independent Variables: Key Stage 1 assessments}

The KS1 assessments consist of standardised tests in reading, writing, spelling and mathematics, administered in Year 2 of primary school when pupils are 6-7 years old. For this sample, the tests would have been conducted in the period 1997/98 to $1999 / 2000$. The metric of these assessments is only available in terms of discrete Key Stage levels and consists of Levels 1, 2, 3 and 4+, with Level 4+ being the highest ${ }^{v}$ and grades $A$ (high), B and C (low) separating out Level 2. In addition, code W ('working towards Level 1') means the child was assessed but did not achieve Level 1. Children who were absent or disapplied $^{\mathrm{vi}}$ from the KS1 tests are excluded from all analyses. The target level for all children at Key Stage 1 is Level 2, specifically Level $2 B$.

Despite the discrete level categories, the relationship between KS1 assessments and KS2 attainment is remarkably linear (results not reported). As such, in the analysis presented below, the KS1 measures are treated as continuous. For simplicity, we use an overall measure of literacy taken as the first factor solution of the reading, writing and spelling assessments. Sensitivity checks on these data revealed remarkably linear relations within each assessment and in their predictive associations with the KS2 assessments. Therefore the use of an overall literacy score is not considered problematic. KS1 assessments were standardised with mean $=0$, standard deviation $=1$.

\section{Key Independent Variables: Clinic assessments at age 8}

Inattention. Three tasks, taken from the TEACh (Tests of Everyday Attention for Children) adapted from the adult version by Robertson 1996), were given to children during the clinic assessment at age 8 , reflecting three attentional domains: selective attention; the ability to divide attention between two tasks, and attentional control (Posner and Petersen 1990). These three latent constructs of underlying cognitive attention processes appear stable across the life course and have been shown to better capture the non-unitary nature of attention (Chan, Lai and Robertson 2006; Manly et al 2001). The overall 
measure of attention used was taken as the first factor of these three scores.

Locus of control. Locus of control assesses selfperceived control in individuals' lives. People who believe that an outcome is largely contingent on their own actions are seen as having a more internal locus of control, while those who feel that their lives are determined more by luck, fate, chance and other people, are considered to have an external locus of control (Deci and Ryan 1987). Measures of internality and externality have been shown to be associated with a number of different factors, including academic achievement, psychological well-being and beliefs (Lefcourt 1982). The measure used here was a shortened, 12-item version of the Nowicki-Strickland Internal-External scale (NSIE scales, Nowicki and Duke 1974) for pre-school and primary children, and included questions such as "Is doing well in your class-work just a matter of 'luck' for you?", "Do you think that preparing for tests is a waste of time?" and "Does planning ahead make good things happen?". A high score indicates a more external locus of control.

Self-esteem and scholastic competence. Self-concept is assessed by ratings on the Self-Perception Profile for Children (SPPC) which measures children's selfperception on scales of global self-worth and scholastic competence (Harter 1982). Statements include the following items such as: "some children feel they are very good at their school work but other children worry about whether they can do the school work assigned to them" or "some children are often unhappy with themselves but other children are pretty pleased with themselves". Higher scores represent greater scholastic competence or greater global self-worth.

\section{Covariates}

School Entry Assessment data come from teacheradministered tests, developed by reception teachers in partnership with head teachers, advisors and an educational psychologist, and, while not exactly the same, are remarkably similar to the National Foundation Stage assessments (South Gloucestershire Professional and Curriculum Support Service 1996). The primary purposes of the Entry Assessment were to establish an assessment of strengths and needs for pupils at entry to school, from which to plan, and against which progress can be measured to the end of
KS1. The Entry Assessment is made up of four required areas in language, reading, writing and mathematics, which were administered in the first few weeks of starting Reception (Herrick and Golding 2004).

Strengths and Difficulties at age 6. When the cohort members were 6 , mothers/primary caregivers were asked to complete the Strengths and Difficulties Questionnaire (SDQ), a 25-item behavioural screening questionnaire (Goodman 1997). The SDQ has five sections that cover details of emotional difficulties; conduct problems; hyperactivity or inattention; friendships and peer groups; positive social behaviour.

A number of further control variables were included in the analysis to reduce bias due to omitted variables:

- Household education - combination of both parents' highest level of educational qualifications coded on a scale from 0 to 4: CSE/lower; less than Level 2 academic and vocational qualifications; Olevel/GCSE/Level 2 vocational qualifications; Alevels/Level 3 vocational qualifications; University degree and higher. ${ }^{\text {vii }}$

- Registrar General's classification of Social Class (RGSC) social class

- Experience of financial difficulties

- Mothers' age at the time of the child's birth

- Partner status

- Household tenure

- Birth weight

- Whether (and for how long) the mother breastfed

- Mother-reported locus of control

- Mother-completed Edinburgh Post Natal Depression scale (Cox, Holden and Sagovsky 1987) and Crown Crisp Experiential Index measuring depression, anxiety and somatic symptoms (Crown and Crisp 1979) 
- Mother-child interactions were assessed using the summed responses from the mother/parents to questions about how frequently they sing and read to/with their children, play with them and try to teach them colours, letters and nursery rhymes etc. during the pre-school years. Questions regarding activities outside the home and the number of books and toys in the home during this time were also asked.

\section{Analysis plan}

The focus of this paper is to examine progress and attainment during primary school and understand the balance that exists between change and stability in children's school test scores. To investigate how children progress from Key Stage 1 to 2, as well as what skills predict success at the end of primary school, we adopt two main analytic methods.

\section{How do children progress from Key Stage 1 to Key Stage 2?}

We use transition matrices to investigate Key Stage level and quartile patterns of normative movement and overall stability in progression, also referred to as quartile continuities and discontinuities (see, for example, Blanden and Machin 2007; Feinstein 2004). Transition matrices report the conditional probabilities of being at a certain level or quartile at $\mathrm{KS} 2$, given the relative position in the distribution at KS1. viii They therefore enable a focus on mobility in Key Stage attainment, not only with respect to being 'on-' or 'off-target', but also in terms of who is making the expected levels of progress, and who is exceeding or falling short of the two-level improvement expectations. This information is also used to examine the likelihood of persistence in the top and bottom quartiles by gender and social background.

\section{What Key Stage 1 tests are most important in predicting success at Key Stage 2?}

The second stage of these analyses uses multivariate Ordinary Least Squares (OLS) regression analysis to examine the importance of progress over the KS1 period for attainment at KS2. The interest here lies in estimating the contribution made by each of the key independent variables to attainment in
English and mathematics at KS2. The focus is on the balance between literacy and numeracy-related skills in relation to the different subject domains examined at the end of primary school, and on the particular contribution of attention relative to other developing features of self-regulation. In order to counter problems of omitted variable bias, which is likely to arise if unobserved family or child characteristics are correlated with children's developing academic skills and capabilities and their subsequent educational achievement, we include as many prior measures of relevant child and family characteristics as possible.

\section{Missing data}

The problem of missing data is inherent in the use of longitudinal datasets. Only individuals with complete data for the outcome variables (Key Stage 2) are used in our analysis. We also exclude those who are missing parental education information, in order that we have crucial socio-demographic measures for subsequent analysis, yielding a sample size of $\mathrm{N}=$ 9,994 , approximately $71 \%$ of the original sample of live births. To handle the missing data, we used multiple imputation (MI) techniques (Rubin 1987; Schafer 1997), implemented in STATA. MI does not attempt to estimate each missing value through simulated ones, but rather completes the data several times by imputing multiple random draws of the missing values from a predictive distribution. These multiply imputed datasets are then analysed using standard procedures for complete data, combing the results to obtain overall estimates and standard errors that reflect variability across imputations. This approach assumes that data were missing at random, that is missing, but conditional on other observed characteristics in the data set, although not on the outcome of interest (Schaffer 1997). The advantage of the $\mathrm{MI}$ approach is that these auxiliary variables, while not in the model of interest, can be conditioned on at the imputation stage to improve the efficiency of the imputed data, and so produce more robust and reliable statistical inferences about the population of interest, that better reflect uncertainty due to missing values (see Goldstein 2009, for further discussion of handling attrition and non-response in longitudinal data). 


\section{Results}

In Table 1, we present bivariate correlations between the outcome and key independent variables. For the attainment outcomes, the strengths of these relationships are greatest within the Key Stage assessment period, but the associations over time are also strongly correlated, indicating a high degree of stability across primary school assessment. Correlations are also strongest within subject domains: the KS1 combined measure of literacy is more strongly associated with KS2 English, and KS1 mathematics more with KS2 mathematics. The measures of attention problems are negatively associated - and comparable in size - with the achievement measures at both KS1 and KS2 and, as predicted, more so than any of the other age 8 assessments.

Transition matrices (Table 2) show the average probability, or the likelihood, of a pupil attaining a certain level in Key Stage 2 assessments, given the level they attained at Key Stage 1. Boxes are shaded dark grey to show the (minimum) expected level of progression for each Key Stage level attained over the Key Stage 2 period (lighter grey boxes indicate progress above the two expected levels). For example, within-domain mathematics attainment, $36 \%$ of those achieving the lowest level at
KS1,working towards Level 1, were still below the level of the Key Stage 1 test in their assessments at Key Stage 2. At the top end of the distribution, $73 \%$ of pupils achieving Level 3 or above went on to get at least Level 5 in their mathematics assessment at the end of primary school.

Table 2 also clearly demonstrates that the majority of pupils are achieving the two-level advancement over this Key Stage period, i.e. the considerable stability in mathematics attainment across the two assessments suggested by the correlation matrix: $54 \%$ of pupils gaining Level 1 in KS1 mathematics achieve Level 3 in KS2; $63 \%$ of those on target at Level 2B go on to Level 4 four years later. However, there is also evidence of discontinuity, with pupils both accelerating from and falling behind or off these expected trajectories. For example, the acceleration rate, i.e. those who advance more than the projected two levels (light grey area), from Level 1 at KS1 is $27 \%$, with $4 \%$ of these pupils getting Level $5+$ in KS2. The corresponding fall off rate is $18 \%$, with $7 \%$ progressing to Level 2 and $11 \%$ appearing to have made little or no progress over the KS2 period. The within-domain literacy skill transitions from KS1 reading to KS2 English (Table 3) are comparable.

Table 1. Bivariate correlations between all outcome and key independent variables
(1)
(2)
(3)
(4)
(5)
(6)
(7)

(8)

\begin{tabular}{|c|c|c|c|c|c|c|c|c|c|}
\hline (1) & Key Stage 2 Mathematics & 1 & & & & & & & \\
\hline (2) & Key Stage 2 English & .71 & 1 & & & & & & \\
\hline (3) & Key Stage 1 Mathematics & .66 & .55 & 1 & & & & & \\
\hline (4) & Key Stage 1 English* & .58 & .67 & .71 & 1 & & & & \\
\hline (5) & Age 8 Inattention & -.29 & -.28 & -.31 & -.30 & 1 & & & \\
\hline (6) & Age 8 Locus of Control & -.25 & -.25 & -.24 & -.24 & .12 & 1 & & \\
\hline (7) & Age 8 Scholastic Competence & .22 & .20 & .23 & .23 & -.11 & -.21 & 1 & \\
\hline (8) & Age 8 Self Esteem & .09 & .11 & .09 & .11 & -.08 & -.16 & .42 & 1 \\
\hline
\end{tabular}

Table notes. All significant at $5 \%$

* Key Stage 1 English is the first factor solution of the reading, writing and spelling assessments 
Table 2. Transition matrix: Key Stage 1 mathematics to Key Stage 2 mathematics KS2 Mathematics

\begin{tabular}{lc|c|c|c|c}
\hline KS1: Mathematics & Below Lev 2 & Lev 2 & Lev 3 & Lev 4 & Lev 5+ \\
\hline Working towards L1 & .36 & .11 & .39 & .10 & .03 \\
Level 1 & .11 & .07 & .54 & .23 & .04 \\
Level 2C & .01 & .02 & .39 & .50 & .08 \\
Level 2B & .00 & .00 & .16 & .63 & .21 \\
Level 2A & .00 & .00 & .05 & .55 & .40 \\
Level 3+ & .00 & .00 & .02 & .25 & .73 \\
\hline Total & .01 & .01 & .16 & .45 & .36 \\
\hline
\end{tabular}

Table notes. $\mathrm{N}=9,444$

Table 3. Transition matrix: Key Stage 1 mathematics to Key Stage 2 English KS2 English

\begin{tabular}{|c|c|c|c|c|c|}
\hline KS1: Reading & Below Lev 2 & Lev 2 & Lev 3 & Lev 4 & Lev 5 \\
\hline $\begin{array}{l}\text { Working towards } \\
\text { L1 }\end{array}$ & .30 & .12 & .41 & .15 & .01 \\
\hline Level 1 & .09 & .07 & .47 & .34 & .04 \\
\hline Level 2C & .01 & .02 & .32 & .56 & .09 \\
\hline Level 2B & .00 & .00 & .12 & .71 & .17 \\
\hline Level 2A & .00 & .00 & .05 & .66 & .29 \\
\hline Level 3+ & .00 & .00 & .01 & .35 & .63 \\
\hline Total & .01 & .01 & .14 & .51 & .33 \\
\hline
\end{tabular}

Table notes. $N=9,444$ 


\section{The relative importance of developing capabilities during middle childhood}

The findings so far highlight both change and continuity in the development of literacy and numeracy skills throughout the primary school years as measured by Key Stage assessments. The second stage of this analysis examines what skills predict success at KS2 and uses regression analysis to estimate the importance of changes measured in literacy and numeracy achievement, attentional skills, and related features of self-regulation during middle childhood for predicting success at KS2 in English and mathematics.

Tables 4 and 5 show the regressions of the KS2 English and mathematics, respectively, on the KS1 assessments in mathematics and literacy, and the age 8 clinic assessments of self-regulation and individual adjustment. All models control for age in weeks and gender. Model 1 in each table, shows the bivariate association between each on the key independent variables and the outcome of interest. Model 2 adds both KS1 measures into the model simultaneously, and model 3 shows the associations with each outcome when only the age 8 clinic assessments are included. Model 4 gives the associations when all the key independent variables are included. The next model, Model 5, adds the controls for child and family background characteristics. This is our preferred model of the "effects" of early skills and capabilities on KS2 attainment: given that when we control for prior measures of mathematics and English attainment and earlier attention and self-regulatory skills, the coefficients on the key independent variables of interest carry a change interpretation. While this change model is considerably more robust to omitted variable bias than is a model using static measures at a given age, we remain cautious in making strong claims of causality. ${ }^{\text {ix }}$ Finally, Model 6 reports the conditional estimates for the five age 8 clinic assessments only, i.e. it excludes the KS1 and Entry Assessment achievement measures, in order to better assess the contributions that these broader capabilities and self-regulatory skills make to later academic attainment, that could have been diluted through their inclusion; while attentional skills have been shown to relate to academic achievement independent of prior cognitive performance, it is likely that aspects of self-regulatory capabilities are picked up within the assessment of academic skills. Coefficients are shown in the adjusted metric of KS2 levels summarised above, such that each unit increase in the KS1 test or age 8 clinic assessment, equates to a corresponding increase in the KS2 level. 
Table 4. Coefficients and standard errors from regression models of Key Stage 2 mathematics on Key Stage 1 assessments and age 8 clinic measures

Key Stage 2 Mathematics

\begin{tabular}{|c|c|c|c|c|c|c|c|c|c|c|c|c|}
\hline Model: & $(1)$ & & $(2)$ & & $(3)$ & & $(4)$ & & $(5)$ & & $(6)$ & \\
\hline \multicolumn{13}{|l|}{ Key Stage 1 assessments } \\
\hline Mathematics & $\begin{array}{l}.56 \\
(.01)\end{array}$ & $* * *$ & $\begin{array}{l}.40 \\
(.01)\end{array}$ & $* * *$ & & & $\begin{array}{l}.38 \\
(.01)\end{array}$ & $* * *$ & $\begin{array}{l}.34 \\
(.01)\end{array}$ & $* * *$ & & \\
\hline English & $\begin{array}{l}.50 \\
(.01)\end{array}$ & $* * *$ & $\begin{array}{l}.23 \\
(.01)\end{array}$ & $* * *$ & & & $\begin{array}{l}.20 \\
(.01)\end{array}$ & $* * *$ & $\begin{array}{l}.15 \\
(.01)\end{array}$ & $* * *$ & & \\
\hline \multicolumn{13}{|l|}{ Clinic assessments at age 8} \\
\hline Inattention & $\begin{array}{l}-.25 \\
(.01)\end{array}$ & $* * *$ & & & $\begin{array}{l}-.23 \\
(.01)\end{array}$ & $* * *$ & $\begin{array}{l}-.06 \\
(.01)\end{array}$ & $* * *$ & $\begin{array}{l}-.06 \\
(.01)\end{array}$ & $* * *$ & $\begin{array}{l}-.18 \\
(.01)\end{array}$ & $* * *$ \\
\hline Locus of control & $\begin{array}{l}-.22 \\
(.01)\end{array}$ & $* * *$ & & & $\begin{array}{l}-.17 \\
(.01)\end{array}$ & $* * *$ & $\begin{array}{l}-.06 \\
(.01)\end{array}$ & $* * *$ & $\begin{array}{l}-.03 \\
(.01)\end{array}$ & $* * *$ & $\begin{array}{l}-.09 \\
(.01)\end{array}$ & $* * *$ \\
\hline Scholastic competence & $\begin{array}{l}.18 \\
(.01)\end{array}$ & $* * *$ & & & $\begin{array}{l}.13 \\
(.01)\end{array}$ & $* * *$ & $\begin{array}{l}.04 \\
(.01)\end{array}$ & $* * *$ & $\begin{array}{l}.04 \\
(.01)\end{array}$ & $* * *$ & $\begin{array}{l}.10 \\
(.01)\end{array}$ & $* * *$ \\
\hline Self esteem & $\begin{array}{l}.07 \\
(.01)\end{array}$ & $* * *$ & & & $\begin{array}{l}-.02 \\
(.01)\end{array}$ & $*$ & $\begin{array}{l}-.01 \\
(.01)\end{array}$ & & $\begin{array}{l}-.01 \\
(.01)\end{array}$ & & $\begin{array}{l}-.03 \\
(.01)\end{array}$ & $* *$ \\
\hline \multicolumn{13}{|l|}{ Entry assessments } \\
\hline Mathematics & & & & & & & & & $\begin{array}{l}.07 \\
(.01)\end{array}$ & $* * *$ & & \\
\hline English & & & & & & & & & $\begin{array}{l}.03 \\
(.01)\end{array}$ & $* *$ & & \\
\hline \multicolumn{13}{|l|}{ Strengths and Difficulties at age 6} \\
\hline Inattentive/Hyperactive behaviour & & & & & & & & & $\begin{array}{l}-.04 \\
(.01)\end{array}$ & $* * *$ & $\begin{array}{l}-.12 \\
(.01)\end{array}$ & $* * *$ \\
\hline Conduct Disorder & & & & & & & & & $\begin{array}{l}-.02 \\
(.01)\end{array}$ & & $\begin{array}{l}-.03 \\
(.01)\end{array}$ & $*$ \\
\hline Prosocial behaviour & & & & & & & & & $\begin{array}{l}-.02 \\
(.01)\end{array}$ & $*$ & $\begin{array}{l}-.03 \\
(.01)\end{array}$ & $* *$ \\
\hline Emotional problems & & & & & & & & & $\begin{array}{l}-.01 \\
(.01)\end{array}$ & & $\begin{array}{l}-.01 \\
(.01)\end{array}$ & \\
\hline Peer problems & & & & & & & & & $\begin{array}{l}.00 \\
(.01)\end{array}$ & & $\begin{array}{l}-.01 \\
(.01)\end{array}$ & \\
\hline Girl & & & $\begin{array}{l}-.17 \\
(.01)\end{array}$ & $* * *$ & $\begin{array}{l}-.12 \\
(.02)\end{array}$ & $* * *$ & $\begin{array}{l}-.17 \\
(.01) \\
\end{array}$ & $* * *$ & $\begin{array}{l}-.17 \\
(.01) \\
\end{array}$ & $* * *$ & $\begin{array}{l}-.13 \\
(.02) \\
\end{array}$ & $* * *$ \\
\hline Controls & & & & & & & & & $x$ & & $x$ & \\
\hline Observations & 9994 & & 9994 & & 9994 & & 9994 & & 9994 & & 9994 & \\
\hline R-squared & - & & .47 & & .19 & & .48 & & .51 & & .29 & \\
\hline
\end{tabular}

Table notes. $* * * \mathrm{p}<.001, * * \mathrm{p}<.01, * \mathrm{p}<.05$

All independent variables shown are standardised $(M=0$, Std. Dev. $=1)$. Robust standard errors in brackets.

Control variables include: parents' education, parents' socioeconomic group, housing tenure, experience of financial difficulties, mothers' age at birth of child, birth weight, maternal general and postnatal depression, mothers' social networks, mother-child interaction, educational behaviours and number of books in the home. 
Table 5. Coefficients and standard errors from regression models of KS2 English on KS1 assessments and age 8 clinic measures

\section{Key Stage 2 English}

Model: (1) (2)

\begin{tabular}{|c|c|c|c|c|c|c|c|c|c|c|c|c|}
\hline \multirow{3}{*}{$\begin{array}{l}\text { Key Stage } 1 \text { assessments } \\
\text { Mathematics }\end{array}$} & \multicolumn{2}{|c|}{ (1) } & \multicolumn{2}{|c|}{ (2) } & \multicolumn{2}{|c|}{ (3) } & \multicolumn{2}{|c|}{ (4) } & \multicolumn{2}{|c|}{ (5) } & \multicolumn{2}{|c|}{ (6) } \\
\hline & .41 & $* * *$ & .14 & $* * *$ & & & .11 & $* * *$ & .08 & $* * *$ & & \\
\hline & $(.01)$ & & $(.01)$ & & & & $(.01)$ & & $(.01)$ & & & \\
\hline English & .52 & $* * *$ & .41 & $* * *$ & & & .39 & $* * *$ & .33 & $* * *$ & & \\
\hline & $(.01)$ & & $(.01)$ & & & & $(.01)$ & & $(.01)$ & & & \\
\hline \multicolumn{13}{|l|}{ Clinic assessments at age 8} \\
\hline \multirow[t]{2}{*}{ Inattention } & -.22 & $* * *$ & & & -.18 & $* * *$ & -.04 & $* * *$ & -.05 & $* * *$ & -.14 & $* * *$ \\
\hline & $(.01)$ & & & & $(.01)$ & & $(.01)$ & & (.01) & & $(.01)$ & \\
\hline \multirow[t]{2}{*}{ Locus of control } & -.19 & $* * *$ & & & -.15 & $* * *$ & -.06 & $* * *$ & -.04 & $* * *$ & -.08 & $* * *$ \\
\hline & $(.01)$ & & & & $(.01)$ & & $(.01)$ & & $(.01)$ & & $(.01)$ & \\
\hline \multirow[t]{2}{*}{ Scholastic competence } & .14 & $* * *$ & & & .08 & $* * *$ & .01 & & .01 & & .06 & $* * *$ \\
\hline & $(.01)$ & & & & $(.01)$ & & $(.01)$ & & $(.01)$ & & $(.01)$ & \\
\hline \multirow[t]{2}{*}{ Self esteem } & .08 & $* * *$ & & & .00 & & .01 & & .01 & & .00 & \\
\hline & $(.01)$ & & & & $(.01)$ & & $(.01)$ & & $(.01)$ & & $(.01)$ & \\
\hline \multicolumn{13}{|l|}{ Entry assessments } \\
\hline \multirow[t]{2}{*}{ Mathematics } & & & & & & & & & .03 & $* * *$ & & \\
\hline & & & & & & & & & $(.01)$ & & & \\
\hline \multirow[t]{2}{*}{ English } & & & & & & & & & .06 & $* * *$ & & \\
\hline & & & & & & & & & $(.01)$ & & & \\
\hline \multicolumn{13}{|l|}{ Strengths and Difficulties at age 6} \\
\hline \multirow[t]{2}{*}{ Inattentive/Hyperactive behaviour } & & & & & & & & & -.04 & $* * *$ & -.11 & $* * *$ \\
\hline & & & & & & & & & $(.01)$ & & $(.01)$ & \\
\hline \multirow[t]{2}{*}{ Conduct Disorder } & & & & & & & & & -.01 & & -.03 & $* *$ \\
\hline & & & & & & & & & $(.01)$ & & $(.01)$ & \\
\hline \multirow[t]{2}{*}{ Prosocial behaviour } & & & & & & & & & -.01 & & -.02 & $* *$ \\
\hline & & & & & & & & & $(.01)$ & & $(.01)$ & \\
\hline \multirow[t]{2}{*}{ Emotional problems } & & & & & & & & & .00 & & .00 & \\
\hline & & & & & & & & & $(.01)$ & & $(.01)$ & \\
\hline \multirow[t]{2}{*}{ Peer problems } & & & & & & & & & -.01 & & -.01 & \\
\hline & & & & & & & & & $(.01)$ & & $(.01)$ & \\
\hline \multirow[t]{2}{*}{ Girl } & & & .12 & $* * *$ & .23 & $* * *$ & .12 & $* * *$ & .11 & $* * *$ & .21 & $* * *$ \\
\hline & & & $(.01)$ & & $(.01)$ & & $(.01)$ & & $(.01)$ & & $(.01)$ & \\
\hline Controls & & & & & & & & & $x$ & & $\mathrm{x}$ & \\
\hline Observations & 9994 & & 9994 & & 9994 & & 9994 & & 9994 & & 9994 & \\
\hline R-squared & - & & .46 & & .20 & & .48 & & .51 & & .32 & \\
\hline
\end{tabular}

Table notes. ${ }^{* * *} p<.001, * * p<.01, * p<.05$

All independent variables shown are standardised $(M=0$, Std. Dev. $=1)$. Robust standard errors in brackets.

Control variables include: parents' education, parents' socioeconomic group, housing tenure, experience of financial difficulties, mothers' age at birth of child, birth weight, maternal general and postnatal depression, mothers' social networks, mother-child interaction, educational behaviours and number of books in the home. 
Beginning with the bivariate relationships shown in Model 1, all the coefficients are statistically significant in the expected direction. ${ }^{\times}$As expected, the KS1 coefficients are largest, followed by inattention. Taken together, the results support the claim regarding the simple predictiveness of a broad set of skills for subsequent academic achievement.

Models 2 and 3 estimate models when both KS1 achievement measures and, respectively, all five age 8 clinic assessments are included. Model 2 highlights the domain-specific continuity in Key Stage assessments, whereby earlier mathematics is more predictive of later mathematics than later English score and vice versa. The bivariate relationships are reduced for both KS1 measures when they are included simultaneously, but it is interesting to note that the overall measure of KS1 literacy is more predictive of later mathematics than earlier mathematics is for subsequent English, reflecting the fundamental need to be able to read and write to do well in mathematics. For both KS2 outcomes considered, just under half of the variance is explained by the KS1 tests alone, $47 \%$ for mathematics and $46 \%$ for English. In Model 3, of the clinic assessments, age 8 inattention remains the most important predictor of both KS2 English and mathematics, followed by locus of control and scholastic competence. Approximately $20 \%$ of the variance in the KS2 outcomes is explained by these four variables. In Model 4, all the key independent variables are included in the estimation. The associations of both KS1 measures are reduced further, but those for attention and individual adjustment drop considerably - often by three quarters and for some, to the point of statistical insignificance. Thus, it appears that important portions of the simple associations between achievement at the end of primary school and middle childhood capabilities, are the result of their mutual correlation.

Estimates presented in Model 5 are derived from our preferred model of the "effects" of early skills and capabilities on KS2 attainment, which adjust the bivariate associations for prior attainment and selfregulation and for family and child characteristics. These results again show a very strong pattern of stability within the Key Stage assessments, with the KS1 tests being substantial predictors of both subsequent KS2 English and mathematics achievement, conditional on earlier levels of attainment, attentional skills and related features of self-regulation and individual adjustment, as well as other comprehensive measures of the child and family background characteristics. Moreover, the size of these estimates on the key independent variables hardly change when these additional control sets are introduced, with both KS1 predictors, attentional skills, locus of control and, for mathematics, scholastic competence remaining highly statistically significant. The results also show that girls do better in KS2 English, but boys do better in mathematics.

As noted above, the strength of these relationships is strongest within subject areas, reflecting strong within-domain continuity, with attentional skills and locus of control being roughly equal in size for both KS2 outcomes. For example, the conditional estimates show that each standard deviation increase in mathematics achievement over the KS1 period, results in an additional .34 of a level in KS2 mathematics - this equates to approximately 8 months' progress. There is also evidence that development in literacy and numeracy skills over the KS1 period is important for later cross-domain outcomes - particularly regarding prior literacy skills. For example, a one unit increase in KS1 literacy, results on average, in an increase of .15 of a level in KS2 mathematics - roughly 4 months' progress. An increase in one level in KS1 mathematics raises KS2 English attainment by .08 of a level, or 2 months' learning.

The final model, Model 6, includes earlier controls for individual adjustment and our comprehensive control set, but not the attainment measures, in order to highlight the relative magnitude of the attention and related self-regulatory skills measured at age 8 , which may be diminished owing to the strong degree of continuity in the Key Stage assessments. For both KS2 English and mathematics, the measure of inattention is at least twice the size of the other predictors, and is the coefficient most reduced through the inclusion of the attainment measures, suggesting, in line with the correlations reported above and literature reviewed, that attentional skills are a particularly salient element of academic achievement and performance. 


\section{Discussion}

\section{Stability and change in primary school attainment}

In line with other developmental research, the results presented here emphasise a high degree of continuity in academic attainment. Examination of the correlations, transition matrices, and regression models all indicate a great deal of stability in attainment in the primary school National Curriculum tests. The majority of pupils are advancing the expected two levels over the KS2 period, more so at the top end of the KS1 distribution, and at an average level, progression between Key Stage 1 and 2 appears remarkably stable. However, detailed consideration of the transition matrices, suggests that there is also some movement away from this "normative" pattern in pupils' progression during primary school. That is, although the majority of pupils are advancing the expected two levels over the KS2 period, there are others who buck this trend, both accelerating from and falling off these average 'target' trajectories. In future analysis, we hope to concentrate in more detail on these "off-diagonal" individuals, to investigate what predicts this departure, and how it relates to subsequent performance, as well as the extent to which it might result from mis-classification.

These findings support earlier work by Feinstein (2004) and Schoon (2006) which report mobility in the relative position of pupils' attainment in primary and secondary school for the 1958 National Child Development Study (NCDS) and 1970 British Cohort Study (BCS). Using similar quartile-based transition matrix analysis, Feinstein (2004) shows that, in the NCDS, 35 per cent of those in the bottom quartile of general academic ability at age 7, have 'escaped', i.e. are no longer in, the bottom quartile by age 11 . Conversely the probability of 'dropping out' of the top quartile between 7 and 11 is 44 per cent. For the 1970 cohort, the escape rate from the bottom quartile between 5 and 10 years was 46 per cent and the drop out rate from the top quartile was 50 per cent. The results presented in this paper show a similar likelihood of escaping the bottom quartile, with $37 \%$ per cent of pupils moving out of the bottom quartile by $\mathrm{KS} 2$ for mathematics and a higher probability, nearly $43 \%$, of exiting the top quartile. ${ }^{\mathrm{xi}}$

\section{Effects within and between subjects}

In line with other research (for example, Melhuish et al 2006), these results also demonstrate the strength of within-subject influences of pupils' literacy and numeracy skills. As children move from early childhood into middle childhood and gain increasing experiences of formal education, they become more adept at acquiring new information and using this to develop more mature modes of thought. Consequently, specific literacy and numeracy skills become more advanced as children move through primary school and thus show greater within-domain continuity over time. Feinstein (1998) also finds evidence of cross-domain skills in the early years, which lessen with experience of formal schooling. The relative contribution of attentional skills, however, is roughly the same for both KS2 mathematics and English, reflecting the ways in which attentional resources underpin educational success, broadly defined.

Further research is required to establish the longitudinal stability and validity of the Key Stage curriculum assessments, and whether the high degree of stability observed in these assessments signals genuine continuity in development and resulting attainment, or is merely a product of common assessment.

\section{The relative importance of attentional skills}

Like those of Duncan et al (2007) and Breslau et al $(2009,2010)$, the results presented here show evidence of the important role of attention skills in predicting later achievement. The measure of inattention at age 8 carries particularly strong negative predictions for both measures of achievement at the end of primary school. Moreover, when the KS1 and entry assessment measures are excluded from the estimation (Model 6), the coefficients for inattention increase considerably, by approximately three times, indicating that measures of school performance also measure aspects of attention-related skills. This finding is consistent with other research, highlighting that attentional skills operate independently of cognitive ability (Alexander et al 1993; Duncan et al 2007; McClelland et al 2000; Yen et al 2004). These findings thus suggest that, to the extent that pupils' poor attentional skills can be 
improved in the early school years, their potential for academic achievement might be improved as well.

The earlier SDQ measure of inattentive/ hyperactive behaviour also shows a strong negative association with achievement at the end of primary school, over and above the age 8 TEACh assessment of attentional skills. As noted above, attention is not a unitary brain process, and several authors note the difficulties faced by psychometrists in capturing such a construct with precision (Manly et al 2001). That both the behavioural manifestation of attention problems reflected in the maternal report of the $S D Q$, ${ }^{x i}$ and the individual performance-based measures of attentional control, independently predict academic achievement, reflects such complexity.

Future research would thus benefit from studies which illuminate the natural course of development in both attention-related skills, related behavioural problems and the interactions between them during primary school, examining whether there is variation by gender, social background or at different skill levels. For example, recent research from the US by Diprete and Jennings (2009) finds gender differences in the acquisition of attention and related selfregulation skills, and shows that it is this difference that explains a considerable proportion of the gender gap in academic outcomes during early schooling. Their results indicate that boys get roughly the same academic return to social and behavioural skills as their female peers, but girls retain an advantage both because they start school with more advanced selfregulatory skills and because their skill advantage grows over time. Breslau et al (2010) also suggest that changes in self-regulation skills occurring during middle childhood, may be an important mechanism for the observed declines in academic achievement of some children during this period.

\section{The role of the wider developmental context}

The results of the multiple regression analyses indicate that the substantial continuity observed in the Key Stage assessments is fairly independent of wider developmental contexts. The four KS1 scores alone, account for $47 \%$ and $46 \%$ of the variance in KS2 mathematics and English assessments respectively, and when comprehensive controls for family background, parenting, and earlier child-level skills and capabilities are entered into the regression estimation, the proportion of variance explained does not substantially increase. That is not to say that features of the child and their family background do not matter for attainment in primary school, but that family background factors might have already exerted their considerable influence in the pre-school years (Feinstein 2003; Schoon 2006; Schoon et al (this issue). Furthermore, research by Sacker and colleagues (2002) demonstrates the importance of the timing of contextual influences on children's development, and suggests that family influences, such as parental involvement, become less important and school composition more so, in relation to educational achievement and psychosocial adjustment, as children move from middle to late childhood. An important avenue for research to pursue in the future, would be to similarly decompose the differential impact of changing contextual influences on attentional skills over time.

The analyses presented in this study show that while the average picture in children's academic achievement during primary school is one of stability, in line with the literature reviewed in the introduction, there is considerable mobility in attainment. Academic achievement is far from set in stone, yet neither is it a function of cognitive competencies alone, but a multi-dimensional construct involving skills and support structures that enable pupils to regulate their own learning. The results presented here thus highlight the need to understand better the balances of stability and change, continuity and discontinuity, alongside more holistic approaches and definitions of educational success, in order that all children are to be able to make the most of their learning opportunities and make good progress. Recognition and appreciation of these shifts and fluctuations are central to a focus on personalised learning, and are fundamental to closing the attainment gaps. Failure to appreciate this malleability is likely to lead to over-determining the meaning of these tests, and the result is likely to be that under-achievement becomes entrenched. 


\section{Acknowledgements}

The analysis and writing of this paper were supported by grants from the UK Economic and Social Research Council (ESRC): RES-594-28-0001 and RES-060-23-0011. Those who carried out the original collection of the data bear no responsibility for its further analysis and interpretation.

We are grateful to all the mothers who took part in the study and to the midwives for their cooperation and help in recruitment. The whole ALSPAC Study Team comprises interviewers, computer technicians, laboratory technicians, clerical workers, research scientists, volunteers and managers who continue to make the study possible. The ALSPAC study has been supported by funding from the Medical Research Council, the Wellcome Trust, UK government departments, medical charities and others, and is part of the World Health Organisationinitiated European Longitudinal Study of Pregnancy and Childhood.

\section{References}

Alexander KL, Entwisle DR and Dauber SL. (1993) First grade classroom behavior: its short- and long-term consequences for school performance. Child Development, 64, 801-814.

Barriga AQ, Doran JW, Newell SB, Morrison EM, Barbetti V and Robbins BD. (2002) Relationships between problem behaviors and academic achievement in adolescents: the unique role of attention problems. Journal of Emotional and Behavioral Disorders, 10(4), 233-240.

Blackwell LS, Trzesniewski K and Dweck CS. (2007) Implicit theories of intelligence predict achievement across an adolescent transition: a longitudinal study and an intervention. Child Development, 78(1), 246-263.

Blanden J and Machin S. (2007) Recent changes in intergenerational mobility in Britain. The Sutton Trust, London.

Breslau J, Breslau N, Bohnert K, Lucia VC and Schweitzer J. (2009) The impact of early behavior disturbances on academic achievement in high school. Pediatrics, 123(6), 1472-1476.

Breslau N, Breslau J, Peterson E, Miller E, Lucia VC, Bohnert K et al. (2010) Change in teachers' ratings of attention problems and subsequent change in academic achievement: a prospective analysis. Psychological Medicine, 40, 159-166.

Chan RCK, Lai MK and Robertson IH. (2006) Latent structure of the Test of Everyday Attention in a non-clinical Chinese sample. Archives of Clinical Neuropsychology, 21, 477-485.

Collins WA. (1984) Development during middle childhood. National Academy Press,

Washington, DC.

Cox JL, Holden JM and Sagovsky R. (1987) Edinburgh Postnatal Depression Scale (EPDS). Department of Psychiatry, University of Edinburgh.

Crown S and Crisp AH. (1979) Manual of the Crown-Crisp Experiential Index. Hodder and Stoughton, London.

Deci EL and Ryan RM. (1987) The support of autonomy and the control of behavior. Journal of Personality and Social Psychology, 53(6), 1024-1037.

Department for Education and Skills (2003). Statistics First Release Bulletin SFR 33/2003: http://www.dcsf.gov.uk/rsgateway/DB/SFR/s000433/sfr33-2003.pdf.

Department for Education and Skills. (2006) Making Good Progress: How can we help every pupil to make good progress at school? Consultation document.

Diamond A, Barnett WS, Thomas J and Munroe S. (2007) Preschool program improves cognitive control. Science, $318,1387-1388$

Diprete TA and Jennings JL. (2009) Social/Behavioral skills and the gender gap in early educational achievement (CPRC Working Paper No. 09-08). Columbia Population Research Center, New York.

Duncan G J, Dowsett C J, Claessens A, Magnuson K, Huston AC, Klebanov P, Pagani LS, Feinstein L, Engel M, Brooks-Gunn J, Sexton H, Duckworth K and Japel C. (2007). School Readiness and Later Achievement. Developmental Psychology, 43(6), 1428-1446.

Feinstein L. (1998) Pre-School Educational Inequality: British Children in the 1970 Cohort (Discussion Paper 404). Centre for Economic Performance, London.

Feinstein L. (2004) Mobility in pupils' cognitive attainment during school life. Oxford Review of Economic Policy, 20(2), 213-229.

Feinstein L and Bynner J. (2004) The importance of cognitive development in middle childhood for adulthood socioeconomic status, mental health, and problem behaviour. Child Development, 75(5), 1329-1339.

Golding J, Pembrey M, Jones R and the ALSPAC Study Team. (2001) The Avon Longitudinal Study of Parents and Children. I. Study methodology. Paediatric Perinatal Epidemiology, 15, 74-87. 
Goldstein H. (2009) Handling attrition and non-response in longitudinal data. Longitudinal and Life Course Studies, 1(1), 63-72.

Goodman R. (1997) The Strengths and Difficulties Questionnaire: a Research Note. Journal of Child Psychology and Psychiatry, 38, 581-586.

Hallam S, Rhamie J and Shaw J. (2006) Evaluation of the Primary Behaviour and Attendance Pilot (RR 717). Department for Education and Skills, London.

Harter S. (1982) The perceived competence scale for children. Child Development, 53, 87-97.

Heckman JJ and Rubinstein Y. (2001) The importance of noncognitive skills: lessons from the GED Testing Program. The American Economic Review, 91(2), 145-149.

Heckman JJ, Stixrud J and Urzua S. (2006) The effects of cognitive and non-cognitive abilities on labor market outcomes and social behavior. Journal of Labor Economics, 24, 411-482.

Hiebert J and Wearne D. (1996) Instruction, understanding, and skill in multidigit addition and subtraction. Cognition and Instruction, 14, 251-283.

Huang-Pollock CL, Carr TH and Nigg JT. (2002) Development of selective attention: perceptual load influences early versus late attentional selection in children and adults. Developmental Psychology, 38, 363-375.

Huston AC and Ripke MN. (2006) Developmental contexts in middle childhood. New York: Cambridge University Press.

Keating DP. (2004) Cognitive and brain development. In RJ Lerner and LD Steinberg eds. Handbook of adolescent psychology. Pp 45-84, $2^{\text {nd }}$ vol, Wiley \& Sons, New York.

Kowleski-Jones L and Duncan GJ. (1999) The Structure of Achievement and Behavior across Middle Childhood. Child Development, 70(4), 930-943.

Lefcourt H. (1982) Locus of control: current trends in theory and research. (2nd ed). Lawrence Erlbaum, Hillsdale, NJ.

Leppänen U, Niemi P, Aunola K and Nurmi J. (2006) Development of reading and spelling Finnish from preschool to Grade 1 and Grade 2. Scientific studies of reading, 10(1), 3-30.

Levačić R, Jenkin A, Vignoles A, Steele F and Allen R. (2005) Estimating the relationship between school resources and pupil attainment at Key Stage 3. (Research Report No.679). DfES, London.

Manly T, Anderson V, Nimmo-Smith I, Turner A, Watson P and Robertson IH. (2001) The differential assessment of children's attention: The Test of Everyday Attention for Children (TEA-Ch), normative sample and ADHD performance. Journal of Child Psychology and Psychiatry, 42(8), 1065-1081.

McCall RB, Appelbaum MI and Hogarty PS. (1973) Developmental changes in mental performance. Monographs of the Society for Research in Child Development, 38 (3, Serial No. 150).

McClelland M, Morrison FJ and Holmes DL. (2000) Children at risk for early academic problems: the role of learning-related social skills. Early Childhood Research Quarterly, 15, 307-329.

Melhuish E, Romaniuk H, Sammons P, Sylva K, Siraj-Blatchford I and Taggart B. (2006) The effectiveness of primary schools in England in Key Stage 2 for 2002, 2003 and 2004. DfES / Institute of Education, London.

Nowicki S and Duke MP. (1974) A preschool and primary internal-external control scale. Developmental Psychology, 10, 874-881.

Posner MI and Petersen SE. (1990) The attention system of the human brain. Annual Review of Neuroscience, 13, 25-42.

Pungello EP, Kupersmidt JB, Burchinal MR and Patterson CJ. (1996) Environmental risk factors and children's achievement from middle childhood to early adolescence. Developmental Psychology, 32(4), 755-767.

Raver CC, Smith-Donald R, Hayes T and Jones SM. (2005) Self-regulation across differing risk and sociocultural contexts: preliminary findings from the Chicago School Readiness Project. Paper presented at the biennial meeting of the Society for Research in Child Development, Atlanta, GA.

Rimm-Kaufmann SE, Fan X, Chiu Y and You W. (2007) The contribution of the responsive classroom approach on children's academic achievement: results from a three year longitudinal study. Journal of School Psychology, 45, 401-421.

Robertson IH. Ward T, Ridgeway V and Nimmo-Smith I. (1996) The structure of normal human attention: the Test of Everyday Attention. Journal of the International Neuropsychological Society, 2, 525-534.

Rubin DB. (1987) Multiple Imputation for Nonresponse in Surveys. Wiley and Sons, New York.

Sacker A, Schoon I and Bartley M. (2002) Social inequality in educational achievement and psychosocial adjustment throughout childhood: magnitude and mechanisms. Social Science and Medicine, 55, 863880.

Scarborough HS. (2001) Connecting early language and literacy to later reading (dis)abilities: evidence, theory, and practice. In SB Neuman and DK Dickinson. eds. Handbook of early literacy research. The Guilford Press, New York. 
Schafer JL. (1997) Analysis of incomplete multivariate data. Chapman and Hall, London.

Schoon I. (2006) Risk and resilience: adaptations in changing times. Cambridge University Press, Cambridge.

Schoon I, Hope S, Ross A and Duckworth K. (2010) Family hardship and school readiness: a study of mediating processes in the first three years of life. Longitudinal and Life Course Studies 1, 209-222.

Siegler RS and Alibali MW. (2004) Children's thinking. Prentice Hall, Upper Saddle River, NJ.

South Gloucestershire Professional and Curriculum Support Service. (1996) Entry Assessment in South Gloucestershire. Woodspring Educational Resource Centre, Weston-super-Mare.

Storch SA and Whitehurst GJ. (2002) Oral language and code-related precursors to reading: evidence from a longitudinal structural model. Developmental Psychology, 38, 934-947.

Wilson RS. (1983) The Louisville twin study: developmental synchronies in behaviour. Child Development, 54, 298-316.

Yen C, Konold TR and McDermott PA. (2004) Does learning behavior augment cognitive ability as an indicator of academic achievement? Journal of School Psychology, 42, 157-169.

Zins JE, Bloodworth MR, Weissberg RP and Walberg HJ. (2004) The scientific base linking social and emotional learning to school success. In JE Zins, RP Weissberg, MC Wang and HJ Walberg. eds. Building academic success on social and emotional learning: what does the research say? Pp 3-22. Teachers College Press, New York.

\section{Endnotes}

${ }^{i}$ Key Stage 1 is the term for the two years of schooling in maintained schools in England and Wales normally known as Year 1 and Year 2, when pupils are aged between 5 and 7.

ii An area around Bristol in the South West of England

iii Mothers who were resident in the area but left shortly after enrolment were omitted from further follow-up. However, those who had completed the questionnaire scheduled for the third trimester of pregnancy before leaving the study area have been kept in the study, even if they had not delivered at the time of moving.

iv The National Curriculum Key Stages are built on 10 levels which cover the range $5-16$ years and are arranged so that, on average, pupils are expected to progress one level every two years. A coefficient of 0.5 therefore equates to approximately one year's progress, a coefficient of 0.25 , approximately six months' progress and so on.

${ }^{v}$ Level $4+$ is assessed by means of KS2 materials. However, there were so few children achieving Level $4+(\mathrm{N}=10)$ that it has been combined with Level 3.

vi "Disapplied" is a formal DCSF term defined as the very small number of pupils who are not able to take part in some or all of the assessment arrangements, even allowing for the full range of special arrangements that can be made. Usually this only happens if all or part of the National Curriculum is not suitable for a pupil because he or she has certain special educational needs. Source: http://www.dcsf.gov.uk/performancetables/primary_01/glossary.shtml

vii Where father/partner's education is not available, we use mother's education.

viii Information on school level clustering was not available at the time of analysis to carry out multilevel modelling so as to examine any peer group effects here.

${ }^{i x}$ It should be noted, however, that from a developmental perspective, there is not absolute continuity of meaning and measurement across these ages as cognitive ability and behaviour are still being acquired. Hence, it is inevitable that error and instability in measurement remain and so reduce the extent to which a change interpretation in a strict econometric sense is appropriate.

${ }^{x}$ Higher scores in locus of control assessments indicate individuals have a more externalised sense of perceived control in their lives where fate and luck are more in control.

${ }^{x i}$ Owing to space limitations the quartile transition matrices for these data are not shown. Tables are available from the authors on request.

xii The SDQ sub-scale is made up of five items covering parental reports of restless, overactive behaviour; constant fidgeting; easily distracted; thinking before acting; and having a good attention span. 


\title{
Childhood cognitive ability and adult academic attainment: evidence from three British cohort studies
}

\author{
Ingrid Schoon \\ Institute of Education, London \\ I.Schoon@ioe.ac.uk
}

(Received May 2010 Revised June 2010)

\section{Abstract}

This paper examines the association between general cognitive ability directly measured at age 10/11, and adult academic attainment in three British birth cohorts born in 1946, 1958, and 1970, controlling for family socio-economic background and gender. The study uses structural equation modeling to link latent variables indicating family socio-economic background, childhood general cognitive ability, and academic attainment, assessed through school leaving age and highest qualifications achieved by age 26. In addition, logistic regression modeling is used to establish the odds of obtaining degree level qualifications in times of social change. The results show that the association between family social background and academic attainment has remained more or less the same over time, gender inequalities have reduced, while the association between general cognitive ability and academic attainment has decreased for the 1970 cohort. Although more young people achieve degree level qualifications in the later born cohort, the findings suggest persisting social inequality in the realisation of cognitive potential and educational opportunities. The findings are discussed in terms of their policy implications.

\section{Introduction}

The aims of this paper are threefold. First, to examine changes in the association between family socio-economic background, general cognitive ability and academic attainment in a changing sociohistorical context. Second, to assess gender differences in the associations. Third, to assess the predictive power of social background, gender, general cognitive ability and the interactions between these variables for gaining a degree level qualification in a changing social context. The study will draw on evidence from three British birth cohorts born in 1946, 1958 and 1970 respectively. The three birth cohorts were born at crucial turning points in British social history, as the 1946 cohort grew up during a period of extraordinary economic growth and social transformation which started after the post-war years and ended in the mid 1970s (see Sutherland, this issue). Eric Hobsbawm (1995) had described this period as a 'Golden Age' which was followed by the 'Crisis Decades'. The 1958 cohort completed their compulsory education in 1974 and made the transition into the labour market at the beginning of a major economic recession, while the 1970 cohort reached compulsory school leaving age in 1984, just at the height of the 1980's recession. Evidence from the three birth cohorts will thus provide crucial information about changes in educational opportunities in times of social change, and can assess changes in the odds of realizing one's cognitive potential. 


\section{Socio-historical change}

There is persisting evidence of the positive association between general cognitive ability, academic attainment and career success (Deary, Strand, Smith, and Fernances 2007; Gottfredson 1997; Jensen 1998; Mackintosh 1998; Sternberg, Grigorenko and Bundy 2001). Yet a number of key questions regarding this association have remained unanswered, especially those regarding historical changes in the relationship between cognitive ability and career success, and the role of family socioeconomic status in shaping both childhood cognitive ability and later attainments (Strenze 2007). The role of these interlinked variables in predicting academic attainment in times of social change is generally difficult to disentangle, especially due to the lack of suitable longitudinal studies, enabling the comparison of similar indicators in different age cohorts. Furthermore, the role of historical changes in the relationship between general cognitive ability and socio-economic success is a particularly controversial issue, following the publication of the 'Bell Curve' by Hernstein and Murray (1994). These authors argue that the association between mental ability and career success has been growing in western societies throughout the $20^{\text {th }}$ century, and that cognitive ability is becoming more important in influencing where one ends up in the socio-economic hierarchy. Although some studies have found support for this thesis of achievement over ascription (Murnane, Willet and Levy 1995; Saunders 1997, 2002), there is also contradictory evidence, calling into question the increasing importance of general cognitive ability in shaping career success (Bowles 1972; Flynn 2004; Hauser and Huang 1997). Reviewing evidence from eleven surveys conducted in the USA between 1928 and 1974, Jencks and colleagues (1979) found no clear trend in the correlations between cognitive ability and socio-economic success. Evidence from the UK, drawing on data collected for the 1946 and the 1958 cohort, showed a reduced association between childhood cognitive ability and adult educational attainment for the later born 1958 cohort (Richards, Power and Sacker 2009). Furthermore, findings from a comparison of data collected for the 1958 and 1970 cohort, suggests that the association between general cognitive ability and adult socio-economic status is further declining (Breen and Goldthorpe 2001; Schoon 2008).

In the UK, the 1944 Education Act was introduced with the aim of increasing educational opportunities irrespective of financial means or socio-economic background, and to raise the overall educational level in the population (Kerckhoff and Trott 1993; Sutherland, this issue). During the 'Golden Age' (Hobsbawm, 1995), educational spending had been growing, while after the mid-1970s it started to fall, followed by a recovery in the 1990s. At the same time, education and employment opportunities have changed dramatically. Between 1951 and 1991 the United Kingdom witnessed a significant decline in manual jobs, while employment in clerical occupations has increased, and work in professional and managerial professions has tripled (Gallie 2000). Following the introduction of new technologies and the disappearance of manual jobs, increasing numbers of young people are expected to participate in further education beyond compulsory schooling age (Bynner and Parsons 2002; Furlong and Cartmel 1997; Rosenbaum 2001), and during the last two decades a growing number of young people have participated in higher education, once the preserve of a privileged minority (Blossfeld and Shavit 1993; Bynner 2005; McVicar and Rice 2001). Some have taken increased education participation as indicating that talented individuals from less privileged backgrounds are taking advantage of expanding opportunities to gain educational credentials (Bond and Saunders 1999; Saunders 1997). On the other hand, it has been argued that the not so able individuals from privileged backgrounds have benefited most from the educational expansion, i.e. that although absolute rates of education participation have increased, relative differences between individuals from different social backgrounds have remained (Blanden and Machin 2003; Bynner and Joshi 2002; Galindo-Rueda and Vignoles 2005; Marshall, Swift and Roberts 1997; Schoon 2008). 


\section{Gender differences}

Another aspect to be addressed in this paper is the gender gap in academic attainment. Until recently, the majority of research on gender differences in educational opportunities and attainment had focused on the ways in which girls are disadvantaged in comparison to boys. Until the early 1970s, young women tended to gain fewer formal qualifications and were generally underrepresented in the Universities. By the early 1980s the situation started to change, and girls began to catch up with or even overtake boys in their academic attainments (Arnot, David, and Weiner 1999; Francis 2000). The 'underachievement' of boys has to some extent brought about something of a moral panic, with appeals to the government to act in support of struggling boys (Epstein, Elwood, Hey and Maw 1998; Younger and Warrington 2006). The success and achievements of girls in the school system, on the other hand, has been hailed as a story of extraordinary success of post-war egalitarian movements. It has been argued that prior to the 1970s, boys and girls were educated for very different occupational and domestic roles (Riddell 2000), while the 1975 Sex Discrimination Act made it unlawful to treat girls differently from boys regarding access to courses, and educational and occupational opportunities. On the other hand, continuing inequalities and persistent disadvantages for women regarding subject choice and opportunities in higher education and socio-economic status attainment have received less attention (Francis 2002; Marini and Fan 1997; Tinklin 2003). Although women make up more than half of higher education students and almost half of the labour force, proportionately fewer women than men rise to the top of their professions (Crompton 2006; Farmer 1997, 2006). There continue to be barriers and obstacles to female career development, as reflected in gender role stereotypes, gender discrimination, and occupational sexsegregation (Scott, Dex, Joshi, Purcell and Elias 2008).

\section{The Model}

Changes in the associations between social background, academic ability, educational attainment, and gender will be examined in three British birth cohorts. It is assumed that, following the introduction of the 1975 Sex Discrimination Act and the increasing expansion of further and higher education, the association between gender, social background and academic attainment is decreasing for the later born cohorts. To test this assumption, the study will advance methodologically from previous studies by using structural equation modeling (SEM) as well as multiple regression analysis. Using latent variables instead of directly observed measures, facilitates a comparative approach to data collected during different sociohistorical periods and with different assessments (Bollen 1989).

\section{Figure 1. The Model}

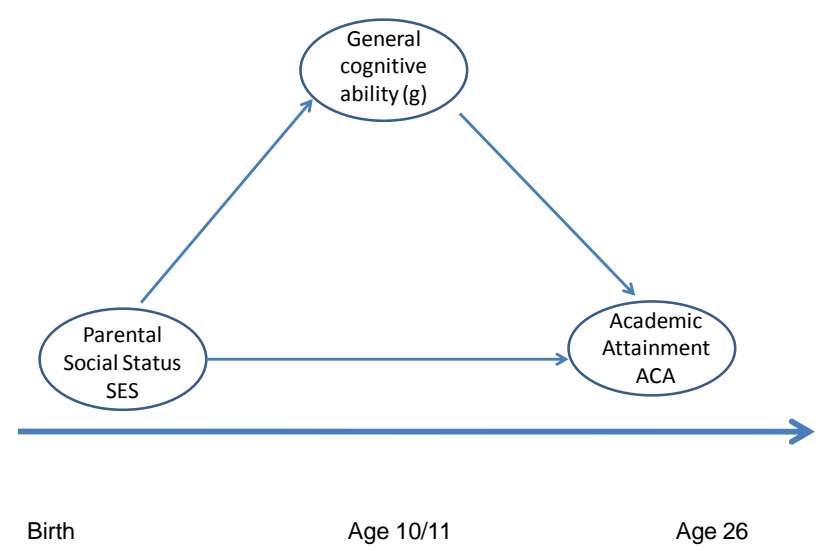


Figure 1 illustrates the associations to be tested in all three cohorts. The usual SEM conventions are used, with latent variables shown as oval shapes. Singleheaded arrows represent causal influences. Unique and error variance for each manifest variable and disturbance on the latent variables are included in the model (not shown in the diagram). Family social status at birth is assumed to be associated with general cognitive ability in mid-childhood, and both variables are assumed to shape later academic attainment. Family social position is indicated through the combination of father's occupational status and mother's education, following the assumption that a single social class measure might be an unreliable and incomplete indicator of social status (Korenman and Winship 2000; Lampard 1995), and that the combination of occupational class and education can be used to indicate social position, reflecting socio-economic resources as well as cultural characteristics relevant to the study of life chances (Gershuny 2000). Academic attainment in young adulthood is indicated by the age at leaving full-time education and highest qualifications achieved by age 26 .

\section{Method}

\section{Samples}

The study draws on three national birth cohort studies: the 1946 National Survey of Health and Development (NSHD), 1958 National Child Development Study (NCDS), and the 1970 British Cohort Study (BCS70) following the lives of cohort members from birth into adulthood. Each of the studies covers England, Wales and Scotland and their populations represent the national population of the same age (Ferri, Bynner and Wadsworth 2003). The 1946 cohort (Wadsworth et al 2005) followed a third of all individuals born within one week in the year in question $(n=5,362)$, and the later two studies followed up all individuals born within a chosen week, comprising 17,414 cohort members born in 1958 and 17,198 born in 1970 . The analytic samples are based on cohort members with complete information on parental socio-economic status and direct cognitive assessments at age 10 or 11 , which was then linked to information on academic attainments by age 26 , comprising 3,730 cohort members of the 1946 cohort, 9270 of the 1958 cohort and 7,310 of the 1970 cohort. Compared to the analytic samples, those individuals who did not complete the adult follow-up sweeps had a lower score on the test of general cognitive ability and a more disadvantaged family social background. To account for sample attrition and missingness between survey sweeps we used multiple imputation, as described in the section on statistical analysis.

\section{Measures \\ Family social status at birth}

Family social status is indicated by parental occupational social class and maternal education. Parental occupational social class was measured through the father's current or last held job, coded according to the Registrar General's measure of social class (RGSC). The RGSC is defined according to job status and the associated education, prestige (OPCS and Surveys, 1980) or lifestyle (Marsh, 1986). It is coded on a six-point scale: I professional; II managerial and technical; IIINM skilled non-manual; IIIM skilled manual; IV partly skilled; V unskilled (Leete and Fox 1977)'. Class I represents the highest level of prestige or skill and class $V$ the lowest. Maternal education is coded as a dichotomous variable indicating whether or not the mother has participated in further education beyond compulsory school leaving age.

\section{Childhood cognitive ability at age 10/11 years}

Childhood cognitive ability was assessed differently in the three cohorts. In the 1946 cohort, general cognitive ability was assessed at age 11 years, using a verbal and non-verbal test, both devised by the National Foundation for Educational Research (NFER) (see also Richards, Stephen and Mishra, this issue). In the 1958 cohort a general ability test has been completed by cohort members at age 11, comprising the assessment of both verbal and non-verbal skills. Scores from this test correlate strongly with scores on an IQ-type test used for secondary school selection $(r=0.93)$, suggesting that the test can serve as a good proxy for IQ scores (Douglas, 1964). In the 1970 cohort a modified version of the British Ability Scales (BAS) was directly administered at age 10 (Elliott, Murray and Pearson 1979), using four sub-scales: word definitions and word similarities were used to measure verbal ability, and recall of digits and 
matrices was used to measure non-verbal ability. For all three cohorts, a principal components analysis (PCA) was carried out for each of the verbal and nonverbal sub-tests, in order to establish the presence of a general cognitive ability factor (g). In all three cohorts, the examination of the scree slope suggested the presence of a single component. The first principal component scores were saved for each subject as an indicator of each person's general cognitive ability (g) and were standardised to a mean of 0 and an SD of 1.

\section{Academic attainment by age 26}

Academic attainment was indicated by age at leaving full-time education, and the highest educational qualifications achieved by age 26 . In all three cohorts, a broad classification of academic and vocational qualifications based on a scale related to the National Vocational Qualification (NVQ) levels was used (Makepeace, Dolton, Woods, Joshi and Galinda-Rueda 2003), differentiating between cohort members who had left school with no qualifications, those with qualifications up to NVQ level 2 (equivalent to GCSE or ordinary secondary qualifications and their training equivalents), those with advanced secondary education or NVQ level 3 ('A' levels or university entry qualifications and their equivalents), or NVQ level 4 and above (degree level or equivalent).

\section{Statistical analysis}

All SEM analyses were carried out using the software package Mplus v5 (Muthén and Muthén 2007). The program applies a robust full information EM estimator that corrects for bias under the assumption that missing data are missing at random, which means that 'missingness' is permissible even when it is related to covariates or outcomes, so long as covariate status does not determine presence or absence of data (Little and Rubin 2002). Probit regressions were used, based on robust weighted least squares estimation. Because of the ordered categorical variables which functioned as both independent and dependent, the theta parameterization was necessary. Estimation is based on the covariance matrices between observed variables for all patterns of missing data in the other observed variables. Regression estimates convert probit estimates for ordinal dependent variables to a common metric that allows comparison with standardised linear regression estimates for the continuous variables.

In line with current practice, several criteria were used to assess the fit of the data to the model. The $\chi^{2}$ statistic is overly sensitive to model misspecification when sample sizes are large, or the observed variables are non-normally distributed. The root mean square error of approximation (RMSEA) gives a measure of the discrepancy in fit per degrees of freedom (<.05 indicates a good fit). The final index of choice is the comparative fit index (CFI) where values above .95 indicate acceptable fit (Bentler 1990).

In addition to SEM, multiple logistic regression analysis was used to assess the predictive power of social background, general cognitive ability and gender, in predicting who gains a degree level qualification in times of social change, pooling information from the different data sets.

\section{Results}

Table 1 gives the descriptive statistics of the categorical variables used in the model. There has been an upward shift in the distribution of parental social class. In the 1946 cohort, 85 per cent of fathers were in a manual occupation, compared to about two-thirds of fathers of the 1958 and 1970 cohort. There also has been an increase in professional and managerial occupations among fathers of the later born cohorts. About two-thirds of mothers of the 1946 and 1970 cohort left school a minimum age, compared to three quarters of mothers of the 1958 cohort. It has to be kept in mind that after World War II the minimum school leaving age was raised to 15 years. In 1972 compulsory school leaving age was increased from 15 to 16, with the 1958 cohort members being the first cohort to remain in school until age 16. However, in both the 1958 and 1970 cohort there were a small number of young people who left school before compulsory school leaving age.

By age 26 only about one in ten individuals born in 1946 succeeded in gaining degree level qualifications, compared to about a fifth in the 1958 cohort and nearly a third in the 1970 cohort.

There were no gender differences regarding the socio-demographic background variables. However, 
while in the 1946 cohort, fewer women than men stayed on in full-time education beyond age 15 (27 per cent of men versus 22.8 per cent of women), women in the later-born cohorts are catching up, with 32.4 per cent of men and 39.1 per cent of women in the 1958 cohort and 40.4 per cent of men versus 49.8 per cent of women in the 1970 cohort, staying on beyond age 16. Likewise in the 1946 cohort, fewer women than men succeeded in gaining a degree level qualification (5.4 per cent of women compared to 13.1 per cent of men) while in the later born cohorts, gender parity was more or less achieved in this respect.

Table 1. Descriptive Statistics of Cohort Characteristics (in percent)

\begin{tabular}{|c|c|c|c|}
\hline & 1946 Cohort & 1958 Cohort & 1970 Cohort \\
\hline Gender (\% male) & 52.5 & 51.7 & 48.1 \\
\hline \multicolumn{4}{|l|}{ Father's occupational status } \\
\hline Professional & 2.3 & 4.7 & 5.0 \\
\hline Managerial & 6.1 & 14.7 & 12.5 \\
\hline Skilled non-manual & 6.6 & 10.6 & 15.3 \\
\hline Skilled manual & 45.1 & 50.1 & 46.0 \\
\hline Semi-skilled & 30.2 & 11.4 & 15.6 \\
\hline Unskilled & 9.7 & 7.9 & 5.6 \\
\hline \multicolumn{4}{|l|}{ Mother's education } \\
\hline Left education at min. age & 64.2 & 75.0 & 64.4 \\
\hline \multicolumn{4}{|l|}{ Age left education } \\
\hline 15 & 54.5 & 3.4 & 2.3 \\
\hline 16 & 20.5 & 58.0 & 52.1 \\
\hline $17-18$ & 23.0 & 19.6 & 24.9 \\
\hline $18+$ & 2.0 & 16.1 & 20.7 \\
\hline \multicolumn{4}{|l|}{ Highest Qualifications } \\
\hline None & 38.6 & 12.1 & 3.3 \\
\hline NVQ1-2 (some) & 27.2 & 48.9 & 47.3 \\
\hline
\end{tabular}


(Table 1 cont'd)

\begin{tabular}{|l|c|c|c|}
\hline NVQ3 (A-level) & 24.7 & 17.3 & 18.0 \\
\hline NVQ4 (degree) & 9.5 & 21.7 & 31.4 \\
\hline $\mathrm{N}$ & 3730 & 9270 & 7310 \\
\hline
\end{tabular}

Table 2 gives the bivariate correlations between the observed variables. General childhood cognitive ability (g), indicated by the PCA factor scores, shows moderate associations with the parental social status indicators, with little variation in size between the cohorts. The correlations between $\mathrm{g}$ and academic attainment, i.e. age leaving school and highest qualifications, were moderate to strong and weaken over time. Furthermore, there appears to be a reduction in the strength of correlation between academic attainment and parental socio-economic background, possibly reflecting increasing education participation of relative disadvantaged young people, which is also shown by Gregg and Macmillan (this issue).

There were significant gender differences in general cognitive ability as well as academic attainment. Women in the 1946 and 1958 cohorts score higher than men in the cognitive assessment, while in the 1970 cohort they score lower than men.
In all three cohorts, women were less likely than men to obtain higher level qualifications, although, with the exception of the 1946 cohort, they were more likely to stay on longer in full-time education. The question of gender differences in cognitive ability continues to be debated, and there is uncertainty about their extent, or their even existence (Jensen 1998; Lynn 1999; Mackintosh 1996). Evidence from the UK suggests that even when sex differences in mean IQ scores are found, they tend to be small, with greater variance among boys (Deary, Strand, Smith, and Fernances 2007; Dykiert, Gale and Deary 2009; Strand, Deary and Smith 2006). However, it must also be kept in mind that cognitive ability scores obtained in the different cohorts are not directly comparable, as they have been assessed with different test instruments. Furthermore, there had been sample restrictions from the baseline population, with fewer males than females participating in the follow-up sweeps, especially in the 1970 cohort. 
Table 2. Bivariate correlations in the 3 cohorts

\begin{tabular}{|c|l|l|l|}
\hline & 1946 Cohort & 1958 Cohort & 1970 Cohort \\
\hline Correlation with general ability (g)\# & & & \\
\hline Father's occupational status & $-.337^{*}$ & $-.297^{*}$ & $-.304^{*}$ \\
\hline Mother's education & $-.311^{*}$ & $-.255^{*}$ & $-.305^{*}$ \\
\hline Age leaving ft education & $.540^{*}$ & $.466^{*}$ & $.364^{*}$ \\
\hline Highest qualifications & $.556^{*}$ & $.482^{*}$ & $.412^{*}$ \\
\hline Gender & $.072^{*}$ & $.067^{*}$ & $-.040^{*}$ \\
\hline Correlation with age leaving ft education & & & \\
\hline Father's occupational status & $-.432^{*}$ & $-.367^{*}$ & $-.322^{*}$ \\
\hline Mother's education & $-.403^{*}$ & $-.326^{*}$ & $-.317^{*}$ \\
\hline Highest qualifications & $.714^{*}$ & $.638^{*}$ & $.593^{*}$ \\
\hline Gender & $-.039^{*}$ & $-.043^{*}$ & $.066^{*}$ \\
\hline Correlation with highest qualification & $-.403^{*}$ & $-.288^{*}$ & $-.086^{*}$ \\
\hline Father's occupational status & $-.116^{*}$ & $-.052^{*}$ & \\
\hline Mother's education & & & \\
\hline
\end{tabular}

\section{Notes}

\# General cognitive ability $(\mathrm{g})$ is here measured by the factor score of the Principal Component Analysis, which has a mean of 0 and a standard deviation of 1 .

$* p<0.001$

Table 3 gives the estimates for the SEM model depicted in Figure 1, which was run separately for each cohort. The numerical values refer to standardized regression weights, taking into account all variables in the model simultaneously. The model has two components: one giving the relationships between the latent variables and their indicators (the measurement model), and the other defining the relationships among the latent variables (the structural model). Information is also provided for the model fit. The measured variables loaded strongly on the latent variable, all path coefficients were significant at the $5 \%$ level or less (parameter estimates divided by their standard errors), and the model showed a good fit. In the 1946 cohort the model explained 75 per cent of variance in academic attainment, in the 1958 cohort 51 per cent, and in the 1970 cohort 54 per cent. 
Table 3. Results from the Structural Equation Model, linking Parental Social Status to general ability and academic attainment: Standardised Estimates, standard errors, and model fit

\begin{tabular}{|c|c|c|c|}
\hline Measurement Model & 1946 Cohort & 1958 Cohort & 1970 Cohort \\
\hline \multicolumn{4}{|l|}{ Parental Social Status (SES) } \\
\hline Father's occupational status & $.68(.01)$ & $.65(.01)$ & $.62(.01)$ \\
\hline Mother's education & $.77(.02)$ & $.73(.01)$ & $.72(.01)$ \\
\hline \multicolumn{4}{|l|}{ General Ability (g) } \\
\hline Verbal ability (BCS: definitions) & $.93(.01)$ & $.90(.01)$ & $.81(.01)$ \\
\hline Verbal ability (BCS: similarities) & & & $.75(.01)$ \\
\hline Nonverbal ability (BCS: matrixes) & $.87(.01)$ & $.88(.01)$ & $.56(.01)$ \\
\hline Nonverbal ability (BCS: digits) & & & $.40(.01)$ \\
\hline \multicolumn{4}{|l|}{ Academic Attainment (ACA) } \\
\hline Age leaving $\mathrm{ft}$ education & $.92(.01)$ & $.88(.01)$ & $.86(.01)$ \\
\hline Highest qualifications at age 26 & $.89(.01)$ & $.87(.01)$ & $.76(.01)$ \\
\hline \multicolumn{4}{|l|}{ Pathway Coefficients } \\
\hline $\mathrm{SES} \rightarrow \mathrm{g}$ & $-.54(.02)^{\mathrm{ab}}$ & $-.48(.01)^{\mathrm{ac}}$ & $-.60(.01)^{b c}$ \\
\hline $\mathrm{SES} \rightarrow \mathrm{ACA}$ & $-.57(.02)^{\mathrm{ab}}$ & $-.49(.02)^{\mathrm{ac}}$ & $-.54(.03)^{\mathrm{bc}}$ \\
\hline $\mathrm{g} \rightarrow \mathrm{ACA}$ & $.41(.02)^{b}$ & $.41(.01)^{c}$ & $.27(.02)^{b c}$ \\
\hline \multicolumn{4}{|l|}{ Model Fit } \\
\hline$X^{2}(d f)$ & $18.11(6)$ & $112.04(6)$ & $166.94(15)$ \\
\hline CFI & 0.999 & 0.996 & 0.989 \\
\hline RMSEA & 0.024 & 0.037 & 0.035 \\
\hline $\mathrm{N}$ & 3730 & 9270 & 7310 \\
\hline
\end{tabular}

Note. Differences in pathway coefficients between cohorts were tested using t-tests. Significant $(p<.001)$ differences are indicated through letters a-c:
a -1946 and 1958
b -1946 and 1970
c- 1958 and 1970 
The standardized regression weights linking parental social status with childhood cognitive ability were significant, and the association increases over time, especially between assessments for the 1958 and 1970 cohort. Although the association was strong, it does not explain more than a quarter (in the two older birth cohorts) to a third of the variation in cognitive ability (in the youngest cohort). Both family socio-economic background and childhood cognitive ability were significantly associated with academic attainment. The association between parental social background and academic attainment remained more or less of similar strength for the three cohorts, although, compared to the 1958 cohort, it appears to have increased for the 1970 cohort. On the other hand, the association between childhood general cognitive ability and academic attainment has reduced for the 1970 cohort.

The model was also fitted for men and women separately for the three cohorts. Multiple group analysis suggests significant gender differences in the estimated coefficients, although the actual coefficients for men and women in the different cohorts are quite similar. Table 4 shows the standardized estimates, standard errors and model fit for men and women in the three cohorts separately.

For men in the 1946 and 1958 cohort, the association between family social background and general cognitive ability is slightly less strong than for women. The same applies for the association between family social background and adult academic attainment in the 1946 cohort. The association between general cognitive ability and academic attainment, on the other hand, was stronger for men than for women in the 1946 and 1958 cohort. In the 1970 cohort, the pathway coefficients were of similar size for men and women. The findings could thus indicate that for women in the earlier born cohorts, educational opportunities and the realization of cognitive potential were more constrained by social background factors, than for men. For the 1970 cohort, the findings suggest more gender equality in academic attainment. 
Table 4. Results from the Structural Equation Model linking Parental Social Status to general ability and academic attainment: Standardised Estimates, standard errors, and model fit for men and women in the three birth cohorts

\begin{tabular}{|c|c|c|c|c|c|c|}
\hline & \multicolumn{2}{|c|}{1946 Cohort } & \multicolumn{2}{|c|}{1958 Cohort } & \multicolumn{2}{|c|}{1970 Cohort } \\
\hline Measurement Model & Men & Women & Men & Women & Men & Women \\
\hline \multicolumn{7}{|l|}{ Parental Social Status (SES) } \\
\hline Father's occupational status & $.68(.02)$ & $.68(.02)$ & $.64(.02)$ & $.65(.02)$ & $.63(.02)$ & $.62(.01)$ \\
\hline Mother's education & $.78(.02)$ & $.75(.02)$ & $.73(.02)$ & $.73(.02)$ & $.73(.02)$ & $.72(.01)$ \\
\hline \multicolumn{7}{|l|}{ General Ability (g) } \\
\hline Verbal ability (BCS: definitions) & $.95(.01)$ & $.94(.01)$ & $.89(.01)$ & $.93(.01)$ & $.81(.01)$ & $.82(.01)$ \\
\hline Verbal ability (BCS: similarities) & & & & & $.76(.01)$ & $.75(.01)$ \\
\hline Non-verbal ability (BCS: matrixes) & $.87(.01)$ & $.85(.01)$ & $.88(.01)$ & $.87(.01)$ & $.57(.01)$ & $.56(.01)$ \\
\hline Non-verbal ability (BCS: digits) & & & & & $.40(.01)$ & $.39(.01)$ \\
\hline \multicolumn{7}{|l|}{ Academic Attainment (ACA) } \\
\hline Age leaving $\mathrm{ft}$ education & $.93(.01)$ & $.89(.01)$ & $.85(.01)$ & $.90(.01)$ & $.84(.01)$ & $.87(.01)$ \\
\hline Highest qualifications at age 26 & $.86(.01)$ & $.95(.01)$ & $.85(.01)$ & $.91(.01)$ & $.79(.01)$ & $.76(.01)$ \\
\hline \multicolumn{7}{|l|}{ Pathway Coefficients } \\
\hline $\mathrm{SES} \rightarrow \mathrm{g}$ & $-.53(.03)$ & $-.56(.03)$ & $-.45(.02)$ & $-.52(.02)$ & $-.60(.02)$ & $-.60(.01)$ \\
\hline
\end{tabular}


(Table 4 cont'd)

\begin{tabular}{|l|l|l|l|l|l|l|}
\hline $\mathrm{SES} \rightarrow \mathrm{ACA}$ & $-.54(.03)$ & $-.60(.03)$ & $-.48(.02)$ & $-.49(.02)$ & $-.54(.04)$ & $-.54(.03)$ \\
\hline $\mathrm{g} \rightarrow \mathrm{ACA}$ & $.46(.03)$ & $.37(.03)$ & $.46(.02)$ & $.37(.02)$ & $.28(.03)$ & $.27(.02)$ \\
\hline Model Fit & & & & & & \\
\hline $\mathrm{X}^{2}$ (df) & $12.41(6)$ & $6.67(6)$ & $50.44(6)$ & $19.01(6)$ & $97.32(15)$ & $67.78(15)$ \\
\hline $\mathrm{CFI}$ & 0.999 & 1.00 & 0.997 & 0.999 & 0.988 & 0.993 \\
\hline RMSEA & 0.022 & 0.008 & 0.033 & 0.018 & 0.037 & 0.028 \\
\hline $\mathrm{N}$ & 1937 & 1793 & 4792 & 4478 & 3519 & 3791 \\
\hline
\end{tabular}


Table 5. Logistic Regression. Predicting obtaining a degree level qualification by general cognitive ability, social background and gender (odds ratios and 95\% confidence interval)

\begin{tabular}{|c|c|c|c|}
\hline & $\operatorname{Exp}(B)$ & $95 \% \mathrm{Cl}$ & $\mathbf{p}$ \\
\hline General cognitive ability & 2.91 & $(2.62,3.23)$ & 0.000 \\
\hline \multicolumn{4}{|l|}{ Cohort (1946 as baseline) } \\
\hline 1958 cohort & 4.42 & $(3.77,5.17)$ & 0.000 \\
\hline 1970 cohort & 4.68 & $(3.17,6.91)$ & 0.000 \\
\hline \multicolumn{4}{|l|}{ Gender (male as baseline) } \\
\hline female & .75 & $(0.57,0.99)$ & 0.000 \\
\hline \multicolumn{4}{|c|}{$\begin{array}{l}\text { Parental Social Status (Professional } \\
\text { as baseline) }\end{array}$} \\
\hline Managerial/technical & .62 & $(0.51,0.77)$ & 0.000 \\
\hline Skilled non-manual & .44 & $(0.33,0.59)$ & 0.000 \\
\hline Skilled manual & .32 & $(0.22,0.48)$ & 0.000 \\
\hline Semi skilled & .24 & $(0.14,0.40)$ & 0.000 \\
\hline Unskilled & .17 & $(0.09,0.31)$ & 0.000 \\
\hline Mother's education & .51 & $(0.47,0.55)$ & 0.000 \\
\hline \multicolumn{4}{|l|}{ Interaction terms } \\
\hline Cohort x gender & 1.06 & $(0.97,1.15)$ & 0.183 \\
\hline Cohort x RGSC & 1.02 & $(0.99,1.06)$ & 0.203 \\
\hline Cohort x g & .90 & $(0.85,0.94)$ & 0.000 \\
\hline Gender x RGSC & .99 & $(0.93,1.06)$ & 0.823 \\
\hline Nagelkerke $\mathrm{R}^{2}$ & .30 & & \\
\hline
\end{tabular}


In a next step, a logistic regression was run to test the odds of obtaining a degree level qualification (NVQ4), simultaneously taking into account cohort membership, general cognitive ability, family social background, and gender - as well as the interactions between these variables. For the analysis, the data from all three data sets were pooled to enable the assessment of cohort differences. Table 5 gives the odd ratios and 95\% Confidence interval for the estimates. Controlling for general cognitive ability, the odds for obtaining a degree are higher in the later born cohorts (the 1946 cohort was used as the baseline). Women were less likely than men to gain a degree, as were those from relatively disadvantaged family backgrounds. The effect of socioeconomic factors is however stronger than gender effects. Of the interaction terms, only the interaction between cohort and general cognitive ability was significant, suggesting that, in the later born cohorts, high ability is not a sufficient condition for gaining a degree level qualification. Rather than suggesting that the linkage between cognitive ability and academic attainment has tightened, these results point in the opposite direction.

\section{Discussion}

The findings from the SEM model suggest that the strength of the association between family socioeconomic status and academic attainment has remained more or less the same for the three birth cohorts, while the association between general cognitive ability and academic attainment has reduced for the latest born 1970 cohort. Although the absolute rates of education participation have increased, relative differences between individuals from different social backgrounds have remained. The findings are in agreement with other studies based on the British cohort studies suggesting persisting social inequalities in attainment (Breen and Goldthorpe 2001; Bynner and Joshi 2002; Marshall, Swift and Roberts 1997).

Young people scoring high on the general cognitive ability tests at age 10-11 years have generally greater educational opportunities than low scorers, yet the findings also suggest that the predictive power of general cognitive ability has reduced, especially in the latest born cohort. The findings thus support the hypothesis that less able individuals from privileged backgrounds have benefited most from the educational expansion, not the most able (Blanden and Machin 2003; Bynner and Joshi
2002; Galindo-Rueda and Vignoles 2005; Marshall et al 1997; Schoon 2008), as the association between general cognitive ability and academic attainment has reduced for the 1970 cohort, while the association between social background and cognitive ability has increased. Despite considerable reforms of the education system in the UK, the findings suggest persistence of inequality in educational opportunity. This represents loss of talent and under-utilization of skills, since academic attainment should primarily be based on ability rather than socioeconomic background. On a positive note, gender inequalities in attainment appear to have reduced. However, although the gender gap is considerably smaller than inequalities associated with social background, after controlling for social background, significant gender differences in academic attainment remain.

Family social status at birth is significantly associated with general childhood cognitive ability. The observed associations do however not imply causal relationships between the factors, as there might be other explanatory processes not included in the model. The two variables share some genetic as well as environmental influences, and there is an ongoing debate about how these two variables are interlinked (Deary et al 2005; Flynn 2006). The paths in the model track development over time, yet the study cannot measure all the family characteristics that affect test scores and education; nor does it account for possible alternative explanations linking family social background and general cognitive ability to later academic attainment. Young people growing up in relative privileged families are likely to have better access to material and financial resources, role models, and parental encouragement (Duncan, Featherman and Duncan 1972; Featherman and Lerner 1985; Pilling 1990; Schoon 2006) than their less privileged peers. They might also have access to better schools, be treated differently by their teachers (Jencks 1979; Kerckhoff 2001; Marcenaro-Gutierrez, Galindo-Rueda and Vignoles 2007; Shavit and Featherman 1988), and choose different peers. Future studies should examine in more detail how characteristics of the family and the school environment affect test scores and subsequent attainment as well as other unmeasured characteristics including genetic effects.

In interpreting the findings, some other limitations of the study have to be acknowledged. The study has made use of data collected for three longitudinal studies, 
following cohort members born in 1946, 1958, and 1970 from childhood to early adulthood. As in most longitudinal studies, the analysis presented here is constrained by having to make best use of the available data, their measurement level and timing. In all three cohorts similar measures of parental social background and academic attainment could be identified, as well as measures of general cognitive ability at age 10-11 years, although different test instruments were used in the different studies. The test data has been standardized for comparison across cohorts, and SEM modeling was applied, using latent variables instead of direct measures for cohort comparison. Using theta parameterization, as implemented in the program Mplus 5 (Muthén and Muthén 2007), allowed the analysis of data on mixed measurement levels, although in interpreting the regression coefficients, the measurement level and assessment of the variables has to be taken into consideration, as well as the sample size, since smaller samples produce larger correlations.

Another issue to be addressed here is missing data, which might have affected the validity of the results. Response bias at the individual level would tend to underestimate the magnitude of effects of social disadvantage, as sample attrition is greatest among men and cohort members in more deprived circumstances (Plewis et al 2004). The problem of missingness in the data was addressed using multiple imputations as implemented in Mplus 5 (Muthén and Muthén 2007) as a 'best effort' technique. Nonetheless, the results might provide a conservative estimate of social inequalities in the sample.

Despite these concerns, the study provides an unique opportunity to assess changes in the association between family social background, gender, cognitive ability and academic attainment in a changing socio-historical context. General cognitive ability was directly assessed at entry to secondary school and prior to completing secondary schooling. It has been pointed out that IQ scores of children might be less reliable predictors than test scores of older individuals (Strenze 2007), although there is evidence of stability of intelligence during childhood (Burchinal et al 1997; Jensen 1980). However, correlations between IQ and subsequent educational and occupational success have shown to grow stronger as individuals grow older (Jencks 1970; Deary et al 2005; Schoon 2008). On the other hand, there is evidence to suggest that social origin factors have stronger effects on earlier transitions than on later ones (Mare 1980; Shavit and Blossfeld 1993; Jonsson, Mills and Müller 1996), and that socio-economic selection is more likely to occur at early stages of the educational career.

Increasing the school leaving age to 18 years, to be implemented in the UK by 2015, might provide a base for continued education participation for all. Current generations of young people expect and attain more education than previous ones, including those from less privileged backgrounds (Gregg and Macmillan, this issue; McVicar and Rice 2001; Schoon 2010). It has been argued that a new norm is emerging, promoting 'college for all', regardless of academic aptitude or social background (Schneider and Stevenson 1999; Reynolds and Pemberton 2001; Rosenbaum 1998). Further education for all is, however, not necessarily the solution to all problems, unless it will give students access to the same quality of education or jobs. In the USA nearly 70 per cent of high school students will begin a post-secondary experience, yet only a third of post-secondary students will complete a degree in a seven year period (NCES 2007). Moreover, many high school graduates find themselves unemployed after school or in casual, shortterm employment, and those who found employment were often only continuing the same dead-end jobs they already held during high school (Rosenbaum 2001).

Given the risk for failure, especially for those who are least prepared for further studies, or who can least afford it, there is a need to rethink the structure of support and educational policy. Policy makers are however torn between two conflicting pressures: the demand for greater access requires the expansion of the system, whereas the wish to maintain academic excellence requires more stringent selection on the basis of ability. When academic credentials are awarded indiscriminately they are devalued. Previous research has shown that a consequence of educational expansion in the 1980 was the creation of a bottleneck in the transition from secondary to tertiary education (Mare 1981; Shavit and Blossfeld 1993), where staying on beyond minimum school leaving age expanded massively, increasing students' expectations for a university education, while the tertiary level did not expand sufficiently to absorb the full extent of the new demand. As more young people, and in particular women, opted for admission into further and higher education, more stringent selection criteria were applied, which tended to exclude lower class applicants. 
The findings presented here suggest that the strength of the association between cognitive ability and academic attainment has reduced for the more recent cohort, indicating that high cognitive ability has not necessarily been rewarded in the changing education system. Children from disadvantaged backgrounds, starting their schooling at broadly the same high level of cognitive ability as other pupils, are falling behind in their course of education (Duckworth et al, this issue; Feinstein 2004; Schoon 2006), and are leaving school with lower levels of achievement than their less able peers from more privileged backgrounds. It is thus crucial to provide an educational environment that supports the realization of abilities and skills, avoids unnecessary waste of talent, and reduces the probability that social origin or gender determines destination in society, instead of ability. Evidence from the more recent age cohort, suggests that this picture of persisting social inequality in attainment, at least in secondary education, might be changing (Gregg and Macmillan, this issue). The long-term outcomes and returns to increasing education participation have yet to be assessed.

\section{Acknowledgements}

The analysis and writing of this chapter were supported by grants from the UK Economic and Social Research Council (ESRC): RES-225-25-2001 and RES-594-28-0001. Data from the Cohort Studies were supplied by the ESRC Data Archive. Thanks are also due to Michael Wadsworth for providing data from the 1946 cohort for analysis in this paper.

\section{References}

Arnot M, David M and Weiner G. (1999) Closing the gender gap. Polity Press , Cambridge.

Bentler PM. (1990) Comparative fit indexes in structural models. Psychological Bulletin, 107(2), 238-246.

Blanden J and Machin S. (2003) Educational inequality and the expansion of UK higher education. London School of Economics, Centre for Economic Performance, London.

Blossfeld H-P. (2005) Globalization, uncertainty and youth in society. Routledge, London.

Blossfeld H-P and Hofmeister HA. (2006) Globalization, uncertainty and women's careers : an international comparison. Edward Elgar, Cheltenham.

Blossfeld H-P and Shavit Y. (1993) Persisting barriers. Changes in educational opportunities in thirteen countries. In Persistent inequality : changing educational stratification in thirteen countries (pp. 1-23). Westview Press, Boulder, Co.

Bollen KA. (1989) Structural equations with latent variables. Wiley, New York.

Bond R and Saunders P. (1999) Routes to success: influences on the occupational attainment of young British males. British Journal of Sociology, 50, 217-249.

Bowles S. (1972) Schooling and inequality from generation to generation. Journal of Political Economy, 80, 219251.

Breen R and Goldthorpe JH. (2001) Class, mobility and merit - the experience of two British birth cohorts. European Sociological Review, 17(2), 81-101.

Burchinal MR, Campbell FA, Bryant DM, Wasik BH and Ramey CT. (1997) Early intervention and mediating processes in cognitive performance of children of low-income African-American families. Child Development, 68, 935-954.

Bynner J. (2001) British youth transitions in comparative perspective. Journal of Youth Studies, 4(1), 5-23.

Bynner J. (2005) Rethinking the youth phase of the life course: the case for emerging adulthood. Youth and Society, 8(4), 367-384.

Bynner J and Joshi H. (2002) Equality and opportunity in education: evidence from the 1958 and 1970 birth cohort studies. Oxford Review of Education, 28(4), 405-425.

Bynner J and Parsons S. (2002) Social exclusion and the transition from school to work: the case of young people not in education, employment, or training (NEET). Journal of Vocational Behaviour, 60(2), 289-309.

Deary IJ, Strand S, Smith PK and Fernances C. (2007) Intelligence and educational achievement. Intelligence, 35, 13-21.

Deary IJ, Taylor MD, Hart CL, Wilson V, Davey Smith G, Blane D et al. (2005) Intergenerational mobility and midlife status attainment: influences of childhood intelligence, childhood social factors, and education. Intelligence, 33, 455-472.

Douglas JWB. (1964) The home and the school: a study of ability and attainment in the primary school. MacGibbon and Kee, London. 
Duncan OD, Featherman DL and Duncan B. (1972) Socio-economic background and achievement. Seminar Press, New York.

Dykiert D, Gale CR and Deary IJ. (2009) Are apparent sex differences in mean IQ scores created in part by sample restriction and increased male variance? Intelligence, 37(1), 42-47.

Elliott CD, Murray D and Pearson L. (1979) British ability scales. National Foundation for Educational Research (NFER), Slough.

Epstein D, Elwood J, Hey V and Maw J. eds. (1998) Failing Boys? Open University Press, Buckinghamshire.

Featherman DL and Lerner RM. (1985) Ontogenesis and sociogenesis - problematics for theory and research about development and socialization across the lifespan. American Sociological Review, 50(5), 659-676.

Feinstein L. (2004). Mobility in pupils' cognitive attainment during school life. Oxford Review of Economic Policy, 20(2), 213-229.

Ferri E, Bynner J and Wadsworth MEJ. (2003) Changing Britain, changing lives: three generations at the turn of the century. Institute of Education, London.

Flynn JR. (2004) IQ trends over time: intelligence, race and meritocracy. In K Arrow, S Bowles and S Durlauf. eds. Meritocracy and economic inequality (pp. 35-60). Princeton University Press, Princeton, NJ.

Flynn JR. (2006) Towards a theory of intelligence beyond g. Behavioral and Brain Sciences, 29(2), 132-133.

Francis B. (2000) Boys, girls and achievement: addressing the classroom issues. Routledge Falmer, London.

Francis B. (2002) Is the future really female? The impact and implications of gender for 14-16 year olds' career choices. Journal of Education and Work, 15(1), 75-88.

Furlong A and Cartmel F. (1997) Young people and social change. Open University Press, Buckingham.

Gallie D. (2000) The labour force. In AH Halsey and J Webb. eds. Twentieth Century British Social Trends pp. 281323. Macmillan, London.

Galindo-Rueda F and Vignoles A. (2005) The declining relative importance of ability in predicting educational attainment Journal of Human Resources, 40(2), 335-353.

Gershuny J. (2000) Social position from narrative data. In R Crompton, F Devine, M Savage and J Scott. eds. Renewing class analysis. Blackwell/The Sociological Review, Oxford.

Goyette KA. (2008) College for some to college for all: social background, occupational expectations and educational expectations over time. Social Science Research, 37, 461-484.

Gottfredson, LS. (1997) Why g matters: the complexity of everyday life. Intelligence, 24, 79-132.

Hauser RM and Huang MH. (1997) Verbal ability and socio-economic success: a trend analysis. Social Science Research, 16, 331-376.

Hobsbawm EJ. (1995) The age of extremes: the short twentieth century, 1914-1991. Abacus, London.

Herrnstein RJ and Murray C. (1994) The bell curve. Intelligence and class structure in American life. Free Press, New York.

Jensen AR. (1998) The $g$ factor. The science of mental ability. Praeger, Westport.

Kerckhoff, AC. (2001) Education and social stratification processes in comparative perspective. Sociology of Education, (Extra Issue) 3-18.

Kerckhoff AC and Trott JM. (1993) Educational attainment in a changing educational system. In Y Shavit and H-P Blossfeld. eds. Persistent inequality : changing educational attainment in thirteen countries (pp. 133156). Westview Press, Boulder, Colo.

Korenman S, Miller JE and Sjaastad JE. (1995) Long-term poverty and child development: evidence from the NLSY. Children and Youth Services Review, 17(1-2), 127-155.

Krieger N, Williams DR and Moss NE. (1997) Measuring social class in US public health research: concepts, methodologies, and guidelines. Annual Review of Public Health, 18, 341-378.

Lampard R. (1995) Parents' occupation and their children's occupational attainment: a contribution to the debate on the class assignment of families. Sociology, 29, 715-728.

Leete R and Fox J. (1977) Registrar General's social classes: origins and users. Population Trends, 8, 1-7.

Little RJA and Rubin DB. (2002) Statistical analysis with missing data, 2nd edition. Wiley, Hoboken.

Lynn R. (1999). Sex differences in intelligence and brain size: a developmental theory. Intelligence, 27(1), 1-12.

Mackintosh NJ. (1998) IQ and human intelligence. Oxford University Press, Oxford.

Makepeace G, Dolton P, Woods L, Joshi H and Galinda-Rueda F. (2003) From school to the labour market. In E Ferri, J Bynner and MEJ Wadsworth. eds. Changing Britain, changing lives: three generations at the turn of the century (pp. 29-70). Institute of Education, London.

Marcenaro-Gutierrez O, Galindo-Rueda F and Vignoles A. (2007) Who actually goes to university? Empirical Economics, 32(2-3), 333-357.

Mare RD. (1981) Change and stability in educational stratification. American Sociological Review, 46, 72-87

Marini MM and Fan P-L. (1997) The gender gap in earnings at career entry. American Sociological Review, 62, 588-604. 
Marsh C. (1986) Social class and occupation. In RG Burgess. ed. Key variables in social investigation. Routledge, London.

Marshall G, Swift A and Roberts S. (1997) Against the odds?: social class and social justice in industrial societies. Clarendon Press, Oxford.

McVicar D and Rice P. (2001) Participation in further education in England and Wales: an analysis of post-war trends. Oxford Economics Papers, 53, 47-66.

Murnane R J, Willet J B and Levy F. (1995) The growing importance of cognitive skills in age determination. Review of Economics and Statistics, 87, 235-255.

Muthén LK and Muthén BO. (2007) Mplus user's guide. 5th edition, Muthén and Muthén, Los Angeles, CA.

Office for Population and Census Studies (1980) Classification of occupations and coding index. HMSO, London.

Pilling D. (1990) Escape from disadvantage. Falmer Press, London.

Richards M, Power C and Sacker A. (2009) Paths to literacy and numeracy problems: evidence from two British birth cohorts. Journal of Epidemiology and Community Health, 63(3), 239-244.

Richards M and Sacker A. (2003) Lifetime antecedents of cognitive reserve. Journal of Clinical and Experimental Psychology, 25, 614-624.

Riddell S. (2000) Equal opportunities and educational reform in Scotland: the limits of liberalism. In JAR Salisbury. ed. Gender, policy and educational change. Routledge, London.

Rosenbaum JE. (1998) College-for-All: do students understand what college demands? Social Psychology of Education, 2, 55-80

Rosenbaum J. (2001). Beyond college for all: career paths for the forgotten half. Russel Sage Foundation, New York.

Saunders P. (1997) Social mobility in Britain: an empirical evaluation of two competing theories. Sociology, 31, 261-288.

Saunders P. (2002) Reflections on the meritocracy debate in Britain: a response to Richard Breen and John Goldthorpe. British Journal of Sociology, 53, 559-574.

Schoon I. (2006) Risk and resilience. Adaptations in changing times. Cambridge University Press, Cambridge.

Schoon I. (2008) A transgenerational model of status attainment: the potential mediating role of school motivation and education. National Institute Economic Review, 205, 72-82.

Schoon I. (2010) Planning for the future: changing education expectations in three British cohorts. Historical Social Research, 35(2), 99-119

Schoon I, Martin P and Ross A. (2007) Career transitions in times of social change. His and her story. Journal of Vocational Behavior, 70(1), 78-96.

Schneider B and Stevenson D. (1999) The ambitious generation: America's teenagers, motivated but directionless. Yale University Press, New Haven.

Scott J, Dex S, Joshi H, Purcell K and Elias P. eds. (2008) Women and employment: changing lives and new challenges. Edward Elgar, Northampton.

Shavit $Y$ and Blossfeld H-P. (1993) Persistent inequality : changing educational attainment in thirteen countries. Westview Press, Boulder, Colo.

Shavit $Y$ and Featherman DL. (1988) Schooling, tracking, and teenage intelligence. Sociology of Education, 61(1), 42-51.

Strand S, Deary IJ and Smith P. (2006) Sex differences in cognitive abilities test scores: a UK national picture. British Journal of Educational Psychology, 76, 463-480.

Sternberg RJ, Grigorenko EL and Bundy DA. (2001) The predictive value of IQ. Merrill-Palmer Quarterly, 47, 1-41.

Strenze T. (2007) Intelligence and socioeconomic success: a meta-analytic review of longitudinal research. Intelligence, 35(5), 401-426.

Tinklin T. (2003) Gender differences and high attainment. British Educational Research Journal, 29(3), 307-325.

Wadsworth MEJ, Kuh D, Richards M, Hardy R. (2005) Cohort profile: the 1946 National Birth Cohort (MRC National Survey of Health and Development). International Journal of Epidemiology, 35, 49-54

Younger M and Warrington M. (2006) Raising boys' achievement. Department for Education and Skills, Research Report RR636.

\section{Endnotes}

\footnotetext{
'The occupational categories used in the US census and other European countries are similarly based on the skills and status of different occupations (Krieger, Williams, \& Moss, 1997).
} 


\title{
Family income, education and cognitive ability in the next generation: exploring income gradients in education and test scores for current cohorts of youth
}

\author{
Paul Gregg and Lindsey Macmillan \\ Centre for Public and Market Organisation and Department of Economics \\ University of Bristol \\ Lindsey.Macmillan@Bristol.ac.uk
}

(Received April 2010 Revised June 2010)

\section{Abstract}

The relationship between the incomes of the family a child is growing up in and the education level the child obtains, has been of great interest to researchers for a number of reasons. Firstly, this gives us a measure of educational inequality in its own right, and secondly, because the relationship between family income and education is also one of the key drivers of intergenerational income mobility across time in the UK, and gradients in life chances across a range of other domains. This paper explores the evolution of the relationship between family income and education, for a group of cohorts from those born in 1958 to those born in 1991/92. The range of educational relationships we can measure depends on the age of the child. For older cohorts, whom we assume have completed their education, we can measure the full range of educational outcomes up to degree level, and their relationship with family income. For younger cohorts who are in earlier stages of education, we can measure test scores and GCSE results but not later educational outcomes.

JEL Classifications: J62, J13, J31

\section{Key words}

Intergenerational mobility, children, education

\section{Introduction and previous literature}

The relationship between the incomes of the family a child is growing up in and the education level and cognitive abilities of the child, has been of great interest to researchers for a number of reasons. Firstly, this gives us a direct measure of educational inequality in its own right, and secondly, because the relationship between family income, education and earlier cognitive test scores is also one of the key drivers of intergenerational income mobility across time in the UK (Blanden, Gregg and Macmillan 2007) and gradients in life chances across a range of other domains.

There have been a number of recent studies exploring whether family income actually influences a child's educational attainment, or rather is just a marker for many other aspects of social (dis)advantage such as parents education level, social class etc. Dahl and Lochner (2008) exploit the introduction of the Earned Income Tax Credit in the US, Milligan and Stabille (2006) explore the variation in child benefits across time and Canadian provinces, and Gregg et al (2010) use fathers' job displacement. All of the studies suggest that sustained income shocks do impact on child educational outcomes and Oreopolous et al (2008) and Gregg et al (2010) suggest that this also influences intergenerational mobility.

Likewise there have been a large number of studies assessing whether a person's education actually does impact on outcomes, or whether it is instead reflecting other underlying abilities and attitudes. A number of studies have considered what happens when the school leaving age is 
raised, to attempt to identify a causal relationship between education and outcomes. For example, Meghir and Palme (2005) Oreopoulus (2006) and Dickson (2009) explore the impact on a person's earnings as an adult, Black et al (2008) look at teen pregnancy, and Orepolous and Page (2006), on a person's children's education. Again, all of these studies suggest that educational attainment has a direct causal influence on life chances.

Given the evidence that income causally impacts education and education causally impacts outcomes, the strength of the relationship between family background and a child's education attainment, represents the extent to which adult outcomes mirror the individual's childhood circumstances, and are thus an indicator of equality of opportunity. This may mean that an individual, who is born into a poor family, faces life-long penalties regardless of their own abilities or effort. For this reason, this is currently a highly topical area in the UK, where the notion of 'opportunity for all' has been cited as a central policy goal by all three major political parties. This has resulted in a number of policy initiatives, a government white paper on social mobility, and a Commission on Fair Access to the Professions chaired by a former Cabinet Minister, Alan Milburn (the Milburn Commission).

There has been a large literature centred on the measurement of mobility, and more recently on both international comparisons and cross-cohort comparisons for the UK. The broad consensus is that in international terms, the UK has a low level of mobility (Solon 2002, Corak 2006), rivalled only by the United States, and across cohorts, the UK's level of intergenerational income mobility declined between cohorts born in 1958 and those born in 1970 (Blanden et al 2004). For policy makers, one of the main problems when attempting to think about intergenerational mobility is the need for individual level data over a large number of years. To capture an intergenerational elasticity, information is needed on the individual's family socio-economic status in childhood, and on the individual's own socio-economic status in adulthood. Previous research from the cohort studies provides evidence on the levels of mobility for children growing up in the 1970 s and the 1980 s. Policy makers wishing to assess the impact of recent policy innovations on social mobility, will therefore have to wait at least another decade until the children experiencing these policy innovations have reached an age in the labour market, where their own financial circumstances are fully apparent.

This research will therefore estimate the relationships between family income and education, in terms of both educational attainment and earlier cognitive test scores, for a group of cohorts from those born in 1958 to those born in $1991 / 92$. This in itself is a valuable addition to the current literature, given the variety of data sources that we use. The range of educational relationships we can measure obviously depends on the age of the child. For older cohorts, whom we assume to have completed their education, we can measure the full range of educational outcomes up to degree level, and their relationship with family income. For younger cohorts who are in earlier stages of education, we can measure earlier test scores and GCSE results, but not later educational outcomes. Although it is beyond the scope of this research to examine the direct relationship between cognitive abilities and educational attainment, we draw upon other literature that finds strong correlations between the two in the UK (Deary et al 2007). We therefore use these test scores as a good proxy for later educational attainment for children that we do not yet observe educational attainment for.

In the next section we lay out our modelling approach in more detail. In section 3 we discuss the data sources used before presenting our results in section 4 . Section 5 offers conclusions.

\section{Methodology}

The main objective in this paper is to say something about the changing relationship between family income and educational outcomes across a range of cohorts. The relationship of interest for examining the association between the family income of the child and their educational attainment and cognitive abilities, is captured by $\lambda$ in the following regression, where $E d_{i}$ is a range of measures from test scores to degree attainment. The parental income variable is logged to ensure that the relationship is constant across the distribution of income; a $10 \%$ increase in the standard of living is the same for a family in the $10^{\text {th }}$ percentile of the income distribution compared to the $90^{\text {th }}$ percentile.

$$
E d_{i}=\alpha+\lambda \ln Y_{i}^{\text {Parents }}+\text { Sage }_{i}+\pi a g e_{i}^{2}+\text { female }_{i}+\varepsilon_{i}
$$


Quadratic age controls for the parents are included to adjust for life-cycle biases in family income, and a gender dummy is included to account for the differential educational experiences of males and females in each of the surveys.

\section{Data}

For this analysis, we use the two British birth cohorts, as in Blanden et al (2007). In addition, we introduce three younger cohorts using data from the UK household panel study and two new cohorts where the focus children have just completed compulsory education.

The National Child Development Study is a study of those born in 1958 and the British Cohort Study is a study of those born in 1970. Both cohorts, run by the Centre for Longitudinal Studies (CLS) at the Institute of Education (IOE), London, began with around 18,000 children. Our final samples are reduced to around 5,000-7,000 respondents, given the requirement of parental income information and educational attainment. The issue of attrition in the cohorts is explored in greater detail in the robustness section. The National Child Development Study (NCDS) obtained data at birth and ages $7,11,16,23,33,42$, 46 and 50 for children born in a week in March 1958. The BCS originally included all those born in Great Britain in a week in April 1970. Information was obtained about the sample members and their families at birth and at ages 5, 10, 16, 26, 30, 34 and 38 (for more details see http://www.cls.ioe.ac.uk).

The British Household Panel Survey (BHPS) is not a birth cohort. It is run by the Institute for Social and Economic Research (ISER) at the University of Essex and tracks a representative sample of 10,000 households from 1991 onwards (http://www.iser.essex.ac.uk/survey/bhps). As it is a household panel study, members of the original households' from 1991 are followed into new households, including any children, after leaving the family home. Hence, the BHPS can track small numbers of children who reach age 16 in any year through to adulthood. However, as these samples are small, we pool a number of years to create cohort windows of people entering in waves 1-6 (BHPS 1) that are born in 1975-1980, those entering in waves 7 12 (BHPS 2) that are born in 1981-1986, and those entering in waves 13-16 (BHPS 3 ) that are born in 1987-1990. Despite these attempts however, the samples remain small, at around 900 children for our oldest cohort and 300 for our youngest. Statistical inference is therefore a problem for this data.

The LSYPE is a longitudinal survey of young people, collected by the Department for Children, Schools and Families (DCSF), who were aged 13/14 in 2004 and so were born in 1989 and 1990 (http://www.esds.ac.uk/longitudinal/access/lsype) $\underline{\text { L5545.asp). }}$. These individuals were beginning junior school in 1997 with the change in UK Government and have thus been exposed to national policy developments in the New Labour period. The survey follows the young people and their families with data currently available up to wave 4, 2007 at age 17/18. These individuals are therefore comparable with our third cohort of BHPS individuals, as they have just finished their GCSEs. The additional benefit of the LSYPE is that it is a large survey with around 14,000 participants in wave 1 , and around 11,000 respondents for our purposes. We are therefore able to gain much stronger inferences from using this sample.

ALSPAC is a birth cohort of children born in the former region of Avon (an area centred on Bristol) from 1991 to 1992, making them a very similar age to those in the LSYPE. The collection and provision of this data is available directly from ALSPAC, based within the University of Bristol (http://www.bristol.ac.uk/alspac/). Due to data backlogs, data is only available for these individuals up to the age of 11 currently, so there is no information available on later educational attainment. Information is available however for Key Stage 2 test scores and an IQ clinic measure.

Table 1 summarizes all of the available information for analysing the relationship between family income, educational attainment and test scores. Much work has been done to ensure that the income, education and test score measures are comparable, and that any attrition from these large surveys is not driving the main findings of this research. This will be discussed in greater detail at the end of the results section. 
Table 1. Observable data for second stage analysis

\begin{tabular}{lccccccc} 
Data source & NCDS & BCS & BHPS 1 & BHPS 2 & BHPS 3 & LSYPE & ALSPAC \\
\hline Year of birth & 1958 & 1970 & $1975 / 80$ & $1981 / 86$ & $1987 / 90$ & $1989 / 90$ & $1991 / 92$ \\
\hline Family income & $\mathrm{V}$ & $\mathrm{V}$ & $\mathrm{V}$ & $\mathrm{V}$ & $\mathrm{V}$ & $\mathrm{V}$ & $\mathrm{V}$ \\
(age) & $(16)$ & $(16)$ & $(16-18)$ & $(16-18)$ & $(16-18)$ & $(14)$ & $(11)$ \\
IQ at 8/10/11 & $\mathrm{V}$ & $\mathrm{V}$ & & & & & $\mathrm{V}$ \\
Reading at & $\mathrm{V}$ & $\mathrm{V}$ & & & & $\mathrm{V}$ & $\mathrm{V}$ \\
7/10/11 & & & & & & $\mathrm{V}$ & $\mathrm{V}$ \\
Maths at 10/11 & $\mathrm{V}$ & $\mathrm{V}$ & & & & $\mathrm{V}$ & \\
No. of GCSEs & $\mathrm{V}$ & $\mathrm{V}$ & $\mathrm{V}$ & $\mathrm{V}$ & $\mathrm{V}$ & $\mathrm{V}$ & \\
Staying on at 16 & $\mathrm{V}$ & $\mathrm{V}$ & $\mathrm{V}$ & $\mathrm{V}$ & $\mathrm{V}$ & & \\
No. of A-levels & $\mathrm{V}$ & $\mathrm{V}$ & $\mathrm{V}$ & $\mathrm{V}$ & & & \\
Staying on at 18 & $\mathrm{V}$ & $\mathrm{V}$ & $\mathrm{V}$ & $\mathrm{V}$ & & & \\
Degree & $\mathrm{V}$ & $\mathrm{V}$ & $\mathrm{V}$ & $\mathrm{V}$ & & & \\
Early labour & $\mathrm{V}$ & $\mathrm{V}$ & $\mathrm{V}$ & & & & \\
market & & & & & & & \\
\hline Aget & & & & & &
\end{tabular}

Age at which family income is available in parenthesis

\section{Income measures}

Parental income data is available at age 16 in both of the older birth cohort studies. In the NCDS, the data is banded for mother's earnings, father's earnings and other income, with an average of the mid-points of all three categories used as a final broadly continuous measure. In the BCS, parental income is derived from information obtained at age 16. We generate continuous income variables by fitting a Singh-Maddala distribution (Singh and Maddala 1976) to the data using maximum likelihood estimation. This is particularly helpful in allocating an expected value for those in the open top category. We then adjust the income variable to a net measure, using the FRS (1986), and impute child benefit for all families. Furthermore both of the income measures are standardised, as with all other income measures, to mean 0 , standard deviation 1. This is to ensure that changes in income inequality across the cohorts or small changes in the variance in income due to minor definitional or reporting differences, will not drive the results. These measures have been used on a number of occasions and a great deal of work has been done already to test their robustness and comparability
(Blanden 2004, Blanden, Gregg and Macmillan 2010).

In the BHPS, the family income of the parents is observed when the study children enter the survey at age 16. The family income measure is taken from the 'Derived current and annual net household income' dataset, an unofficial supplement to the derived gross income variables released with the BHPS. The income measure is adjusted to monthly income, logged and standardised for comparability.

For the LSYPE, the income measure is created using data from wave 1 , when the cohort members are 14. The original family income measure in the LSYPE is gross banded income including benefits. The measure is coded to monthly income, and the measure is transformed from gross to net using information from the Family Resources Survey (FRS 2004). There are a large number of bands in the LSYPE, with only two individuals falling into the open top category, so a Singh-Maddala transformation is unnecessary in this case. An interval regression technique is then used instead, to distribute the families within each band. As with all income measures, the measure is logged and standardised to mean 0 , standard deviation 1 . A number of robustness tests are carried out to assess 
the impacts of using different methods to create comparable income measures, which are discussed in the results section. Given that the LSYPE is a study of young people in England, robustness tests are also carried out on the significant results for sub-samples of the other cohorts from England only.

The income measure from ALSPAC is taken from banded household net income at age 11 and put through the same Singh-Maddala process as that which is used to deal with banded income in the BCS. The measure is then logged before being standardised to mean 0 , standard deviation 1 . Robustness tests using income at 10 from the BCS, show that education and test score income gradients using earlier income measures are comparable, given high levels of persistence in income.

\section{Educational attainment measures}

Educational attainments were obtained from information provided at ages 16, 23 and 33 in the NCDS and ages 16, 26 and 30 for the BCS sample. This includes detailed information on the number of exams passed (both GCE 'O' level and CSE (Certificate of Secondary Education)). Information on educational achievements beyond age 16 is also available at these ages. The GCSE measure we construct is the number of O-levels graded A-C obtained by the cohort member, and the A-level measure is the total number of A-levels obtained where an A/S level (taken halfway through the 2year course of study) counts for half an A-level. The two staying on variables are dummies to capture staying on decisions at 16 and 18 , and the degree measure is also a dummy to measure degree attainment. In addition, information on all periods of labour market and educational activity from age 16 to 24 can be derived from an additional work history data source, available for every month from age 16 to 42 (NCDS) and 16 to 30 (BCS). This information is used to generate the measure of labour market attachment, which is the proportion of months between leaving full-time education and age 24 , when the individual is not in education, employment or training.

For the first BHPS cohort, BHPS 1, we can observe educational attainment measures constructed in the same way as the cohort studies, and the proportion of time since leaving full-time education that they have spent not in education, employment or training, comparable with the two birth cohorts. For the second cohort, BHPS 2, we can observe all individuals' educational attainment until the age of 20. As we do not observe them later than 20, there is no information on their labour market attachment, and the degree variable also includes individuals who are at university but have not yet necessarily completed their degree. All other measures remain consistent with previous cohorts. The third BHPS cohort, BHPS3, can only be observed until the age of 17 . We can therefore use measures of educational attainment between 16 and 17 but no further.

LSYPE educational attainment is created using administrative data from Key Stage 4 to create a total number of GCSEs level $A^{*}-C$ measure. In addition, information from wave 4 on the main activity of the young person is used to create a dummy indicator for staying in education post- 16 . Given concerns that grade inflation might affect the relationship between family income and educational attainment over time, more restrictive measures of GCSE attainment are also used for robustness checks. The problem is that, if there is grade inflation, the distribution of grades will get more compressed around the top of the distribution, because the top of the scale is capped and will cause lower attaining groups to appear to catch up with higher attaining ones. Measures of attainment that are more demanding, will have lower means at all parts of the distribution when expressed as dummy variables, and thus are not so prone to this problem. The measures, which are comparable with measures constructed in the BCS, include the total points score, a dummy variable for obtaining $5 \mathrm{~A}^{*}$ - $C$ grades and a dummy variable indicating those who have obtained $5 \mathrm{~A}^{*}$ - $C$ grades including maths and english. This will be discussed in greater detail in our robustness section.

\section{Earlier test score measures}

When we look to bring in younger cohorts by comparing the relationship between income and earlier test scores, information is available in the NCDS at age 7 and 11 and the BCS at age 10. The reading, maths and IQ tests are broadly comparable across the cohorts from ages 11 and 10 respectively, with an additional reading measure atage 7 used from the NCDS for comparability with a similar measure from ALSPAC. All test scores in the cohorts are administered by the cohort studies 
and standardised to mean 0 , standard deviation 1 for comparison. The birth cohorts test scores have been used comparatively in a number of studies in the past including Galindo-Rueda and Vignoles (2005) and (Schoon 2006).

In the BHPS, given that the study children do not enter the panel until age 16 , we have no comparable early test scores available for these three cohorts. However in the LSYPE, we can also observe earlier outcomes for these individuals, as administrative data has been linked into the study including Key Stage 2 test scores. We can therefore extend our analysis to include the relationship between family incomes and test scores for this cohort of individuals, as with the cohort studies. Key Stage 2 scores are constructed using the discrete level obtained, and adjusting for the marks within each level, to create a 'fine point's score' for both reading and maths. These scores are then standardised to mean 0 , standard deviation 1 .

We can also introduce the ALSPAC cohort at this point, as although later educational attainment is not yet available in this data, earlier test score information is. The IQ measure from ALSPAC is slightly earlier than the cohorts at aged 8 , but as IQ measures are seen as a more permanent measure of intelligence, this may not be a major concern. The maths and reading scores are taken from the Key Stage 2 individual test marks, in the same way they are derived in the LSYPE. As with the cohort studies and LSYPE, the three scores are standardised to mean 0 , standard deviation 1 .

To ensure that there are no concerns over differences between the tests administered by the cohort studies and the key stage tests which children may be 'taught to', we also include for robustness a reading test at 7 administered in an ALSPAC clinic at 7. This is again standardised to mean 0 , standard deviation 1 . The correlation between the reading test at 7 and that of the reading component of key stage 2 at 11 is high, with a correlation coefficient of 0.6766 .

\section{Results}

The relationship between family income and educational attainment

We start by showing the patterns of the number of GCSE $A^{*}$ to $C$ grades achieved for each cohort we can consider. Table 2 shows this information by family income quintile.

Table 2. Average number of GCSE O-levels or equivalent at grade $A^{*}-C$ by income quintile for NCDS, BCS, BHPS 1 (1975-80), BHPS 2 (1981-86), BHPS 3 (1987-1990) and LSYPE (1989-90)

\begin{tabular}{lcccccc} 
& NCDS & BCS & BHPS 1 & BHPS 2 & BHPS 3 & LSYPE \\
& $\mathbf{1 9 5 8}$ & $\mathbf{1 9 7 0}$ & $\mathbf{1 9 7 5 - 1 9 8 0}$ & $\mathbf{1 9 8 1 - 1 9 8 6}$ & $\mathbf{1 9 8 7 - 1 9 9 0}$ & $\mathbf{1 9 8 9 / 1 9 9 0}$ \\
\hline Inc quintile 1 & 1.6153 & 2.6693 & 3.9149 & 4.5952 & 4.6364 & 3.6972 \\
Inc quintile 2 & 1.9673 & 3.2020 & 4.7485 & 5.8197 & 4.5672 & 3.9431 \\
Inc quintile 3 & 2.2362 & 3.7363 & 5.1299 & 6.0083 & 6.1558 & 4.8232 \\
Inc quintile 4 & 2.5081 & 4.4377 & 5.5538 & 6.2897 & 6.4746 & 5.7901 \\
Inc quintile 5 & 3.6936 & 5.7410 & 6.7162 & 6.6220 & 7.2632 & 7.3534 \\
\hline
\end{tabular}

Unconditional means by income quintile, boys and girls

As has been widely observed, there has been a steady increase in numbers of $O$ levels / GSCEs secured across the cohorts. The NCDS cohort sat $O$ levels (the precursor to GCSEs) in 1974 when a large proportion of the cohort would have entered into selective education. Although most schools moved to be comprehensives by 1974 , those attending secondary moderns (and former secondary moderns) were much less likely to be entered for 0 levels at this time. In this cohort the average child got just over $2 \mathrm{~A}-\mathrm{C}$ grade $\mathrm{O}$ levels. The cohort of the
BCS sat O levels (also known as GCEs (General Certificate of Education) and CSEs (Certificate of Secondary Education) where the top grade of the latter was equivalent to a GCSE grade C) in 1986 and on average, pupils obtained just under $4 \mathrm{O}$ levels or top CSEs. This was just before the implementation of reforms laid out by Sir Keith Joseph, which moved the examination system from one where essentially a fixed proportion of students could get any particular A-C grade (around one third) to there being a fixed line over which any 
number could pass. The subsequent increase in the proportion getting higher grades has lead to concerns over grade inflation, where it has been argued that exam standards are falling.

The BHPS 1 cohort sat the new combined GCSEs from 1991 to 1996, after a period of rapid increase in GCSE attainment which has continued since at a slower rate. This generation was now achieving $51 / 2$ GCSE A*-Cs. The BHPS can add new five year cohort data here, a second and third more recent BHPS cohort born between 1981 and 1986 (BHPS 2) and 1987 to 1990 (BHPS 3) who were achieving an average of 6 GCSEs $A^{*}-C$ grades per pupil. The LYPSE cohort, tracked since they were 14, has just turned 17, and whilst we have GCSE result for those taken at age 16 in the academic year 2005/2006, this cohort lacks any information regarding those sitting the exams at ages $17+$. This means the mean number of GCSEs $A *-C$ grade students achieve inthe LYPSE cohort is a little below that of the preceding BHPS cohorts.

In what follows next, we explore how the attainment gaps have changed across these different cohorts. So, we need to get an idea of the direction of any bias, that may arise from the lack of exam data referred to above, for those sitting additional GCSEs at age $17+$ in the LYPSE. The Department of Children, Schools and Families (DCSF) reported on the proportion of young adults obtaining 5 or more $A^{*}-C$ grade GCSEs, as the required level 2 attainment at ages 16 to 19 in 2007. These figures included vocational qualifications that can also be ranked as level 2 attainments. The figures from DCSF, shown in Table 3 , suggest that level 2 attainment increases through to age 19. This table illustrates attainment by those in receipt of Free School Meals (FSM) and non-FSM students, a commonly-used proxy for family income, as this does not exist in Government data. The table summarizes both the gap between the percentage of FSM and non-FSM level 2 attainment, and the likely relative odds of reaching this attainment for both categories. For example, a nonFSM child is twice as likely at age 16 to reach a level 2 attainment relative to an FSM child.

Table 3. Proportion of FSM and non-FSM individuals obtaining 5 or more GCSEs or equivalent at grade $A$ *C for those born 1989-1992 by age in 2008

\begin{tabular}{lcccc} 
Age in 2008 & $\mathbf{1 6}$ & $\mathbf{1 7}$ & $\mathbf{1 8}$ & $\mathbf{1 9}$ \\
\hline Non-FSM & 58.2 & 66.6 & 73.6 & 76.9 \\
FSM & 29.4 & 39.5 & 48.4 & 53.2 \\
\hline Difference & $\mathbf{2 8 . 8}$ & $\mathbf{2 7 . 1}$ & $\mathbf{2 5 . 2}$ & $\mathbf{2 3 . 7}$ \\
\hline Ratio & $\mathbf{1 . 9 8}$ & $\mathbf{1 . 6 9}$ & $\mathbf{1 . 5 2}$ & $\mathbf{1 . 4 5}$
\end{tabular}

Source: http://www.dcsf.gov.uk/rsgateway/DB/SFR/s000835/index.shtml - Additional level 2 qualifications by FSM 2008

The rise by age 17 is primarily through GCSEs obtained, rather than two year vocational courses, and this extension adds another $9 \%$ of students achieving 5+ $A *-C$ GCSEs. Crucially here, the FSM/nonFSM gap narrows by 1.7 percentage points, as most of those already achieving $5+$ passes go on to level 3 courses (mainly A-Levels), but some of those just missing this benchmark do further exams. Furthermore, information from wave 4 of LYPSE, on the main activity of the young person, can shed further light on the likely direction of this bias. Looking directly at the LSYPE data, for those young people who report in wave 4 that they are staying on at school or college full-time to study for GCSEs, the average family income at 14 was just $£ 1432.66$ per month, compared to the sample average of $f 1841.35$. Hence the bias from missing later GCSE exam information for the most recent cohort, is likely to overstate the relationship between family background and educational attainment, as later information reduces the gap between higher and lower income children.

Table 2 shows how, as well as a rise in the average number of passes, there was increasing numbers of passes for all quintiles of income. However, between the NCDS and BCS this occurred more slowly for the poorest income group ( 1 extra $A^{*}-C$ pass) than for the middle (1.5 passes) and for the top quintile (2 passes). Since then, increases in pass rates were slightly faster at the middle (1.4 extra passes) and bottom (1.2) than at the top (1) between the BCS and first of the BHPS 
cohorts. This pattern has continued through the available BHPS data.

Table 4 shows the separate univariate relationships between family income and all education qualification levels, and the proportion of time spent not in education, employment or training (NEET) before age 24 (see equation (1) for each cohort, where the data is available). Across all five cohorts, those individuals from better off families did better at every stage of educational attainment than their less well off counterparts, and were less likely to spend a proportion of their early labour market experiences as a NEET The number of GCSE $A^{*}-C$, the number of Alevels achieved and attachment to the labour market variables are estimates using OLS and our staying on post-16, post-18 and degree measures are estimates using the Linear Probability Model (LPM). The coefficients can therefore be interpreted, in terms of a standard deviation increase in income, as a unit increase for the OLS models, (an increase of 1 GCSE at grade $A^{*}-C$ for a coefficient of 1 ) and as a percentage of likelihood for the LPM models ( $10 \%$ more likely to obtain a degree for a coefficient of 0.10 ).

Table 4. Relationship between standardised family income and education levels for NCDS, BCS, BHPS 1 (1975-80), BHPS 2 (1981-86), BHPS 3 (1987-90) and LSYPE (1989-90)

\begin{tabular}{|c|c|c|c|c|c|c|}
\hline Variable & $\begin{array}{l}\text { NCDS } \\
1958 \\
\end{array}$ & $\begin{array}{l}\text { BCS } \\
1970\end{array}$ & $\begin{array}{l}\text { BHPS 1 } \\
1975-1980\end{array}$ & $\begin{array}{l}\text { BHPS 2 } \\
1981-1986 \\
\end{array}$ & $\begin{array}{l}\text { BHPS } 3 \\
1987-1990 \\
\end{array}$ & $\begin{array}{l}\text { LSYPE } \\
1989 / 1990 \\
\end{array}$ \\
\hline Number of O- & 0.7165 & 1.1315 & 1.0647 & 0.7958 & 0.9880 & 0.9336 \\
\hline levels ( $A *-C)$ & {$[0.036]^{* * *}$} & {$[0.046]^{* * *}$} & {$[0.155]^{* * *}$} & {$[0.258]^{* * *}$} & {$[0.249]^{* * *}$} & {$[0.035]^{* * *}$} \\
\hline$N$ & 7841 & 5428 & 815 & 515 & 345 & 10935 \\
\hline \multirow[t]{2}{*}{ Stay on post -16} & 0.0963 & 0.1360 & 0.1110 & 0.0846 & 0.0885 & 0.0463 \\
\hline & {$[0.006]^{* * *}$} & {$[0.006]^{* * *}$} & {$[0.019]^{* * *}$} & {$[0.031]^{* * *}$} & {$[0.029]^{* * *}$} & {$[0.005]^{* * *}$} \\
\hline$N$ & 7196 & 6420 & 964 & 583 & 386 & 8205 \\
\hline Number of A- & 0.1618 & 0.4164 & 0.4703 & 0.4512 & & \\
\hline levels (any) & {$[0.010]^{* * *}$} & {$[0.023]^{* * *}$} & {$[0.075]^{* * *}$} & {$[0.128]^{* * *}$} & & \\
\hline$N$ & 7841 & 3769 & 638 & 373 & & \\
\hline \multirow[t]{2}{*}{ Stay on post -18} & 0.0621 & 0.1047 & 0.0697 & 0.0730 & & \\
\hline & {$[0.004]^{* * *}$} & {$[0.006]^{* * *}$} & {$[0.021]^{* * *}$} & {$[0.033]^{* *}$} & & \\
\hline$N$ & 7196 & 5529 & 946 & 568 & & \\
\hline \multirow[t]{2}{*}{ Degree } & 0.0553 & 0.1158 & 0.0916 & 0.0884 & & \\
\hline & {$[0.004]^{* * *}$} & {$[0.006]^{* * *}$} & {$[0.017]^{* * *}$} & {$[0.033]^{* * *}$} & & \\
\hline$N$ & 7949 & 5520 & 932 & 484 & & \\
\hline Proportion time & -0.0049 & -0.0197 & -0.0676 & & & \\
\hline NEET & {$[0.002]^{* * *}$} & {$[0.003]^{* * *}$} & {$[0.009]^{* * *}$} & & & \\
\hline$N$ & 5907 & 5546 & 949 & & & \\
\hline
\end{tabular}

Standard errors in parentheses, boys and girls, controls for parental age, parental age squared and gender

$* * *$ Indicates significance at the $99 \%$ confidence level, $* *$ is significant at the $95 \%$ confidence level, and * indicates a $90 \%$ confidence level.

Family income is monthly net logged standardised family income. Income standardised to account for differential variation across cohorts.

The strength of the relationship between family income and educational outcomes increased between those born in 1958 and 1970 for all six outcomes considered. As an example, using standardised income to net out any effect from rising wage inequality, a doubling of family income in the NCDS was associated with an individual being $6 \%$ more likely to gain a degree, whereas in the BCS the same increase saw an individual being $11 \%$ more likely to gain a degree. The BHPS cohorts suggest this was around $9 \%$ for those born in the late 1970s and early 1980s.

The BHPS analysis is based on far smaller data, and so the results need to be assessed with care.Table 5 reports joint tests of significant changes in the coefficients across various cohort comparisons. This was assessed by jointly 
estimating the pooled cohorts with an interaction term for the later cohort. If the interaction was significant, the estimate is observed as significantly different from the previous cohorts estimate.Column 3 indicates that the increase in the relationship between income and education in the
BCS, compared to the NCDS, is significant for every education level and for the early labour market experience. For the BCS, a doubling in income was associated with a gain of an extra half of a GCSE at $A^{*}$-C level, over that achieved by their NCDS counterparts.

Table 5. Cross-cohort tests of significant differences from table 4 results

\begin{tabular}{|c|c|c|c|}
\hline Variable & $\begin{array}{l}\text { NCDS } \\
1958\end{array}$ & $\begin{array}{l}\text { BCS } \\
1970\end{array}$ & $\begin{array}{l}\text { Cross-cohort } \\
\text { Difference }\end{array}$ \\
\hline $\begin{array}{l}\text { Number of O-levels } \\
\left(A^{*}-C\right)\end{array}$ & $\begin{array}{l}0.7165 \\
{[0.036]^{* * *}}\end{array}$ & $\begin{array}{l}1.1315 \\
{[0.046]^{* * *}}\end{array}$ & $\begin{array}{l}0.4150 \\
{[0.058]^{* * *}}\end{array}$ \\
\hline Stay on post - 16 & $\begin{array}{l}0.0963 \\
{[0.006]^{* * *}}\end{array}$ & $\begin{array}{l}0.1360 \\
{[0.006]^{* * *}}\end{array}$ & $\begin{array}{l}0.0397 \\
{[0.008]^{* * *}}\end{array}$ \\
\hline $\begin{array}{l}\text { Number of A-levels } \\
\text { (any) }\end{array}$ & $\begin{array}{l}0.1618 \\
{[0.010]^{* * *}}\end{array}$ & $\begin{array}{l}0.4164 \\
{[0.023]^{* * *}}\end{array}$ & $\begin{array}{l}0.2546 \\
{[0.021]^{* * *}}\end{array}$ \\
\hline Stay on post - 18 & $\begin{array}{l}0.0621 \\
{[0.004]^{* * *}}\end{array}$ & $\begin{array}{l}0.1047 \\
{[0.006]^{* * *}}\end{array}$ & $\begin{array}{l}0.0426 \\
{[0.007]^{* * *}}\end{array}$ \\
\hline Degree & $\begin{array}{l}0.0553 \\
{[0.004]^{* * *}}\end{array}$ & $\begin{array}{l}0.1158 \\
{[0.006]^{* * *}}\end{array}$ & $\begin{array}{l}0.0604 \\
{[0.006]^{* * *}}\end{array}$ \\
\hline Proportion time NEET & $\begin{array}{l}-0.0049 \\
{[0.002]^{* * *}}\end{array}$ & $\begin{array}{l}-0.0197 \\
{[0.003]^{* * *}}\end{array}$ & $\begin{array}{l}-0.0147 \\
{[0.003]^{* * *}}\end{array}$ \\
\hline Variable & $\begin{array}{l}\text { BCS } \\
1970\end{array}$ & $\begin{array}{l}\text { BHPS 1 } \\
1975-1980\end{array}$ & $\begin{array}{l}\text { Cross-cohort } \\
\text { Difference }\end{array}$ \\
\hline $\begin{array}{l}\text { Number of O-levels } \\
\left(A^{*}-C\right)\end{array}$ & $\begin{array}{l}1.1315 \\
{[0.046]^{* * *}}\end{array}$ & $\begin{array}{l}1.0647 \\
{[0.155]^{* * *}}\end{array}$ & $\begin{array}{l}-0.0669 \\
{[0.162]}\end{array}$ \\
\hline Stay on post - 16 & $\begin{array}{l}0.1360 \\
{[0.006]^{* * *}}\end{array}$ & $\begin{array}{l}0.1110 \\
{[0.019]^{* * *}}\end{array}$ & $\begin{array}{l}-0.0251 \\
{[0.021]}\end{array}$ \\
\hline $\begin{array}{l}\text { Number of A-levels } \\
\text { (any) }\end{array}$ & $\begin{array}{l}0.4164 \\
{[0.023]^{* * *}}\end{array}$ & $\begin{array}{l}0.4703 \\
{[0.075]^{* * *}}\end{array}$ & $\begin{array}{l}0.0539 \\
{[0.073]}\end{array}$ \\
\hline Stay on post - 18 & $\begin{array}{l}0.1047 \\
{[0.006]^{* * *}}\end{array}$ & $\begin{array}{l}0.0697 \\
{[0.021]^{* * *}}\end{array}$ & $\begin{array}{l}-0.0349 \\
{[0.019]^{*}}\end{array}$ \\
\hline Degree & $\begin{array}{l}0.1158 \\
{[0.006]^{* * *}}\end{array}$ & $\begin{array}{l}0.0916 \\
{[0.017]^{* * *}}\end{array}$ & $\begin{array}{l}-0.0241 \\
{[0.018]}\end{array}$ \\
\hline Proportion time NEET & $\begin{array}{l}-0.0197 \\
{[0.003]^{* * *}}\end{array}$ & $\begin{array}{l}-0.0676 \\
{[0.008]^{* * *}}\end{array}$ & $\begin{array}{l}-0.0480 \\
{[0.007]^{* * *}}\end{array}$ \\
\hline Variable & $\begin{array}{l}\text { BHPS 1 } \\
1975-1980\end{array}$ & $\begin{array}{l}\text { BHPS 2 } \\
1981-1986\end{array}$ & $\begin{array}{l}\text { Cross-cohort } \\
\text { Difference }\end{array}$ \\
\hline $\begin{array}{l}\text { Number of O-levels } \\
\left(A^{*}-C\right)\end{array}$ & $\begin{array}{l}1.0647 \\
{[0.155]^{* * *}}\end{array}$ & $\begin{array}{l}0.7958 \\
{[0.258]^{* * *}}\end{array}$ & $\begin{array}{l}-0.2689 \\
{[0.291]}\end{array}$ \\
\hline Stay on post - 16 & $\begin{array}{l}0.1110 \\
{[0.019]^{* * *}}\end{array}$ & $\begin{array}{l}0.0846 \\
{[0.031]^{* * *}}\end{array}$ & $\begin{array}{l}-0.0263 \\
{[0.036]}\end{array}$ \\
\hline $\begin{array}{l}\text { Number of A-levels } \\
\text { (any) }\end{array}$ & $\begin{array}{l}0.4703 \\
{[0.075]^{* * *}}\end{array}$ & $\begin{array}{l}0.4512 \\
{[0.128]^{* * *}}\end{array}$ & $\begin{array}{l}-0.0191 \\
{[0.144]}\end{array}$ \\
\hline Stay on post - 18 & $\begin{array}{l}0.0697 \\
{[0.021]^{* * *}}\end{array}$ & $\begin{array}{l}0.0730 \\
{[0.033]^{* *}}\end{array}$ & $\begin{array}{l}0.0033 \\
{[0.039]}\end{array}$ \\
\hline Degree & $\begin{array}{l}0.0916 \\
{[0.017]^{* * *}}\end{array}$ & $\begin{array}{l}0.0884 \\
{[0.033]^{* * *}}\end{array}$ & $\begin{array}{l}-0.0032 \\
{[0.036]}\end{array}$ \\
\hline
\end{tabular}


(Table 5 cont'd)

\begin{tabular}{|c|c|c|c|}
\hline Variable & $\begin{array}{l}\text { BCS } \\
1970\end{array}$ & $\begin{array}{l}\text { BHPS } 2 \\
1981-1986\end{array}$ & $\begin{array}{l}\text { Cross-cohort } \\
\text { Difference }\end{array}$ \\
\hline $\begin{array}{l}\text { Number of O-levels } \\
\left(A^{*}-C\right)\end{array}$ & $\begin{array}{l}1.1315 \\
{[0.046]^{* * *}}\end{array}$ & $\begin{array}{l}0.7958 \\
{[0.258]^{* * *}}\end{array}$ & $\begin{array}{l}-0.3357 \\
{[0.239]}\end{array}$ \\
\hline Stay on post - 16 & $\begin{array}{l}0.1360 \\
{[0.006]^{* * *}}\end{array}$ & $\begin{array}{l}0.0846 \\
{[0.031]^{* * *}}\end{array}$ & $\begin{array}{l}-0.0514 \\
{[0.032]}\end{array}$ \\
\hline $\begin{array}{l}\text { Number of A-levels } \\
\text { (any) }\end{array}$ & $\begin{array}{l}0.4164 \\
{[0.023]^{* * *}}\end{array}$ & $\begin{array}{l}0.4512 \\
{[0.128]^{* * *}}\end{array}$ & $\begin{array}{l}0.0349 \\
{[0.110]}\end{array}$ \\
\hline Stay on post - 18 & $\begin{array}{l}0.1047 \\
{[0.006]^{* * *}}\end{array}$ & $\begin{array}{l}0.0730 \\
{[0.033]^{* *}}\end{array}$ & $\begin{array}{l}-0.0317 \\
{[0.028]}\end{array}$ \\
\hline Degree & $\begin{array}{l}0.1158 \\
{[0.006]^{* * *}}\end{array}$ & $\begin{array}{l}0.0884 \\
{[0.033]^{* * *}}\end{array}$ & $\begin{array}{l}-0.0274 \\
{[0.031]}\end{array}$ \\
\hline Variable & $\begin{array}{l}\text { BHPS 1 } \\
1975-1980\end{array}$ & $\begin{array}{l}\text { BHPS } 3 \\
1987-1990\end{array}$ & $\begin{array}{l}\text { Cross-cohort } \\
\text { Difference }\end{array}$ \\
\hline $\begin{array}{l}\text { Number of O-levels } \\
\left(A^{*}-C\right)\end{array}$ & $\begin{array}{l}1.0647 \\
{[0.155]^{* * *}}\end{array}$ & $\begin{array}{l}0.9880 \\
{[0.249]^{* * *}}\end{array}$ & $\begin{array}{l}-0.0767 \\
{[0.276]}\end{array}$ \\
\hline Stay on post - 16 & $\begin{array}{l}0.1110 \\
{[0.019]^{* * *}}\end{array}$ & $\begin{array}{l}0.0885 \\
{[0.029]^{* * *}}\end{array}$ & $\begin{array}{l}-0.0224 \\
{[0.034]}\end{array}$ \\
\hline Variable & $\begin{array}{l}\text { BCS } \\
1970 \\
\end{array}$ & $\begin{array}{l}\text { BHPS } 3 \\
1987-1990\end{array}$ & $\begin{array}{l}\text { Cross-cohort } \\
\text { Difference }\end{array}$ \\
\hline $\begin{array}{l}\text { Number of O-levels } \\
\left(A^{*}-C\right)\end{array}$ & $\begin{array}{l}1.1315 \\
{[0.046]^{* * *}}\end{array}$ & $\begin{array}{l}0.9880 \\
{[0.249]^{* * *}}\end{array}$ & $\begin{array}{l}-0.1436 \\
{[0.218]}\end{array}$ \\
\hline Stay on post - 16 & $\begin{array}{l}0.1360 \\
{[0.006]^{* * *}}\end{array}$ & $\begin{array}{l}0.0885 \\
{[0.029]^{* * *}}\end{array}$ & $\begin{array}{l}-0.0475 \\
{[0.030]} \\
\end{array}$ \\
\hline Variable & $\begin{array}{l}\text { BCS } \\
1970\end{array}$ & $\begin{array}{l}\text { LSYPE } \\
1989 / 1990 \\
\end{array}$ & $\begin{array}{l}\text { Cross-cohort } \\
\text { Difference }\end{array}$ \\
\hline $\begin{array}{l}\text { Number of O-levels } \\
\left(A^{*}-C\right)\end{array}$ & $\begin{array}{l}1.1315 \\
{[0.046]^{* * *}}\end{array}$ & $\begin{array}{l}0.9336 \\
{[0.035]^{* * *}}\end{array}$ & $\begin{array}{l}-0.1979 \\
{[0.060]^{* * *}}\end{array}$ \\
\hline Stay on post - 16 & $\begin{array}{l}0.1360 \\
{[0.006]^{* * *}}\end{array}$ & $\begin{array}{l}0.0463 \\
{[0.005]^{* * *}}\end{array}$ & $\begin{array}{l}-0.0897 \\
{[0.007]^{* * *}}\end{array}$ \\
\hline
\end{tabular}

Standard errors in parentheses, boys and girls, controls for parental age, parental age squared and gender

$* * *$ Indicates significance at the $99 \%$ confidence level, $* *$ is significant at the $95 \%$ confidence level, and $*$ indicates a $90 \%$ confidence level.

The picture through the BHPS cohorts and the LYPSE, is for moderate reduction in the gradient of GCSE scores by family background, and more dramatically for staying on at age 16 . The relationship between income and education shows no significant changes between those born in the BCS and those born just 5-10 years more recently in BHPS 1 cohort (born between from 1975-1980 - in the second panel of table 5), with nearly all the coefficients being negative but small in magnitude, and insignificantly different from the BCS relationships. So the picture is one of stability for those two cohorts born in the 1970s and attending secondary school in the 1980 s and early 1990 s. However, the relationship between the proportion of time spent not in education, employment or training became significantly more graded by income across these two cohorts. A $100 \%$ increase in family income in the BCS, would reduce the proportion of time spent not in education, employment or training (NEET), between leaving full-time education and the age of 24 , by under $2 \%$, but the same increase for the BHPS 1 cohort would reduce this time by more than three times the magnitude, over $6 \%$. This is in line with much of the work done on NEETs recently, and indicates that this is a group of individuals who are still in need of a lot of help as they are increasingly constrained by their family background.

The second BHPS cohort, those born from 19811986 , show another small reduction in the income gradients associated with most educational attainment outcomes considered (the exception being staying on at age 18) compared with the earlier BHPS1 cohort. Whilst the coefficient for the number of $A^{*}-C$ grades achieved at GCSE level has 
come down markedly from the BCS (panel 4, table $5)$, the large standard errors associated with the small BHPS sample make it hard to judge if this is a true effect rather than sampling. If both the BCS and BHPS 2 cohort were to experience a doubling of their income, the gap in the number of $A^{*}-C$ graded GCSEs, between poorer and more affluent children, would be 0.34 smaller in the later cohort than for individuals born in 1970. An even smaller third cohort of individuals born from 1987 to 1990, BHPS 3 , exhibit a very similar pattern as the previous BHPS cohort, and hence a similar decrease in the social gradient of those obtaining $A^{*}-C$ graded GCSEs (panel 6, Table 5) relative to the BCS. However, even combining the two later BHPS to increase sample size still leads to imprecision in the estimates.

The much larger LSYPE cohort who were born towards the end of the BHPS 3 sample (1989-90) and who would have experienced their junior schooling and secondary schooling under New Labour, further show similar gradients as the last two BHPS cohorts, but here the results are now statistically significant. Column 6 of Table 4 and the final panel of Table 5 show that the coefficient on standardised family income for the LSYPE is in the same range as the BHPS 2 and BHPS 3 cohorts, but the standard errors are now much smaller and suggest that a doubling of family income induces a 0.93 increase in the number of GCSEs grades $A^{*}-C$ compared to 1.13 in the BCS and 0.72 in the old NCDS. The levelling off of the later BHPS data for children born 1981-1990 and the LSYPE is reassuring, and suggests that income gradients in GCSEs have begun to return to the days of the early 1970s. As noted above, the LSYPE can not yet take into account those (re-)taking GCSEs at age 17, which are more often drawn from poorer families. Hence, this relatively small reduction in the family income gradient with respect to GCSE passes may understate the full picture.

Data on staying on decisions post-age 16 are also available across all cohorts, and table 4 illustrates that the pattern of a decrease in the income gradient for those born after 1980, as seen for GCSEs, is replicated here. Across the BHPS cohorts, BHPS 1 again looks very similar in magnitude to that of the BCS, with a reduction in the income gradient kicking in for those born 1980-1986 and 19871990 ii. Again, the magnitude of the standard errors prevents any findings of significant differences for these two cohorts and the BCS (panels $4 \& 6$, table $5)$, but a doubling of family income in the BCS led to a $13 \%$ higher chance of staying on post-16 compared to only $8 \%$ in the BHPS 2 and BHPS 3 cohorts, a reduction of $5 \%$ in the income gradient. For the larger LSYPE cohort this difference is more pronounced, with a $9 \%$ statistically significant reduction in the income gradient from that of the BCS (panel 7, table 5). This is indicative of the widening access to post-16 education seen above, with $76 \%$ of individuals in the LSYPE cohort opting to stay on in full-time school or college post-16, showing that staying on post- 16 is becoming a route that the majority of individuals now take, regardless of their family background.

The data on further educational qualifications is only available up to BHPS 2, given the current age of the younger cohorts. From the data available, there is little suggestion of progress in patterns of the number of $A$ levels secured and degree participation since the BCS cohort, as shown in panel 4 of Table 5 . Hence the patterns suggest that family background is becoming less important in determining attainment at age 16, where the number securing GCSEs graded $A^{*}-C$ has risen sharply and allowed access to further education, but remains significant at post-16 education levels.

\section{Robustness to alternative measures}

The evidence presented so far, suggests an equalising in educational opportunities across family background at age 16, allowing greater access to post-16 education, but no equalisation beyond age 17 (albeit for older cohorts as the members of the most recent cohorts are not yet old enough to report this information). Given the importance of the findings, additional robustness checks need to be carried out to ensure that we can be confident of the results presented here.

First, we explore other data sources that can provide some information on the changing relationship between family background and educational attainment, but do not contain full income data. These are the Youth Cohort Studies, which contain social class rather than income but have a good time span, and second, administrative data on child progress (National Pupil Database) which has Free School Meals (FSM). This is a low income proxy as FSM apply to children who are eligible (though do not necessarily take up) these free meals on the basis of their parents entitlement 
to the major out-of-work benefits (Job Seekers Allowance, Income Support and Incapacity Benefit). An issue with both of these data sources, is that social class sizes and the proportion of the population entitlement to FSM are not constant across time, and hence populations of different sizes are being compared.

Tables 6 and 7 report official DCSF statistics from these two extra sources of data, for level 2 attainments by both FSM status and social class. Table 6 reports information on $5+A^{*}-C$ GCSEs between FSM and non-FSM children born from
1986 to 1992, and hence overlap with the BHPS3 and LSYPE cohorts described above. As in table 2, both the gap in attainment between FSM and nonFSM children, and the relative odds of the two, are reported in the tables. Consistent with the pattern report above, we see the growth in the proportion achieving good GCSEs across both groups, but at a slightly faster rate among the FSM group. Expressed as the odds ratio of achieving 5+ GCSE passes, this declines rapidly from 2.3 times more likely among non-FSM than FSM children, to 1.7 times by 2008.

Table 6. Proportion of FSM and non-FSM individuals obtaining 5 or more GCSEs or equivalent at grade $A^{*}-C$

\begin{tabular}{lccccccc} 
GCSE year & 2002 & 2003 & 2004 & 2005 & 2006 & 2007 & 2008 \\
\hline Birth year & $\mathbf{1 9 8 6}$ & $\mathbf{1 9 8 7}$ & $\mathbf{1 9 8 8}$ & $\mathbf{1 9 8 9}$ & $\mathbf{1 9 9 0}$ & $\mathbf{1 9 9 1}$ & $\mathbf{1 9 9 2}$ \\
\hline Non-FSM & 53.7 & 55.2 & 56.1 & 58.9 & 61 & 62.8 & 67.0 \\
FSM & 23.0 & 24.4 & 26.1 & 29.9 & 31 & 35.5 & 40.0 \\
\hline Difference & $\mathbf{3 0 . 7}$ & $\mathbf{3 0 . 8}$ & $\mathbf{3 0 . 0}$ & $\mathbf{2 9 . 0}$ & $\mathbf{2 9 . 5}$ & $\mathbf{2 7 . 3}$ & $\mathbf{2 7 . 0}$ \\
\hline Ratio & $\mathbf{2 . 3 3}$ & $\mathbf{2 . 2 6}$ & $\mathbf{2 . 1 5}$ & $\mathbf{1 . 9 7}$ & $\mathbf{1 . 9 5}$ & $\mathbf{1 . 7 7}$ & $\mathbf{1 . 6 8}$
\end{tabular}

Source: http://www.dcsf.gov.uk/rsgateway/DB/SFR/s000759/index.shtml National Curriculum Assessment, GCSE and Equivalent Attainment and Post-16 Attainment by Pupil Characteristics, in England 2002-2008

Table 7. Proportion of individuals obtaining 5 or more GCSEs or equivalent at grade $A^{*}-C$ by parental occupation groupings for those born 1972-1990

\begin{tabular}{|c|c|c|c|c|c|c|c|c|c|c|}
\hline GCSE year & '88 & ‘90 & ‘91 & ‘93 & ‘95 & ‘97 & ‘99 & ‘01 & ‘03 & ‘06 \\
\hline Birth year & 72 & '74 & '75 & 97 & 79 & '81 & '83 & '85 & '87 & '90 \\
\hline \multicolumn{11}{|l|}{$\begin{array}{l}\text { PARENTAL OCCUPATION } \\
\text { (SEG) }\end{array}$} \\
\hline Managerial/Professional & 52 & 58 & 60 & 66 & 68 & 69 & 70 & & & \\
\hline Other non-manual & 42 & 49 & 51 & 58 & 58 & 60 & 59 & & & \\
\hline Skilled manual & 21 & 27 & 29 & 36 & 36 & 40 & 45 & & & \\
\hline Semi-skilled manual & 16 & 20 & 23 & 26 & 29 & 32 & 35 & & & \\
\hline Unskilled manual & 12 & 15 & 16 & 16 & 24 & 20 & 30 & & & \\
\hline Top - Bottom & 40 & 43 & 44 & 50 & 44 & 49 & 40 & & & \\
\hline Ratio of top / bottom & 4.3 & 3.9 & 3.8 & 4.1 & 2.8 & 3.5 & 2.3 & & & \\
\hline \multicolumn{11}{|l|}{$\begin{array}{l}\text { PARENTAL OCCUPATION } \\
\text { (NS-SEC) }\end{array}$} \\
\hline Higher professional & & & & & & & 75 & 77 & 76 & 81 \\
\hline Lower professional & & & & & & & 62 & 64 & 65 & 73 \\
\hline Intermediate & & & & & & & 49 & 51 & 53 & 59 \\
\hline Lower supervisory & & & & & & & 34 & 34 & 41 & 46 \\
\hline Routine & & & & & & & 26 & 31 & 33 & 42 \\
\hline Top - Bottom & & & & & & & 49 & 46 & 43 & 39 \\
\hline Ratio of top / bottom & & & & & & & 2.9 & 2.5 & 2.3 & 1.9 \\
\hline
\end{tabular}

Source: http://www.dcsf.gov.uk/rsgateway/DB/SBU/b000795/Bulletin tables final.xls. LSYPE, wave 4 and YCS, cohorts 4-13, sweep 1 
Table 7 uses information from the slightly more informative YCS, given that it covers the BCS period and all the cohorts considered since then. It shows level 2 attainments by measures of head of households' social class. There is a break in the series in 1999 when a new class measure was introduced, but both measures can be observed for that year. This shows a rise in the proportion achieving good GCSEs between cohorts born in 1972 and 1977, though the odds ratio remains broadly stable, in line with the stability between the BCS and BHPS1 cohort. This plateaued for those born up to 1981, before falling sharply for cohorts born between 1983 and 1990. This timing completely coincides with the later BHPS data and LSYPE data shown in Table 4. There is a very high gradient in GCSE attainment across income groups for cohorts born in the 1970s and reaching 16 in the late 1980s and early 1990s, before declining markedly for those born in the 1980s and leaving school from 1997 onwards.

There must be some concern that this is driven by changes in examinations rather than underlying ability, literacy or numeracy skills. There has been a widespread concern that rising pass rates stem from 'grade inflation', which pushes more people into top grade categories. This would tend to narrow the observed income gradient, as a greater proportion of more affluent children will have already achieved a high number of $A^{*}$ $C$ grades. So we need to look at alternative measures not subject to this problem. One approach is to use more restrictive measures of GCSEs.

Appendix Table A1 replicates the main result for the BCS and LSYPE, of a declining social gradient in aged 16 educational attainment, using the total points score, which is a more continuous measure of GCSEs with no cut-off point at grade $C$, as points are assigned to all grades obtained. The coefficients indicate a significant decrease in the additional points associated with a doubling of family income for those born in 1970, compared to $1989 / 90$. However, the increasing numbers getting the top grades means this measure still has problems. LPM estimates of obtaining five $A^{*}-C$ grades and five $A^{*}-C$ grades, including maths and English, indicates a doubling of family income in the BCS is associated with an increase the probability of hitting these targets by around $15 \%$, compared to around $10 \%$ in the LSYPE. All decreases between the cohorts are significant at a $95 \%$ confidence level or higher. As the mean for those achieving $5+A *-C$ grades including maths and English is around ten percentage points lower than any $5 A^{*}-\mathrm{Cs}$, the similarity of the two measures is reassuring, demonstrating that capping is not the source of the narrowing of attainment gaps.

A more informative way to determine whether these findings are driven by changes in underlying ability and literacy and numeracy skills, rather than changes in examinations, is to examine data of $I Q$, literacy and numeracy scores and their relationship with family background across the cohorts. The relationship between family income and educational attainment can be expanded further back into the cohort member's childhood, to consider the relationship between family income and test scores. Blanden et al (2007) found that these test scores, measured at the beginning of secondary school, are strong predictors of earnings at thirty, and that the majority of the effects are coming through later educational attainment. Jencks' (1979) examination of a number of studies on this, finds correlations in the range of 0.40 and 0.6 between cognitive ability and educational achievement. Deary et al (2007) considers the correlation between Cognitive Ability Test (CAT) scores, and GCSE total points scores and best 8 GCSEs, and find an even stronger correlation in the UK of 0.69 for the point score and 0.72 for the best 8 GCSEs respectively. Using path analysis, they find an even stronger correlation of 0.81 between the underlying latent variable from the three CAT tests, and the underlying latent variable for general educational achievement. These test scores can be therefore thought of as a good early proxy for later educational attainment.

This data is not available in the BHPS and is limited in the LSYPE, but there is an additional ALSPAC birth cohort of children born in the old Avon area around Bristol in 1991/2, which can offer some insight here. Using comparable standardised reading and maths tests for the NCDS, BCS, LSYPE and ALSPAC, for children aged 10/11, Table 8 documents the mean test scores across the income quintiles. In addition, we have measures of IQ available in the NCDS, BCS and ALSPAC cohorts at ages 11,10 and 8 respectively, but not for the LSYPE. The mean score gap between the top and bottom income quintiles was 57 points for 10,52 for maths, and 56 for reading in the NCDS. These had risen to 81ppts, 84ppts and 88ppts respectively in the BCS, in line with the widening gaps in qualifications observed earlier. In the LSYPE, these had fallen back to 65ppts and 68ppts for maths and reading respectively, and in ALSPAC to 75ppts for IQ and 76ppts for maths and reading.

Table 9 documents the change in the univariate relationship with standardised family income across the four cohorts, and reports regression coefficients for these gradients. As with educational attainment, the 
NCDS is far less socially graded than the BCS in terms of test scores. An individual experiencing a $100 \%$ increase in family income, or moving from the $10^{\text {th }}$ to the $50^{\text {th }}$ percentile of the income distribution, is on average likely to score one fifth of a standard deviation higher on all three test scores. In comparison, the same income change in the BCS would increase test scores by one third of a standard deviation. These increases are statistically significant across the two cohorts (Panel 1 of Table 10).

Table 8. Average test score deviations from the standardised mean $(0,1)$ by income quintile for NCDS, BCS, LSYPE (1989-90) and ALSPAC (1991-92)

\begin{tabular}{lcccc} 
Variable & $\begin{array}{c}\text { NCDS } \\
\mathbf{1 9 5 8}\end{array}$ & $\begin{array}{c}\text { BCS } \\
\mathbf{1 9 7 0}\end{array}$ & $\begin{array}{c}\text { LSYPE } \\
\mathbf{1 9 8 9 / 9 0}\end{array}$ & $\begin{array}{c}\text { ALSPAC } \\
\mathbf{1 9 9 1 / 9 2}\end{array}$ \\
\hline IQ & & & & \\
\hline Inc quintile 1 & -0.2332 & -0.3262 & & -0.2554 \\
Inc quintile 2 & -0.0549 & -0.0445 & & -0.1041 \\
Inc quintile 3 & 0.0359 & 0.1124 & & 0.2165 \\
Inc quintile 4 & 0.0886 & 0.2350 & & 0.2690 \\
Inc quintile 5 & 0.3453 & 0.4965 & & 0.5019 \\
\hline Maths & & & & \\
\hline Inc quintile 1 & -0.2184 & -0.3030 & -0.2301 & -0.3583 \\
Inc quintile 2 & -0.0511 & -0.0712 & -0.1925 & -0.1038 \\
Inc quintile 3 & 0.0059 & 0.0931 & 0.0026 & -0.0093 \\
Inc quintile 4 & 0.0777 & 0.2284 & 0.2027 & 0.2314 \\
Inc quintile 5 & 0.3864 & 0.5379 & 0.4552 & 0.4099 \\
\hline Reading & & & & \\
\hline Inc quintile 1 & -0.2198 & -0.3409 & -0.2193 & -0.3558 \\
Inc quintile 2 & -0.0604 & -0.0795 & -0.1999 & -0.1259 \\
Inc quintile 3 & 0.0178 & 0.0987 & 0.0254 & 0.0376 \\
Inc quintile 4 & 0.0615 & 0.2723 & 0.2277 & 0.2359 \\
Inc quintile 5 & 0.3408 & 0.5461 & 0.4306 & 0.3963 \\
\hline
\end{tabular}

Unconditional means by income quintile, boys and girls

Table 9. Relationship between standardised family income and cognitive test scores for NCDS, BCS, LSYPE (1989-90) and ALSPAC (1991-92)

\begin{tabular}{lllll} 
Variable & $\mathbf{N C D S}$ & BCS & LSYPE & ALSPAC \\
& $\mathbf{1 9 5 8}$ & $\mathbf{1 9 7 0}$ & $\mathbf{1 9 8 9 / 9 0}$ & $\mathbf{1 9 9 1 / 9 2}$ \\
\hline IQ & 0.1963 & 0.2791 & & 0.2168 \\
& {$[0.011]^{* * *}$} & {$[0.013]^{* * *}$} & & {$[0.015]^{* * *}$} \\
$\boldsymbol{N}$ & 7733 & 5476 & & 4404 \\
Maths & 0.2025 & 0.2874 & 0.1758 & 0.2261 \\
& {$[0.011]^{* * *}$} & {$[0.013]^{* * *}$} & {$[0.010]^{* * *}$} & {$[0.014]^{* * *}$} \\
$\boldsymbol{N}$ & 7729 & 5485 & 9976 & 5419 \\
Reading & 0.1937 & 0.3003 & 0.1662 & 0.2207 \\
$N$ & {$[0.011]^{* * *}$} & {$[0.013]^{* * *}$} & {$[0.010]^{* * *}$} & {$[0.013]^{* * *}$} \\
Reading at 7 & 7732 & 5486 & 9895 & 5270 \\
& 0.1451 & & & 0.1773 \\
$N$ & {$[0.011]^{* * *}$} & & & {$[0.014]^{* * *}$} \\
\hline
\end{tabular}

Standard errors in parentheses, boys and girls, controls for parental age, parental age squared and gender

$* * *$ Indicates significance at the $99 \%$ confidence level, $* *$ is significant at the $95 \%$ confidence level, and * indicates a $90 \%$ confidence level. Family income is monthly net logged standardised family income. Income standardised to account for differential variation across cohorts. IQ at 11, 10 and 8 in the NCDS, BCS and ALSPAC respectively. Maths and reading measured at age 11 in all but the BCS (10).

Correlation between ALSPAC Key Stage reading at 11 and Clinic based Reading at 7 is 0.6766 
The LSYPE and ALSPAC test scores are however, consistent with a decrease in the social gradient in test scores for younger cohorts, with a significant decline in the relationship between family income and test scores from the BCS to both younger cohorts (panels 2 and 3 of Table 10). The social gradients in the two cohorts appear similar to those of the NCDS cohort, and panel 4 of Table 10 indicates there is no significant difference between the NCDS and ALSPAC. The additional ALSPAC clinically assessed reading test at 7 , exhibits a similar magnitude to the reading at 7 test in the NCDS, and similar patterns of a decrease in the social gradient from that of the BCS. This suggests that it is not the fact that age 11 reading and maths tests are derived from administrative data rather than school based assessments, that is driving the differences. IQ tests in ALSPAC are also undertaken in study clinics rather than being school-based. This further supports the notion of a reversal in fortunes of those from lower income families.

Table 10. Cross-cohort tests of significant differences from table 9 results

\begin{tabular}{|c|c|c|c|}
\hline Variable & $\begin{array}{l}\text { NCDS } \\
1958 \\
\end{array}$ & $\begin{array}{l}\text { BCS } \\
1970\end{array}$ & $\begin{array}{l}\text { Cross-cohort } \\
\text { Difference }\end{array}$ \\
\hline IQ & $\begin{array}{l}0.1963 \\
{[0.011]^{* * *}}\end{array}$ & $\begin{array}{l}0.2791 \\
{[0.013]^{* * *}}\end{array}$ & $\begin{array}{l}0.0827 \\
{[0.017]^{* * *}}\end{array}$ \\
\hline Maths & $\begin{array}{l}0.2025 \\
{[0.011]^{* * *}}\end{array}$ & $\begin{array}{l}0.2874 \\
{[0.013]^{* * *}}\end{array}$ & $\begin{array}{l}0.0849 \\
{[0.017]^{* * *}}\end{array}$ \\
\hline Reading & $\begin{array}{l}0.1937 \\
{[0.011]^{* * *}}\end{array}$ & $\begin{array}{l}0.3003 \\
{[0.013]^{* * *}}\end{array}$ & $\begin{array}{l}0.1065 \\
{[0.017]^{* * *}}\end{array}$ \\
\hline Variable & $\begin{array}{l}\text { BCS } \\
1970\end{array}$ & $\begin{array}{l}\text { LSYPE } \\
1989 / 90\end{array}$ & $\begin{array}{l}\text { Cross-cohort } \\
\text { Difference }\end{array}$ \\
\hline Maths & $\begin{array}{l}0.2874 \\
{[0.013]^{* * *}}\end{array}$ & $\begin{array}{l}0.1758 \\
{[0.010]^{* * *}}\end{array}$ & $\begin{array}{l}-0.1116 \\
{[0.017]^{* * *}}\end{array}$ \\
\hline Reading & $\begin{array}{l}0.3003 \\
{[0.013]^{* * *}}\end{array}$ & $\begin{array}{l}0.1662 \\
{[0.010]^{* * *}}\end{array}$ & $\begin{array}{l}-0.1341 \\
{[0.017]^{* * *}}\end{array}$ \\
\hline Variable & $\begin{array}{l}\text { BCS } \\
1970\end{array}$ & $\begin{array}{l}\text { ALSPAC } \\
1991 / 2\end{array}$ & $\begin{array}{l}\text { Cross-cohort } \\
\text { Difference }\end{array}$ \\
\hline IQ & $\begin{array}{l}0.2791 \\
{[0.013]^{* * *}}\end{array}$ & $\begin{array}{l}0.2168 \\
{[0.015]^{* * *}}\end{array}$ & $\begin{array}{l}-0.0623 \\
{[0.020]^{* * *}}\end{array}$ \\
\hline Maths & $\begin{array}{l}0.2874 \\
{[0.013]^{* * *}}\end{array}$ & $\begin{array}{l}0.2261 \\
{[0.014]^{* * *}}\end{array}$ & $\begin{array}{l}-0.0613 \\
{[0.019]^{* * *}}\end{array}$ \\
\hline Reading & $\begin{array}{l}0.3003 \\
{[0.013]^{* * *}}\end{array}$ & $\begin{array}{l}0.2207 \\
{[0.013]^{* * *}}\end{array}$ & $\begin{array}{l}-0.0795 \\
{[0.019]^{* * *}}\end{array}$ \\
\hline Variable & $\begin{array}{l}\text { NCDS } \\
1958\end{array}$ & $\begin{array}{l}\text { ALSPAC } \\
1991 / 2\end{array}$ & $\begin{array}{l}\text { Cross-cohort } \\
\text { Difference }\end{array}$ \\
\hline IQ & $\begin{array}{l}0.1963 \\
{[0.011]^{* * *}}\end{array}$ & $\begin{array}{l}0.2168 \\
{[0.015]^{* * *}}\end{array}$ & $\begin{array}{l}0.0205 \\
{[0.019]}\end{array}$ \\
\hline Maths & $\begin{array}{l}0.2025 \\
{[0.011]^{* * *}}\end{array}$ & $\begin{array}{l}0.2261 \\
{[0.014]^{* * *}}\end{array}$ & $\begin{array}{l}0.0235 \\
{[0.018]}\end{array}$ \\
\hline Reading & $\begin{array}{l}0.1937 \\
{[0.011]^{* * *}}\end{array}$ & $\begin{array}{l}0.2207 \\
{[0.013]^{* * *}}\end{array}$ & $\begin{array}{l}0.0270 \\
{[0.018]}\end{array}$ \\
\hline Reading at 7 & $\begin{array}{l}0.1451 \\
{[0.011]^{* * *}}\end{array}$ & $\begin{array}{l}0.1773 \\
{[0.014]^{* * *}}\end{array}$ & $\begin{array}{l}0.0322 \\
{[0.018]^{*}}\end{array}$ \\
\hline
\end{tabular}

Standard errors in parentheses, boys and girls, controls for parental age, parental age squared and gender

$* * *$ Indicates significance at the $99 \%$ confidence level, ${ }^{* *}$ is significant at the $95 \%$ confidence level, and * indicates a $90 \%$ confidence level. 


\section{Robustness of income measures and attrition}

As we use data from a number of different sources it is important that these are all comparable. A lot of work has been carried out previously on the comparability of the income measures in the NCDS and BCS (see Blanden 2004, Blanden et al 2008). As the main findings here focus on the BCS and LSYPE, appendix Table A2 documents the different income gradients associated with using different measures of income for these two cohorts.

The two main issues are over the technique used to turn the raw banded income into continuous data, and the transformation from gross income to net income required in both sources. The BCS has 11 bands of income data with $5 \%$ in the open top category. The LSYPE has 92 bands of data with $0.01 \%$ in the open top category. The Singh-Maddala transformation that is applied to the BCS banded data is a useful way of assigning those in the open top category within the band. As there are so few in the top category of the LSYPE, it is not necessary to apply this transformation. As can be seen from Table A2, the BCS results show that using midpoints of the bands, or an interval regression technique instead of the Singh-Maddala transformation, produces very similar coefficients. The interval regression technique is favoured as it weights an individual's position within a band and so, given there is little to choose between methods, this is the method chosen for the LSYPE.

Both the BCS and LSYPE are transformed from gross to net family income using the FES (Family Expenditure Survey) (1986) for the BCS and the FRS (Family Resources Survey) (2004) for the LSYPE, for households with children aged 10 to 16 . Gross and net household incomes are observable in these data sources, and therefore the average ratio for each band is used to impute a net income amount. In both cohorts, the transformation increases the relationship between family income and the total number of GCSEs when using non-standardised income. When the income is standardised, this deals with much of the associated differences in variation from applying this transformation, and the results in the BCS are almost identical. In the LSYPE, the net standardised income measure produces coefficients slightly below those from using a gross income measure.

Given that the LSYPE income measure is from the first wave of the study, there may be concerns that there is attrition by age 16 in the NCDS and $B C S$, that cannot have occurred in the LSYPE. Given that we would expect the attrition to be from lower income families, this could be driving the decline in the relationship between family background and educational attainment at 16 from the BCS to the LSYPE. Appendix tables $A 3$ and $A 4$ consider this issue, with panel 1 of table $A 3$ documenting the proportions of each of the father's social class at birth reporting income at 16 , and those not reporting income at 16 , and then panel 2 repeating this and including mother's class and parental education for the BCS. The main point to take from table A3 is that the attrition does not seem to be a particular problem in either cohort. It appears random across all social classes and education levels. For more stringent testing, the LSYPE cohort were weighted by their probability of leaving the sample by their parent's education, based on the findings from the BCS assuming similar patterns of attrition. Table A4 indicates that this makes no difference to the coefficient of the relationship between family income and the number of GCSEs grades $A^{*}$-C obtained in the LSYPE.

A further concern was that the LSYPE is the Longitudinal Survey of Young People in England whereas the other data sources also contain individuals from the rest of the UK. It could be the case that the results are driven purely by this selection if, for example, England had less educational inequality at GCSE level, than had Scotland, Wales and Northern Ireland. Therefore, the first row of Table 4 was replicated for the other data sources, restricting the samples to England only. As can be seen from table A5, this does not change the pattern at all. The significant decline remains, in the relationship between family background and educational attainment at 16 , for this restricted sample.

\section{Conclusions and discussion}

The above information presents a strong picture that the gradient of educational attainment at age 16 by family background (income or class), has lessened between generations born in the 1970s and those born in the 1980s and early 1990s. The government-based statistics on child attainment at age 16 are most commonly summarized by proportion of children attaining 5+ GCSEs grades $A^{*}-C$. This has been rising for nearly 20 years, from around $40 \%$ in the mid-1980s to nearly $60 \%$ by 2003 
the last year of our BHPS 2 sample). Whether this general rise in measured attainment reflects improved true attainment is disputed. Obviously as the proportion gets close to $100 \%$ any gradient must disappear, but in the middle range seen here, an expansion can still lead to larger increases in the top two quintiles than the bottom two.

The government-based data do not contain measures of family income, but there are two possible alternatives. The first is the Free School Meals eligibility, which applies to around $15 \%$ of children from among the poorest families, and the second is average attainment in schools with a higher or low proportion of FSM eligible children. However, even for these measures, the available data does not go very far back. It suggests a small closing of the attainment gap between FSM and non-FSM children in recent years, and a more marked closing of attainment gaps for schools serving a large proportion of FSM children. The Department of Children Schools and Families (DCSF) has used the Youth Cohort Studies to look at the relationship between social class and attainment at age 16, and suggests a narrowing of class gaps after 1997 (DCSF 2006 and Heath et al 2009). Our data, based on birth cohorts and the British Household Panel Survey, confirms this pattern using income data.

The picture of an improvement in equality of opportunity in terms of education attainment at age 16, is also mirrored in IQ and reading and maths test scores in two recent cohorts: LYPSE and ALSPAC. So for younger generations, the educational differences across family backgrounds at age 16, and in literacy and numeracy test scores at age 10/11, do appear to be equalising, but the picture for education after age 16 is less clear. Given the important role of education in accounting for levels of social mobility (Blanden et al 2007) there is a suggestion that this weakening of income gradients in educational attainment at age 16 may improve future mobility levels. However, the impact on future earnings remains to be seen, and will depend on whether the returns to different aspects of education change across time. As GCSEs are becoming more common and less graded by family background, their value in the labour market may also diminish. Indeed McIntosh (2006) finds evidence of this trend in the decline in the labour market returns to the number of GCSEs using LFS (Labour Force Survey) data from 1990-2005.
Whilst the timing of the closing of GCSE attainment gaps can be dated quite closely to cohorts reaching age 16 since 1995-97, or born since the early 1980s, the picture for test score data is less clear, as data is much less frequent but is in place for two cohorts born around 1990. At degree level, the picture of improvement in attainment gaps is far less clear.

The forces shaping the relationship between family income and educational attainment are widely thought to reflect inequality and the education system (see Blanden 2009, for a crosscountry review). The extent of child poverty (children growing up in low income households) rose from $13 \%$ in 1979 to $23 \%$ by 1987 when children born in the 1970s were moving through secondary school. It peaked at $27 \%$ in around 1996 before falling back to $22 \%$ in 2008 after the then Labour Government made a concerted drive to reduce it. This timing of the rise and more recent fall in child poverty thus only partially matched the timing observed. Whilst it is consistent with the growing importance of family background between the 1958 NCDS and 1970 BCS cohorts, the recent fall has come rather late to have had much affect of cohorts born in the early 1980s and sitting GCSEs in late 1990s. Further, the large scale investment in increasing spending on education as a share of GDP and attempts to reduce poverty and its effects on children since 1999 has been mostly heavily focused on younger children (the Sure Start programme and free $1 / 2$ nursery school places are focused on the under $5 \mathrm{~s}$, whereas class size reduction and tax credits have all been focused on children aged under 11). The impact on these children in terms of educational attainment at 16 is still some years away.

In terms of GCSE qualifications, improvements were clearly visible in the cohort preceding these investments and probably has more to do the reforms to age 16 qualifications introduced by Sir Keith Joseph in the Conservative era and started to come into effect in 1988 . This moved away from broadly a fixed proportion of children obtaining an O level in any subject to a fixed level which all children could theoretically achieve. This opened the way for a steady increase in the numbers of students achieving grades A-C since that date, but improved teaching and school quality have probably added to this dynamic. There have been many concerns raised that this rise is artificial grade inflation rather than a genuine improvement in 
standards, but the reductions in income gradients and test scores, including IQ scores, suggest that the narrowing social gradient in cognitive attainment cannot be entirely due to grade inflation in GCSEs but rather there has been a genuine reduction in educational inequalities for children leaving school since the early 1990s. However, the increasing frequency of GCSE achievement by children may serve to reduce their value in the labour market and higher education may be becoming the more important both in terms of well paid jobs and in terms of social patterning.

\section{Acknowledgements}

This work was funded by the ESRC Large Grant RES-060-23-0011 - An Examination of the Impact of Family Socio-economic Status on Outcomes in Late Childhood and Adolescence. The authors would like to thank the reviewers for comments to improve the paper.

\section{References}

Becker G and Tomes N. (1986) Human Capital and the Rise and Fall of Families. Journal of Political Economy, 85, 1141-1188.

Black S, Devereux, P and Salvanes K. (2008) Staying in the Classroom and Out of Maternity Ward? The Effect of Compulsory Schooling Laws on Teenage Births. The Economic Journal, 118, 1025-1054.

Blanden J. (2005) 'Essays on inter-generational mobility and its variation over time, place and family structure'. PhD thesis, University College, London.

Blanden J. (2009) How much can we learn from international comparisons of intergenerational mobility? CEE discussion paper DP0111.

Blanden J, Goodman A, Gregg P and Machin S. (2004) Changes in intergenerational mobility in Britain. In M. Corak ed. Generational Income Mobility in North America and Europe, Cambridge University Press, Cambridge.

Blanden J, Gregg P and Macmillan L. (2007) Accounting for intergenerational income persistence: Noncognitive skills, ability and education, The Economic Journal, 117, C43-C60.

Blanden J, Gregg P and Macmillan L. (2010) Intergenerational Persistence in Income and Social Class: The Impact of Within-Group Inequality. CMPO Working Paper 10/230.

Blanden J and Machin S. (2008) Up and down the Generational Income Ladder in Britain; Past Changes in Future Prospects. National Institute Economic Review No. 205.

Blanden J and Machin S. (2004) Educational inequality and the expansion of UK higher education. Scottish Journal of Political Economy, 51(2), 230-249.

Brewer M, Ratcliffe A and Smith S. (2007) Does Welfare Reform Affect Fertility? Evidence from the UK. CMPO Working paper 07/177.

Corak M. (2006) Do poor children become poor adults? Lessons from a cross-country comparison of generational earnings mobility. IZA Discussion Paper No. 1993.

Dahl G and Lochner L. (2008) The Impact of Family Income on Child Achievement: Evidence from the Earned Income Tax Credit NBER Working Paper No. 14599.

Dearden L, Machin S and Reed H. (1997) Intergenerational mobility in Britain. The Economic Journal, 107(440), 4764.

Dickson M. (2009) The Causal Effect of Education on Wages Revisited. IZA Discussion Paper 4419.

Deary IJ, Strand S, Smith PK and Fernances C. (2007) Intelligence and educational achievement. Intelligence, 35, 13-21.

Ermisch J and Francesconi M. (2004) Intergenerational mobility in Britain : new evidence from the BHPS. In M Corak (ed) Generational Income Mobility in North America and Europe, Cambridge University Press, Cambridge.

Ermisch J and Nicoletti C. (2005) Intergenerational earnings mobility: changes across cohorts in Britain. ISER Working Paper 2005-19. Colchester, University of Essex, Colchester.

Galindo-Rueda F and Vignoles A. (2005) The declining relative importance of ability in predicting educational attainment. Journal of Human Resources, 40(2), 335-53.

Grawe N. (2004) The 3-day week of 1974 and earnings data reliability in the Family Expenditure Survey and the National Child Development Survey. Oxford Bulletin of Economics and Statistics, 66(3), 567-579.

Gregg P, Macmillan L and Nasim B. (2010) The impact of the 1980s recession on educational attainment. Mimeo.

Jäntti M, Bratsberg B, Røed K, Raaum O, Naylor R, Osterbacka E, Bjorklund A and Eriksson T. (2006) American exceptionalism in a new light: a comparison of intergenerational earnings mobility in the Nordic countries, the United Kingdom and the United States. IZA Discussion Paper No. 1938.

Heath N, Lupton R and Salter E. (2009) Social class inequalities in education in England under New Labour. In J Hills, T Sefton and K Stewart. eds. Towards a more equal society? Poverty, inequality and policy since 1997. The Policy Press, Bristol.

Jencks C. (1979) Who gets ahead? The determinants of economic success in America. Basic Books, New York. 
McIntosh, S. (2006) Further Analysis of the Returns to Academic and Vocational Qualifications. Oxford Bulletin of Economics and Statistics, 68(2), 225-251.

Mincer J. (1974) Schooling, experience, and earnings. National Bureau of Economic Research, New York.

Meghir C and Palme M. (2005) Educational Reform, Ability and Parental Background). American Economic Review, 95(1), 414-424.

Milligan K and Stabile M. (2008) Do child tax benefits affect the wellbeing of children? Evidence from Canadian Child Benefit Expansions, National Bureau of Economic Research, WP 14624.

Oreopoulos P. (2006) Estimating Average and Local Average Treatment Effects of Education when Compulsory Schooling Laws Really Matter. American Economic Review, American Economic Association, 96(1), 152175.

Oreopoulos P and Page M. (2006) The Intergenerational Effects of Compulsory Schooling. Journal of Labor Economics, 24(4), 729-760.

Oreopoulos P, Page M and Huff Stevens A. (2008) The Intergenerational Effects of Worker Displacement. Journal of Labor Economics, 26(3), 455-483.

Schoon I. (2006) Risk and resilience. Adaptations in changing times. Cambridge University Press,

Singh S and Maddala G. (1976) A Function for Size Distribution of Incomes. Econometrica, 44(2), 963-970.

Solon G. (1999) Intergenerational mobility in the labor market. In O Ashenfelter and D Card. eds. Handbook of Labour Economics, Volume 3A, North Holland, Amsterdam.

Solon G. (2002) Cross country Differences in Intergenerational Earnings Mobility. Journal of Economic Perspectives, 16(3), 59-66.

\section{Appendix}

\section{Robustness check on educational attainment at 16}

Table A1. Relationship between standardised family income and a range of O-levels or equivalent measures at 16

\begin{tabular}{|c|c|c|c|}
\hline Variable & $\begin{array}{l}\text { BCS } \\
1970\end{array}$ & $\begin{array}{l}\text { LSYPE } \\
1989 / 90\end{array}$ & $\begin{array}{l}\text { Cross-cohort } \\
\text { Difference }\end{array}$ \\
\hline Number of O-levels & $\begin{array}{l}1.1315 \\
{[0.046]^{* * *}}\end{array}$ & $\begin{array}{l}0.9336 \\
{[0.035]^{* * *}}\end{array}$ & $\begin{array}{l}-0.1979 \\
{[0.060]^{* * *}}\end{array}$ \\
\hline O-level point score & $\begin{array}{l}38.365 \\
{[1.965]^{* * *}}\end{array}$ & $\begin{array}{l}31.97 \\
{[1.500]^{* * *}}\end{array}$ & $\begin{array}{l}-6.3973 \\
{[2.7570]^{* *}}\end{array}$ \\
\hline Five $A^{*}$-C grades & $\begin{array}{l}0.1447 \\
{[0.007]^{* * *}}\end{array}$ & $\begin{array}{l}0.0929 \\
{[0.005]^{* * *}}\end{array}$ & $\begin{array}{l}-0.0517 \\
{[0.008]^{* * *}}\end{array}$ \\
\hline $\begin{array}{l}\text { Five } A^{*}-C \text { grades } \\
\text { incl. eng + maths }\end{array}$ & $\begin{array}{l}0.1530 \\
{[0.009]^{* * *}}\end{array}$ & $\begin{array}{l}0.1038 \\
{[0.005]^{* * *}}\end{array}$ & $\begin{array}{l}-0.0493 \\
{[0.010]^{* * *}}\end{array}$ \\
\hline
\end{tabular}

Standard errors in parentheses, boys and girls, controls for parental age, parental age squared and gender

$* * *$ Indicates significance at the $99 \%$ confidence level, ${ }^{* *}$ is significant at the $95 \%$ confidence level, and * indicates a $90 \%$ confidence level.

\section{Robustness check on comparability across income measures}

Table A2. Relationship between various family income measures and the number of O-levels or equivalent at grade $A^{*}-C$ at 16 for the BCS and LSYPE

\begin{tabular}{|c|c|c|c|c|}
\hline & Gross & & Net & \\
\hline & BCS & LSYPE & BCS & LSYPE \\
\hline Variable & 1970 & $1989 / 90$ & 1970 & $1989 / 90$ \\
\hline \multicolumn{5}{|c|}{ Non-standardised income } \\
\hline \multirow[t]{2}{*}{ Singh Madalla } & 1.8619 & & 2.3081 & \\
\hline & {$[0.076]^{* * *}$} & & {$[0.095]^{* * *}$} & \\
\hline$N$ & 5428 & & 5428 & \\
\hline \multirow[t]{2}{*}{ Mid-points } & 1.9566 & 1.0835 & 2.3530 & 1.1571 \\
\hline & {$[0.080]^{* * *}$} & {$[0.039]^{* * *}$} & {$[0.096]^{* * *}$} & {$[0.044]^{* * *}$} \\
\hline$N$ & 5428 & 10925 & 5428 & 10925 \\
\hline Interval & 1.9453 & 1.0838 & 2.3340 & 1.1581 \\
\hline regression & {$[0.080]^{* * *}$} & {$[0.039]^{* * *}$} & {$[0.097]^{* * *}$} & {$[0.043]^{* * *}$} \\
\hline$N$ & 5428 & 10935 & 5428 & 10935 \\
\hline
\end{tabular}


(Table A2 cont'd)

\begin{tabular}{lllll}
\multicolumn{5}{l}{ Standardised income } \\
\hline Singh Madalla & 1.1348 & & 1.1315 \\
& {$[0.046]^{* * *}$} & & {$[0.046]^{* * *}$} & \\
$\boldsymbol{N}$ & 5428 & & 5428 \\
$\mathbf{M i d}-$ points & 1.1399 & 1.0559 & 1.1414 & 0.9308 \\
& {$[0.046]^{* * *}$} & {$[0.038]^{* * *}$} & {$[0.046]^{* * *}$} & {$[0.035]^{* * *}$} \\
$\boldsymbol{N}$ & 5428 & 10925 & 5428 & 10925 \\
Interval & 1.1358 & 1.0579 & 1.1369 & 0.9336 \\
regression & {$[0.047]^{* * *}$} & {$[0.038]^{* * *}$} & {$[0.047]^{* * *}$} & {$[0.035]^{* * *}$} \\
$\boldsymbol{N}$ & 5428 & 10935 & 5428 & 10935 \\
\hline
\end{tabular}

Standard errors in parentheses, boys and girls, controls for parental age, parental age squared and gender

${ }^{* * *}$ Indicates significance at the $99 \%$ confidence level, ${ }^{* *}$ is significant at the $95 \%$ confidence level, and * indicates a $90 \%$ confidence level.

\section{Robustness check on attrition in the NCDS and BCS compared to the LSYPE}

Table A3. Proportions of Permanent indicators at birth for the full sample, those reporting income at 16 and those not reporting income at 16

\begin{tabular}{|c|c|c|c|}
\hline NCDS & Full sample & With income & Without income \\
\hline \multicolumn{4}{|c|}{ Father's social class at birth } \\
\hline Social class 1 & 4.53 & 4.06 & 4.99 \\
\hline Social class 2 & 12.96 & 11.74 & 14.14 \\
\hline Social class 3 NM & 9.67 & 9.47 & 9.89 \\
\hline Social class $3 \mathrm{M}$ & 50.90 & 51.66 & 50.17 \\
\hline Social class 4 & 12.12 & 12.95 & 11.32 \\
\hline Social class 5 & 9.83 & 10.12 & 9.49 \\
\hline Total & 16,468 & 8,006 & 8,430 \\
\hline \multicolumn{4}{|c|}{$\begin{array}{l}\text { Proportions by parental class at birth, boys and girls } \\
\text { BCS }\end{array}$} \\
\hline & Full sample & With income & Without income \\
\hline \multicolumn{4}{|c|}{ Father's social class at birth } \\
\hline Social class 1 & 5.20 & 5.24 & 5.17 \\
\hline Social class 2 & 12.08 & 12.33 & 11.92 \\
\hline Social class 3 NM & 12.20 & 14.03 & 11.03 \\
\hline Social class $3 \mathrm{M}$ & 47.83 & 47.10 & 48.29 \\
\hline Social class 4 & 15.68 & 15.05 & 16.08 \\
\hline Social class 5 & 7.01 & 6.25 & 7.50 \\
\hline Total & 15773 & 6146 & 9627 \\
\hline \multicolumn{4}{|c|}{ Mother's social class at birth } \\
\hline Social class $1 \& 2$ & 13.99 & 14.55 & 13.63 \\
\hline Social class 3 NM & 44.69 & 47.27 & 43.03 \\
\hline Social class $3 \mathrm{M}$ & 8.03 & 7.43 & 8.41 \\
\hline Social class 4 & 31.27 & 29.12 & 32.66 \\
\hline Social class 5 & 2.01 & 1.63 & 2.26 \\
\hline Total & 10476 & 4117 & 6359 \\
\hline
\end{tabular}


(Table A3 cont'd)

\begin{tabular}{|c|c|c|c|}
\hline \multicolumn{4}{|c|}{ Father's highest education level } \\
\hline No quals & 9.56 & 7.31 & 11.01 \\
\hline NVQ level 1 (left 15) & 56.33 & 56.83 & 56.01 \\
\hline NVQ level 2 (left 16) & 14.14 & 14.97 & 13.60 \\
\hline NVQ level 3 (left 17/18) & 11.07 & 11.55 & 10.76 \\
\hline NVQ level 4/5 (left 19+) & 8.90 & 9.34 & 8.62 \\
\hline Total & 16213 & 6347 & 9866 \\
\hline \multicolumn{4}{|c|}{ Mother's highest education level } \\
\hline No quals & 7.86 & 5.65 & 9.24 \\
\hline NVQ level 1 (left 15) & 58.15 & 57.83 & 58.35 \\
\hline NVQ level 2 (left 16) & 16.46 & 18.21 & 15.37 \\
\hline NVQ level 3 (left 17/18) & 11.59 & 12.01 & 11.32 \\
\hline NVQ level 4/5 (left 19+) & 5.95 & 6.30 & 5.72 \\
\hline Total & 17017 & 6552 & 10465 \\
\hline
\end{tabular}

Table A4. Relationship between standardised family income and the number of O-levels or equivalent at grade $A^{*}-C$ at 16 for the LSYPE, weighted by attrition by parental education from the BCS

\begin{tabular}{lll} 
Variable & $\begin{array}{l}\text { Non- } \\
\text { weighted }\end{array}$ & Weighted \\
\hline Number of O-levels & 0.9374 & 0.9377 \\
$\left(\right.$ A $^{*}$ C) & {$[0.035]^{* * *}$} & {$[0.034]^{* * *}$} \\
\hline$N$ & 10605 & 10605 \\
\hline
\end{tabular}

Non-weighted numbers only differ from table 4 as this sample requires parental education information Standard errors in parentheses, boys and girls, controls for parental age, parental age squared and gender

*** Indicates significance at the $99 \%$ confidence level, ${ }^{* *}$ is significant at the $95 \%$ confidence level, and * indicates a $90 \%$ confidence level.

\section{Robustness check on sample for England only for NCDS, BCS and BHPS}

Table A5. Relationship between standardised family income and the number of O-levels or equivalent at grade $A *-C$ at 16 for a sample of those in England only in the NCDS, BCS and BHPS

\begin{tabular}{llllll} 
& NCDS & BCS & BHPS 1 & BHPS 2 & BHPS 3 \\
Variable & $\mathbf{1 9 5 8}$ & $\mathbf{1 9 7 0}$ & $\mathbf{1 9 7 5 - 1 9 8 0}$ & $\mathbf{1 9 8 1 - 1 9 8 6}$ & $\mathbf{1 9 8 7 - 1 9 9 0}$ \\
\hline Number of O-levels & 0.7363 & 1.1591 & 1.1196 & 0.7755 & 0.8874 \\
(A*-C) $_{\boldsymbol{N}}^{[0.040]^{* * *}}$ & {$[0.051]^{* * *}$} & {$[0.163]^{* * *}$} & {$[0.270]^{* * *}$} & {$[0.265]^{* * *}$} \\
\hline
\end{tabular}

Standard errors in parentheses, boys and girls, controls for parental age, parental age squared and gender

$* * *$ Indicates significance at the $99 \%$ confidence level, $* *$ is significant at the $95 \%$ confidence level, and * indicates a $90 \%$ confidence level.

\section{Endnotes}

\footnotetext{
'The coefficient when combining BHPS 2 and BHPS 3 is 0.9777 (0.188)

ii The coefficient of staying on post-16 on income for combined BHPS 2 and BHPS 3 group is 0.0979 (0.022) which is statistically significantly different from the corresponding BCS coefficient at a $10 \%$ level of significance.
} 


\title{
Health returns to cognitive capital in the British 1946 birth cohort
}

\author{
Marcus Richards ${ }^{1}$, Alison Stephen ${ }^{2}$ and Gita Mishra ${ }^{1}$ \\ ${ }^{1}$ MRC Unit for Lifelong Health and Ageing, London UK \\ ${ }^{2}$ MRC Human Nutrition Research, Cambridge, UK \\ m.richards@nshd.mrc.ac.uk
}

Received April 2010 Revised June 2010)

\begin{abstract}
The association between education and health has long been discussed; but more recently the question of whether this association is accounted for by cognitive capital has received considerable attention, including in the British birth cohorts. Following work in the British 1970 cohort, we investigated childhood cognition in relation to six health outcomes in mid-life, linked to risk of cardiovascular disease in the British 1946 cohort. These outcomes were smoking, physical exercise, healthy dietary choice, obesity, hypertension and non insulin-dependent diabetes, at or by age 53 years. Childhood cognition was associated with all of these outcomes, although for all except exercise and healthy diet this was fully mediated by educational attainment and partially so by adult socio-economic attainment. Cognitive capital plays a role in the accumulation of risk for chronic physical disease in mid-life, but it is not a sufficient determinant of this risk and does not account for the association between education and health outcomes related to this risk.
\end{abstract}

\section{Introduction}

It has long been known that educational attainment is associated with health and survival. Schooling directly builds human capital including expertise, personal control and social support (Ross and Mirowsky, 1999) and structures other components of socio-economic status SES, such as occupational status and income (O'Rand 2001; Mirowsky and Ross 2003), all of which promote and protect health. Education may also mediate the effects of early life adversity, or material and sociocultural resources from the family, on mental health (Blane, 2003).

These processes are also thought to be generated by cognitive capital'; indeed, cognitive ability predicts educational attainment (Deary et al 2007), to the extent that it has been argued to be the "fundamental" cause of these educational effects on health (Gottfredson 2004). However, cognitive capital and education are not simply interchangeable determinants in this respect. Cognitive ability is almost certainly a more sensitive marker of underlying physiological processes that regulate health, than educational attainment. For example the autonomic, immune and major endocrine systems, all target neural networks that support higher mental function; thus early cognition may act as an indicator of "system integrity" (Whalley and Deary 2001). It is also substantially genetically determined (Plomin 1999), in ways that are pleiotropic for physical health systems (Deary et al 2009). Conversely, education is capable of influencing health in ways that are not accounted 
for by intelligence quotient IQ and can itself boost cognitive skills independently of prior ability (Snow and Yallow 1982; Hernstein and Murray 1994; Richards and Sacker 2003; Hatch et al 2007a). Schooling socialises the individual for success in adulthood by developing 'non-cognitive' or 'soft' skills such as self-regulation (Duckworth et al 2009, Duckworth and Schoon 2010), although in the current educational environment of assessment and accountability, these broader aspects of learning are in danger of becoming de-emphasised in favour of academic curricular achievement (Duckworth and Schoon, 2010). Educational attainment also provides a readily-identifiable signal (Rosenbaum et al 1990) or credential (Collins 1979) for selection into the labour market. Social position thus achieved in turn, enables access to the collective resources of a community, including those based on its aggregate cognitive capital over and above any returns expected to individual ability (Link and Phelan 2008). Thus cognition may be an important marker of biological pathways to health, whereas education may better represent social pathways. On this basis childhood IQ may be independently associated with health-related outcomes that closely reflect neural function, such as the degenerative dementias and mental health, whereas education and SES may be stronger determinants of chronic physical diseases of ageing (Richards et al 2009). If so, then a 'fundamental cause' approach is unlikely to represent the complex dynamic interplay between cognition, education and adult socio-economic achievement in their determination of health and health inequalities.

Childhood cognition has been investigated as a predictor of a range of health-related outcomes in the adult British birth cohorts (Tables 1 and 2). It can be seen that childhood cognition is associated with a wide range of outcomes, but that for most health behaviours and for cardiovascular risk factors, education or adult SES act as mediating links. Exceptions were seen in the direct associations between childhood cognition and risky alcohol intake, symptoms of anxiety and depression and markers of physiological function ( $\mathrm{FEV}_{1}$ [forced expiratory volume in one second], timing of the natural menopause and cortisol activity). 
Table 1. Published studies on health behaviours in relation to childhood cognition in the adult British birth cohorts

$\begin{array}{llll}\text { Outcome } & 1946 \text { cohort (age } 53 \text { years) } & 1958 \text { cohort (age 33-45 years) } & 1970 \text { cohort (age 30-34 years) }\end{array}$

\begin{tabular}{|c|c|c|c|}
\hline Smoking & ----- & $\begin{array}{l}\text { Inversely associated; mediated by } \\
\text { education and maternal age } \\
\text { (Gale et al 2009) }\end{array}$ & $\begin{array}{l}\text { Inversely associated; mediated by } \\
\text { education and maternal age } \\
\text { (Gale et al 2009a) }\end{array}$ \\
\hline & & & $\begin{array}{l}\text { Inversely associated; mediated by } \\
\text { SES (Batty et al 2007a) }\end{array}$ \\
\hline Alcohol & $\begin{array}{l}\text { Positively and independently } \\
\text { associated with being CAGE } \\
\text { positive (Hatch et al 2007b) }\end{array}$ & $\begin{array}{l}\text { Inversely associated with non-drinking } \\
\text { and binge-drinking; mediated by SES } \\
\text { (Jefferis et al 2008) }\end{array}$ & $\begin{array}{l}\text { Positively and independently } \\
\text { associated with intake and being } \\
\text { CAGE positive (Batty et al 2008) }\end{array}$ \\
\hline Exercise & ----- & ----- & $\begin{array}{l}\text { Positively associated; mediated by } \\
\text { SES (Batty et al } 2007 \mathrm{~b} \text { ) although } \\
\text { independent for intense exercise }\end{array}$ \\
\hline Dietary choice & ----- & ---- & $\begin{array}{l}\text { Positively associated with healthy } \\
\text { intake; part-mediated by SES } \\
\text { (Batty et al 2007b) }\end{array}$ \\
\hline & & & $\begin{array}{l}\text { Positively and independently associated } \\
\text { with vegetarian diet } \\
\text { (Gale et al 2007) }\end{array}$ \\
\hline
\end{tabular}


Table 2. Published studies on mortality and health-related outcomes in relation to childhood cognition in the adult British birth cohorts

\section{Outcome}

1946 cohort (age 53-60 years)

1958 cohort (age 33-46 years)

1970 cohort (age 30 years)
Mortality

Inversely associated with mortality up to age 60 in

men; mediated by SES

(Kuh et al 2004 ${ }^{1}$ )

Hypertension

Inversely associated; mediated by education and SES

(Richards et al 2009)

Obesity

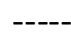

Diabetes

Metabolic

syndrome

(ATPIII criteria)
Not associated with non-fasting glycosolated haemoglobinal

(Richards et al 2009)

Inversely associated; mediated

by education and SES

(Richards et al 2009)
Inversely associated with mortality mortality to age 46; part-mediated

by SES (Jokela et al 2009)

Inversely associated; part-mediated by education (Power et al 2010)

Inversely associated; mediated by education and diet (Chandola et al 2006²)

Inversely associated; mediated by education and health behaviours (Power et al 2010)

Inversely associated; analyses not adjusted for education or adult SES

(Olsson et al 2008)
Inversely associated; mediated by education (Batty et al 2007a)

Inversely associated; mediated by education (Batty et al 2007a) 
Table 2 (continued)

\section{Outcome}

1946 cohort

Inversely and independently

associated in women

(Hatch et al 2007b)

anxiety and

depression

Lung function

$\left(\mathrm{FEV}_{1}\right)$

Positively and independently

associated (Richards et al

2005)

Menopause

Timing

Endocrine function

(cortisol)
Positively and independently associated (Richards et al $1999^{3}$ )
1958 cohort

Inversely and independently associated (Gale et al 2009b)

Inversely and independently associated (Gale et al 2009b)

\section{0 cohort}

Positively associated with level

(mediated by education in males) and

change (mediated by education)

(Power et al 2008)

\footnotetext{
${ }^{1}$ See also Kuh et al 2009

${ }^{2}$ Obesity assessed at ages 16, 23, 33 and 42 years

${ }^{3}$ See also Kuh et al 2005
} 
Some discrepancies can be observed in the findings for alcohol and diabetes. Regarding the former, the study of Jefferis et al (2008), using the 1958 cohort, stands out as being the only one showing an inverse association between childhood cognition and potentially harmful intake; but this was the only study to capture the pattern of binge drinking; and this association was in any case mediated by SES, unlike the positive associations in the 1946 and 1958 cohorts. Cross-cohort comparisons for diabetes are more difficult, because the 1946 cohort study used a biomarker rather than clinical diagnosis; the 1958 cohort study did not control for education or adult SES; and the 1970 cohort study was inadequately powered for this outcome.

The aim of the present study was to fill several of the gaps in Tables 1 and 2 by testing childhood cognition in the 1946 cohort in relation to risk of cardiovascular disease, as indicated by self-reported smoking, physical exercise, dietary choice and measured hypertension and obesity. Findings for hypertension were briefly reported in the 1946 cohort at age 53 (Richards et al 2009) and are revisited in greater detail here and are supplemented by a measured obesity outcome. Our working hypothesis, based on studies summarised in Tables 1 and 2, was that associations between childhood cognition and these outcomes are mediated by educational attainment, which is part-determined by cognitive ability yet provides unique influences on disease risk. Thus we hypothesised that cognition is an important but not sufficient cause of cardiovascular disease risk.

\section{Method}

\section{The 1946 birth cohort}

The Medical Research Council National Survey of Health and Development (NSHD, henceforth the 1946 cohort; Wadsworth et al 2006) was originally established to investigate the cost of childbirth and the quality of associated care in the immediate post-war years. A sample of 5,362 , comprising all single births within marriage to families of nonmanual and agricultural occupation and a random one in four sample of single births within marriage to families of manual occupation, was recruited from all births registered in one week of March 1946 in England, Wales and Scotland. Follow-ups have been completed 21 times, with the major data-sweeps in adulthood conducted at ages 26, 36, 43 and 53 years, when sample size during the latter follow-up was 3,050 . At this age the cohort was shown to be a representative sample, in most respects, of the UK population singly born within marriage in the immediate post-war era. Exceptions were an over-representation among those not interviewed of social disadvantage, medical vulnerability and relatively poor cognitive development.

\section{Health-related outcomes Lifetime smoking}

Lifetime cigarette smoking was classified as 'predominantly no' or 'predominantly yes', based on information at ages 20, 25, 31, 36, 43 and 53 years. From age 36 onwards this information was collected by trained research nurses during home interviews; at the earlier ages this was based on postal questionnaires. At each age, smoking was dichotomised into yes or no regardless of quantity; those classified as 'predominantly no' were nonsmokers for at least three data collections; those classified as 'predominantly yes' were smokers for at least four data collections.

\section{Physical exercise}

At 53 years, survey members were asked if, in the past four weeks, they had taken part in any sports or vigorous leisure activities, or performed any exercises in their spare time (not including travelling to and from work). The outcome was simply classified as yes or no.

\section{Dietary choice}

Dietary intake was assessed by five-day diary at age 43 years (Price et al 1995). All food and drinks consumed both at and away from home were recorded in the diaries, including brand names of food products, food preparation methods and recipes used. Participants were asked to record the amount eaten in household measures, with guidance notes and photographs provided in the diary to assist in estimating portion size (Prynne et al 2005). From this information, an overall score representing level of healthy food choice was derived, by summing scores for four separate criteria: 1 . consumption of breakfast (no/some/all days); 2. type of milk (from whole only to skimmed only); 3 . type of bread (from white only to wholemeal only); 4. number of daily portions of 
fruit and vegetables. The total score was subject to a median split to represent low versus high (energy dense/nutrient poor versus healthier) dietary choice. A measure of total energy derived from fat was also available from this source.

\section{Hypertension at 53 years}

Hypertension at age 53 years was defined as a measured blood pressure of $130 / 85 \mathrm{mmHg}$ or more, on second reading at this age, or use of antihypertensive medication. Blood pressure was measured by trained nurses using calibrated OMRON 705 CP sphygmomanometers.

\section{Obesity at 53 years}

Presence or absence of obesity at age 53 years was based on height and weight, measured by trained nurses according to standard protocol. Obesity was defined as a body mass index (BMI) of $30 \mathrm{~kg} / \mathrm{m}^{2}$ or more. Abdominal circumference and waist-hip ratio were also obtained at this time, according to standard protocol.

\section{Diabetes by age 53 years}

Presence or absence of Type 2 (non-insulindependent) diabetes by age 53 years was based on self-report and information about medication. Diabetes diagnosed under age of 20 years was assumed to be Type 1 and any woman, whose diabetes was diagnosed within a year of the birth of one of her children, was reviewed for possible gestational diabetes.

\section{Childhood cognition}

Four tests devised by the National Foundation for Educational Research (NFER) were used at age 11 years; 1 . General cognitive ability, assessed by a verbal and non-verbal test, where participants were asked to select an appropriate word or shape to complete 80 different series, yielding scores for Verbal Intelligence and Non-Verbal Ability; 2. Word Reading (ability to read and pronounce 50 words); 3. Vocabulary (ability to explain the meaning of the same 50 words); 4. An Arithmetic Test, comprising 50 addition, multiplication, subtraction and division sums. To derive a global measure of cognitive ability at this age, these four separate scores were standardised to a mean of 0 and a standard deviation (SD) of 1 ; these scores were then summed and re-standardised. These standardised scores were used for regression analyses, whereas the raw scores were used for univariate analyses and for descriptive purposes.

\section{Potential confounders}

Following work on the 1970 cohort we selected the following potential confounders:

\section{Occupational social class of origin}

Socio-economic status (SES) of origin was represented by father's social class at age 11 or, if unknown, at age 4 or 15 years. This was classified as professional managerial intermediate, skilled non-manual skilled manual semi-skilled manual or unskilled, according to the UK Registrar General's Classification of Occupations (Office of Population Censuses and Surveys 1970).

\section{Mother's education}

Mother's education was dichotomised to primary school only and secondary school or any training/qualifications.

\section{Educational attainment}

The highest educational qualification attained by 26 years was classified as no qualification, below ordinary secondary qualifications, ordinary secondary qualifications (' $O$ ' levels and their training equivalents), advanced secondary education (' $A$ ' levels and their equivalents), or higher education (degree level or equivalent).

\section{Occupational social class at age $\mathbf{5 3}$ years}

Own occupational social class at 53 years, or earlier if this was unknown, was classified according to the Registrar General (as for social class of origin).

\section{Income at 53 years}

Net household income at age 53 years was defined as the total of own and partner's net earnings, any state benefits and any other sources of income including pensions and interest and contributions from other members of the household. This total was grouped into seven levels with roughly equal numbers of survey members in each.

\section{Statistical analysis}

Logistic regression was used to test the association between childhood cognition and the health-related outcomes. Following work based on the 1970 cohort, unadjusted odds ratios were initially obtained, then adjusted in turn for sex and each of the above potential confounders, then for all potential confounders simultaneously. All multilevel potential confounders (i.e. all except sex and mother's education) were entered into the analyses as categorical variables. 


\section{Results}

For each outcome, those with missing data had significantly lower childhood cognition than those with this information ( $p<0.001$ for all outcomes except for diabetes, where $p=0.001$ ).

Table 3 shows means for the raw childhood cognition score for presence and absence of each outcome. As expected, those who were predominantly smokers and who had measured hypertension or obesity, had significantly lower cognitive scores than those who were predominantly non-smokers and who did not have hypertension or obesity; those who engaged in physical exercise at 53 years and chose a healthy diet at 43 years, had significantly higher childhood cognitive scores.

Table 3. Means and standard deviations (SD) for childhood cognition against the outcomes

N Mean (SD)

p

Lifetime smoking to $53 y$

Mostly no

Mostly yes

Any exercise at $53 y$

No

Yes

Healthy diet at $43 y$

No

Yes

Hypertension at 53y

No

Yes

Obesity at $53 y$

No

Yes

Diabetes by 53 years

No

Yes $\begin{array}{lll}1332 & 146.1 \quad(37.5)\end{array}$

$\begin{array}{llll}777 & 134.2 & (40.9)\end{array}$

$<0.001$

$1070 \quad 131.2 \quad(40.1)$

$1115 \quad 151.3 \quad(35.8)$

$<0.001$

$\begin{array}{lll}752 & 136.4 & (39.1)\end{array}$

$\begin{array}{llll}741 & 154.1 & (35.0)\end{array}$

$<0.001$

$1062 \quad 144.3 \quad(38.2)$

$\begin{array}{llll}1082 & 138.4 & (40.0) & 0.001\end{array}$

$\begin{array}{lll}1636 & 143.3 \quad(38.5)\end{array}$

$\begin{array}{llll}523 & 135.4 & (41.0) \quad<0.001\end{array}$
Table 4 shows associations between the five outcomes and the six potential confounders. Females were significantly more likely to be predominantly non-smokers, to choose a healthy diet and to be normotensive; however, they were less likely to engage in exercise and more likely to be obese at 53 years. Non-manual social class (of origin and own in mid-life), advanced education and higher income were mostly significantly associated with lower cardiovascular risk in regard to each of the six outcomes. The single exception was the association between income and hypertension, which was not significant at the $5 \%$ level. 
Table 4. Descriptive statistics for outcomes against each covariate

\begin{tabular}{|c|c|c|c|c|c|c|c|c|c|c|c|c|}
\hline & \multicolumn{2}{|c|}{ Smoking } & \multicolumn{2}{|c|}{ Exercise } & \multicolumn{2}{|c|}{ Healthy diet } & \multicolumn{2}{|c|}{ Hypertension } & \multicolumn{2}{|c|}{ Obesity } & \multicolumn{2}{|c|}{ Diabetes } \\
\hline & No & Yes & No & Yes & No & Yes & No & Yes & No & Yes & No & Yes \\
\hline Gender (\% female) & 51.9 & 46.3 & 51.8 & 47.5 & 43.6 & 57.1 & 56.6 & 42.1 & 48.2 & 53.2 & 49.6 & 51.5 \\
\hline $\begin{array}{l}\text { Father's social class } \\
\text { (\% non-manual) }\end{array}$ & 46.0 & 34.5 & 33.1 & 50.0 & 34.6 & 54.9 & 46.8 & 37.2 & 44.5 & 32.1 & 42.2 & 25.0 \\
\hline $\begin{array}{l}\text { Mother's education } \\
\text { (\% with qualifications) }\end{array}$ & 40.7 & 32.3 & 29.3 & 45.9 & 32.0 & 47.5 & 40.4 & 35.6 & 39.6 & 31.7 & 38.2 & 25.0 \\
\hline $\begin{array}{l}\text { Education } \\
\left(\% \text { advanced }^{1}\right)\end{array}$ & 42.0 & 25.2 & 23.4 & 47.9 & 27.9 & 49.0 & 38.1 & 33.5 & 38.1 & 28.3 & 36.3 & 19.1 \\
\hline $\begin{array}{l}\text { Mid-life social class } \\
\text { (\% non-manual) }\end{array}$ & 73.5 & 54.3 & 55.4 & 76.9 & 58.4 & 77.5 & 70.2 & 62.3 & 68.7 & 58.9 & 66.8 & 51.5 \\
\hline $\begin{array}{l}\text { Income at } 53 \text { years } \\
\text { (\% higher) }\end{array}$ & 48.0 & 29.2 & 30.3 & 51.1 & 33.2 & 48.9 & 42.7 & 39.6 & 42.5 & 36.7 & 41.5 & 23.5 \\
\hline
\end{tabular}

All comparisons significant at $5 \%$ except for hypertension in relation to earnings and gender in relation to diabetes.

${ }^{1}$ ' $A$ ' level qualification or higher.

Tables 5 and 6 summarise the associations between childhood cognition and the six outcomes, represented as odds ratios (OR) per 1 SD increase in cognitive score. Childhood cognition was significantly associated with all outcomes at the $5 \%$ level.
However, only two of these associations, physical exercise and health diet, were still significant after full adjustment for all the covariates. 
Table 5. Odds ratios and 95\% confidence intervals representing the effect of a 1 SD increase in childhood cognitive score on engagement in three mid-life health behaviours

\section{Predominantly a lifetime} smoker

\section{Unadjusted}

Gender

Parental SES

Own education

Mid-life social class

Mid-life income

All
$0.74(0.68,0.81) p<0.001$

$0.74(0.68,0.81) p<0.001$

$0.79(0.71,0.87) p<0.001$

$0.98(0.87,1.10) p=0.70$

$0.87(0.79,0.97) p=0.01$

$0.82(0.75,0.91) p<0.001$

$1.08(0.95,1.22) p=0.22$
Physical exercise at 53 years

$\begin{array}{ll}1.74(1.59,1.91) \mathrm{p}<0.001 & 1.68(1.50,1.88) \mathrm{p}<0.001 \\ 1.75(1.60,1.92) \mathrm{p}<0.001 & 1.69(1.51,1.90) \mathrm{p}<0.001 \\ 1.56(1.41,1.73) \mathrm{p}<0.001 & 1.48(1.30,1.67) \mathrm{p}<0.001 \\ 1.36(1.21,1.52) \mathrm{p}<0.001 & 1.28(1.11,1.47) \mathrm{p}=0.001 \\ 1.48(1.33,1.64) \mathrm{p}<0.001 & 1.49(1.32,1.70) \mathrm{p}<0.001 \\ 1.58(1.43,1.73) \mathrm{p}<0.001 & 1.56(1.38,1.76) \mathrm{p}<0.001 \\ 1.22(1.07,1.38) \mathrm{p}=0.002 & 1.16(1.00,1.35) \mathrm{p}=0.05\end{array}$

\section{Healthy dietary choice at $\mathbf{4 3}$} years $^{1}$

\footnotetext{
${ }^{1}$ Dietary choice representing frequency of breakfast, type of milk, type of bread and number of daily portions of fruit and vegetables (odds of greater than median total score,
} representing healthy choice) 
Table 6: Odds ratios and 95\% confidence intervals representing the effect of a 1 SD increase in childhood cognitive score on mid-life hypertension and obesity risk

\section{Hypertension at 53 years}

\author{
$0.86(0.79,0.94) \quad p<0.001$
}

$0.86(0.79,0.94) p=0.001$

$0.91(0.83,1.00) p=0.06$

$0.89(0.80,0.98) p=0.02$

$0.86(0.79,0.95) \quad p=0.002$

$0.95(0.85,1.07) p=0.43$
$0.91(0.82,1.02) \quad p=0.11$

Obesity (BMI $\geq 30 \mathrm{~kg} / \mathrm{m}^{2}$ ) at 53 years

\begin{tabular}{|c|c|c|c|c|c|c|}
\hline Unadjusted & $0.86(0.79,0.94)$ & $p<0.001$ & $0.82(0.74,0.90)$ & $p<0.001$ & $0.78(0.62,0.99)$ & $p=0.04$ \\
\hline Gender & $0.86(0.79,0.94)$ & $p=0.001$ & $0.82(0.74,0.90)$ & $p<0.001$ & $0.78(0.62,0.98)$ & $p=0.04$ \\
\hline Parental SES & $0.91(0.83,1.00)$ & $p=0.06$ & $0.90(0.81,1.00)$ & $p=0.06$ & $0.88(0.68,1.14)$ & $p=0.33$ \\
\hline Own education & $0.91(0.82,1.02)$ & $p=0.11$ & $0.95(0.84,1.08)$ & $p=0.41$ & $1.00(0.74,1.35)$ & $p=0.98$ \\
\hline Mid-life social class & $0.89(0.80,0.98)$ & $p=0.02$ & $0.88(0.79,0.98)$ & $p=0.02$ & $0.94(0.72,1.23)$ & $p=0.66$ \\
\hline Mid-life income & $0.86(0.79,0.95)$ & $p=0.002$ & $0.85(0.76,0.94)$ & $p=0.001$ & $0.94(0.73,1.19)$ & $p=0.59$ \\
\hline All & $0.95(0.85,1.07)$ & $p=0.43$ & $1.01(0.88,1.16)$ & $p=0.86$ & $1.14(0.83,1.57)$ & $p=0.41$ \\
\hline
\end{tabular}

Diabetes by age 53 years

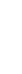

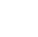

8


For all outcomes except hypertension, adjusting for education had the largest attenuating effect for a single covariate and this alone reduced associations for smoking, hypertension, obesity and diabetes to non-significance. Childhood SES had relatively little effect on the associations with health behaviours, but father's social class also reduced the associations with hypertension, obesity and diabetes to non-significance. The next most important covariate in this respect was mid-life social class, although income had relatively little attenuating effect, except on odds of diabetes. Associations between childhood cognition and abdominal circumference and waist-hip ratio, were similar to those for obesity (data not shown). The association between childhood cognition and obesity was not explained by the exercise or dietary choice outcome variables.

In the fully adjusted analyses, variables remaining in the models at the $5 \%$ significance level were educational attainment and mid-life social class and income for smoking and exercise; childhood cognition and education for healthy diet (with a stronger effect size for education); social class for hypertension and obesity (childhood and mid-life for the former, childhood only for the latter); and income only for diabetes.

For healthy diet, when percent total energy derived from fat was substituted for type of milk, results were broadly similar for all analyses, except that education attenuated the association to nonsignificance and that, for this reason, the association between childhood cognition and healthy diet was no longer significant in the fullyadjusted model.

\section{Discussion}

In this study we investigated cardiovascular risk factors as health returns to childhood cognitive capital in the 1946 birth cohort. This is a topic that has received increasing attention in recent years (see, for example, special edition, Intelligence 2009, volume 37 , number 6 ), although the precise relative contributions of cognition, education and socioeconomic attainment to long-term health outcomes are still a matter of controversy. We found that childhood cognition was significantly associated with six cardiovascular risk factors: lifetime smoking, mid-life physical exercise and dietary choice, mid-life hypertension and obesity and Type
2 diabetes up to mid-life. However, for all these outcomes except exercise and healthy diet, this association was mediated by education and SES, with education playing the stronger role in this respect. These results are broadly consistent with those from the British 1958 and 1970 cohorts (Chandola et al 2006; Batty et al 2007a, 2007b; Gale et al 2009; Power et al 2010).

We should highlight the disproportionate loss to follow-up in this cohort of those of lower cognitive ability in childhood; this limits the generalisability of our findings, although data imputation in a related study suggests that this would not have significantly altered the pattern or strength of these associations (Richards et al 2009). To set against this, the major strengths of this study are the national sampling frame, the large sample and the availability of prospective life course data.

With this in mind, how should the present results be interpreted? Childhood cognitive capital is an important determinant of education (Deary et al 2007), which in turn structures adult social position (Mirowsky and Ross 2003), with multiple consequences for health (Link and Phelan 2008). So while cognitive capital is demonstrably not a sufficient cause of long-term health variation, it might be argued that it is 'fundamental' (Gottfredson 2004), in that it 'sets in motion' this 'chain of events' (Chandola et al 2006) that drives health. Yet even this is only a partial truth. To begin with, the latter authors themselves note that the chain probably begins in early life (ibid) and while this raises the role of genetic influence, cognition is also at its most malleable at this stage of the life course (Deary et al 2009). Moving further along the chain, Chandola et al (2006) also note that education is capable of having an effect on health that is independent of childhood cognition. Indeed, education is capable of augmenting cognition itself, independently of prior ability (Snow and Yallow 1982; Hernstein and Murray 1994; Richards and Sacker 2003; Hatch et al 2007a). There are compelling reasons why education influences health independently of cognitive capital. Schooling teaches specific knowledge, teaches practical skills, refines other cognitive skills and shapes confidence, motivation and self-regulation (Kohn and Slomczynski 1993), all of which are important for self-management of health. This is not purely a matter of 'input' (Rutter 1985); as well as having a clear focus on academic goals and effective use of 
classroom management, teaching and motivational techniques, schools that successfully promote academic achievement tend to encourage student participation in and responsibility for, the running of school life (ibid). Education also provides a readily identifiable credential (Collins 1979), or signal (Rosenbaum et al 1990), that enables employers to select the individual into the workforce and onto an adult SES trajectory.

As noted, we found that social class of origin attenuated associations between childhood cognition and hypertension and obesity to nonsignificance and that these effects remained independent in the fully-adjusted models for these two outcomes. Such attenuating effects of childhood social class on associations between childhood cognition and these two outcomes were not found in the 1958 cohort (Power et al 2010), or the 1970 cohort (Batty et al 2007a). Further work is necessary to determine the reasons for this discrepancy. It may be, for example, that early childhood material home conditions in manual occupational households in the 1946 cohort, which were generally poorer than those in the early years of the 1958 and 1970 cohorts, had a greater longterm impact on health. In this context it should be noted that the 1946 cohort were born during a severe housing shortage, when overcrowding was common, only $57 \%$ of families in 1946 had their own bathroom and $51 \%$ had running hot water (Wadsworth 1991). Furthermore, serious childhood infectious diseases such as diphtheria, lobar pneumonia, poliomyelitis and whooping cough were more common in this cohort than in later years (ibid).

The two outcomes in this study where the association with childhood cognition was robust to the potential confounders, were healthy diet and physical exercise. Reasons for the former are unclear, although they are consistent with the findings of Gale et al (2007) for childhood cognition in relation to vegetarian diet. We should note that education had a strong mediating effect when percent total energy derived from fat was substituted for type of milk in the summary score, although this does not strictly represent dietary choice. Our finding for exercise is consistent with that of Batty et al (2007a) in the 1970 cohort for intense physical exercise. How may the latter apparent independent association be interpreted? From a health behaviour perspective, it is not immediately obvious why childhood intelligence would directly predict engagement in exercise but not avoidance of smoking. However, given the long-term stability of physical activity patterns (Kuh and Cooper 1991) and given the enhancement of neural growth processes by physical exercise (Cotman et al 2007), the possibility of reverse causation occurring relatively early on in the life course cannot be ruled out at this stage.

Even allowing these exceptions of diet and exercise, we do not argue that adult health returns to cognitive capital are all mediated by education and SES, or driven by early life influences, or indeed that cognitive capital only plays a minor role in determining health disparities. We have previously suggested that cognition is likely to exert its strongest influence when the health outcomes in question most closely reflect the functioning of the central nervous system (Richards et al 2009). Above all, this concerns risk of cognitive decline and dementia (Whalley et al 2006), since cognition itself strongly tracks across the life course (Deary et al 2000; Plassman et al 1995; Snowdon et al 1996), even when the influence of education and father's and own occupation are controlled (Richards and Sacker 2003); and it influences rate of cognitive decline (Richards et al 2004). In this context, independent associations were also observed in the British birth cohorts between cognitive capital and affective symptoms (Hatch et al 2007b; Gale et al 2009b), which involve many neural systems common to cognition. Cognition may also act uniquely as a marker for biological programming, as it almost certainly does in the case of natural menopause timing (Richards et al 1999), where not only is the association highly robust, but is stronger the earlier cognition is measured in childhood (ibid). On the other hand associations appear to be more readily explained by education and SES when the outcomes concern risk of chronic physical diseases in ageing. Further work is required to elucidate the detailed factors underlying this mediation, although it seems unlikely that another single 'fundamental cause' (such as health self-management or 'literacy') will be uncovered further downstream; more likely there will be an aggregate effect of schooling, occupational exposures, lifestyle, individual amenities and the macro-level influence of neighbourhood, all layered over the long-term impact of genetic and early life factors. We should be wary of simplification in other ways too; 
Richards et al (2005) found that childhood cognition had a robust independent association with FEV1, which predicts chronic lung disease; whereas associations with the more overt biomarker of cortisol activity were partly or wholly mediated by education (Power et al 2010). These findings will be important to revisit as the birth cohorts move towards later life.

\section{Acknowledgements}

The authors are all funded by the Medical Research Council. We are grateful to the Nuffield Foundation for funding the original seminar series on which this article was based.

\section{References}

Batty GD, Deary IJ, Schoon I and Gale CR. (2007a) Mental ability in relation to risk factors for premature mortality in adult life: the 1970 British Cohort Study. Journal of Epidemiology and Community Health, 61, 997-1003.

Batty GD, Deary IJ, Schoon I and Gale CR. (2007b) Childhood mental ability in relation to food intake and physical activity in adulthood: the 1970 British Cohort Study. Pediatrics, 119, e38-45.

Batty GD, Deary IJ, Schoon I, Emslie C, Hunt K and Gale CR. (2008) Childhood mental ability and adult alcohol intake and alcohol problems: the 1970 British cohort study. American Journal of Public Health, 98, 2237-2243.

Blane D. (2003) Explanations of the difference in mortality risk between different educational groups. International Journal of Epidemiology, 32, 355-356.

Chandola T, Deary IJ, Blane D and Batty GD. (2006) Childhood IQ in relation to obesity and weight gain in adult life: the National Child Developmental (1958) Study. International Journal of Obesity, 30, $1422-1432$.

Collins R. (1979) The credential society: an historical sociology of education and stratification. Academic Press, New York.

Cotman CW, Berchtold NC and Christie LA. (2007) Exercise builds brain health: key roles of growth factor cascades and inflammation. Trends In Neurosciences, 30, 464-472.

Deary IJ, Whalley LJ, Lemmon H, Crawford JR and Starr JM. (2000) The stability of individual differences in mental ability from childhood to old age: follow-up of the 1932 Scottish Mental Survey. Intelligence, 28, 49-55.

Deary IJ, Strand S, Smith P and Fernandes C. (2007) Intelligence and educational achievement. Intelligence, 35, 13-21.

Deary IJ, Johnson W and Houlihan LM. (2009) Genetic foundations of human intelligence. Human Genetics, 126, 215-232.

Duckworth K, Akerman R, MacGregor A, Salter E and Vorhaus J. (2009) Self-regulated learning: a literature review. www.learningbenefits.net/Publications/ResRepIntros/ResRep33intro.htm

Duckworth K and Schoon I. (2010) Progress and attainment during primary school. Longitudinal and Life Course Studies, 1, 223-240.

Elliott J and Shepherd P. (2006) Cohort profile: 1970 British Birth Cohort (BCS70) International Journal of Epidemiology, 35, 836-843.

Gale CR, Deary IJ, Schoon I and Batty GD. (2007) IQ in childhood and vegetarianism in adulthood: 1970 British cohort study. British Medical Journal 334 (7587), 245.

Gale CR, Johnson W, Deary IJ, Schoon I and Batty GD. (2009a) Intelligence in girls and their subsequent smoking behaviour as mothers: the 1958 National Child Development Study and the 1970 British Cohort Study. International Journal of Epidemiology, 38, 173-181.

Gale CR, Hatch SL, Batty GD and Deary IJ. (2009b) Intelligence in childhood and risk of psychological distress in adulthood: the 1958 National Child Development Survey and the 1970 British Cohort Study. Intelligence, 37, 592-599.

Gottfredson LS. (2004) Intelligence: is it the epidemiologists' elusive "fundamental cause" of social class inequalities in health? Journal of Personality and Social Psychology, 86, 174-199.

Hatch SL, Feinstein L, Link B, Wadsworth MEJ, Richards M. (2007a) Continuing benefits of education: adult education and mid-life cognitive ability in the British 1946 birth cohort. Journal of Gerontology Series B, 62, S404-S414. 
Hatch SL, Jones PB., Kuh D, Hardy R, Wadsworth MEJ and Richards M. (2007b) Childhood cognitive ability and adult mental health in the British 1946 birth cohort. Social Science and Medicine, 64, 22852296.

Hernstein RJ and Murray C. (1994) The bell curve: intelligence and class structure in American life. p 591, table, The Free Press, New York.

Jefferis BJ, Manor $\mathrm{O}$ and Power C. Cognitive development in childhood and drinking behaviour over two decades in adulthood. Journal of Epidemiology and Community Health, 62, 506-512.

Jokela M, Batty GD, Deary IJ, Gale CR and Kivimaki M. (2009) Low childhood IQ and early adult mortality: the role of explanatory factors in the 1958 British birth cohort. Pediatrics [epub ahead of print].

Kohn M and Slomcznski KM. (1993) Social structure and self-direction. A comparative analysis of the United States and Poland. Blackwell, Cambridge, MA.

Kuh D and Cooper C. (1991) Physical activity at 36 years: patterns and childhood predictors in a longitudinal study. Journal of Epidemiology and Community Health, 46, 114-119.

Kuh D, Richards M, Hardy R, Butterworth S and Wadsworth MEJ. (2004) Childhood cognitive ability and deaths up until middle age: a post-war birth cohort study. International Journal of Epidemiology, 33, 408-413.

Kuh D, Butterworth S, Kok H, Richards M, Hardy R, Wadsworth MEJ and Leon D. (2005) Childhood cognitive ability and age at menopause: evidence from two cohort studies. Menopause, 12, 475-82.

Kuh D, Shah I, Richards M, Mishra G, Wadsworth MEJ and Hardy R. (2009) Do childhood cognitive ability or smoking behaviour explain the influence of lifetime socio-economic conditions on premature adult mortality in a British post war birth cohort? Social Science and Medicine, 68, 1565-1573.

Langenberg C, Kuh D, Wadsworth MEJ, Brunner E and Hardy R. (2006) Social circumstances and education: life course origins of social inequalities in metabolic risk in a prospective national birth cohort. American Journal of Public Health, 96, 2216-2221.

Link BG and Phelan JC. (2008) The resources that matter: fundamental social causes of health disparities and the challenge of intelligence. Journal of Health and Social Behavior, 49, 367-84.

Mirowsky J and Ross CE. (2003) Education, social status and health. Aldine de Gruyter, New York.

O'Rand A. (2001) Stratification and the life course: the forms of life-course capital and their interrelationships. In RH Binstock and LK George. eds. Handbook of aging and the social sciences. pp 197-213. Academic Press, San Diego.

Office of Population Censuses and Surveys (1970) Classification of occupations. HMSO, London.

Plassman B, Welsh K, Helms M, Brandt J, Page W and Breitner J. (1995) Intelligence and education as predictors of cognitive state in late life: a 50-year follow-up. Neurology, 45, 1446-50.

Plomin R. (1999) Genetics and general cognitive ability. Nature, 402 (6761 Suppl.), C25-C29.

Power C and Elliott J. (2005) Cohort profile: 1958 British birth cohort (National Child Development Study) International Journal of Epidemiology, 35, 34-41.

Power C, Li L and Hertzman C. (2008) Cognitive development and cortisol patterns in mid-life: findings from a British birth cohort. Psychoneuroendocrinology, 33, 530-539.

Power C, Jefferis BJ and Manor O. (2010) Childhood cognition and risk factors for cardiovascular disease in mid-adulthood: the 1958 British birth cohort study. American Journal of Public Health, 100, 129136.

Price GM, Paul AA, Key FB, Harter AC, Cole TJ, Day KC et al. (1995) Measurement of diet in a large national survey: comparison of computerised and manual coding in household measures. Journal of Human Nutrition and Diet, 8, 417-428.

Prynne CJ, Paul AA, Mishra GD, Greenberg DC and Wadsworth MEJ. (2005) Changes in intake of key nutrients over 17 years during adult life of a British birth cohort. British Journal of Nutrition, 94, 368-376.

Richards M and Deary IJ (2010) Children and cognitive capital: an introduction. Longitudinal and Life Course Studies, 1,197-200.

Richards M, Kuh D, Hardy R and Wadsworth MEJ. (2009) Lifetime cognitive function and timing of the natural menopause. Neurology, 1999, 52, 308-14.

Richards M and Sacker A. (2003) Lifetime antecedents of cognitive reserve. Journal of Clinical and Experimental Neuropsychology, 25, 614-24.

Richards M, Hardy R and Wadsworth MEJ. (2003) Does active leisure protect cognition? Evidence from a national birth cohort. Social Science and Medicine, 56, 785-92.

Richards M, Shipley B, Fuhrer R and Wadsworth MEJ. (2004) Cognitive ability in childhood and cognitive decline in mid-life: longitudinal birth cohort study. British Medical Journal 328, 552-4.

Richards M, Strachan D, Hardy R, Kuh D and Wadsworth MEJ. (2005) Cognitive ability and lung function in a longitudinal birth cohort study. Psychosomatic Medicine, 67, 602-608.

Richards M, Black S, Mishra G, Gale C, Deary IJ and Batty GD. (2009) IQ in childhood and the metabolic syndrome in middle age: extended follow-up of the 1946 British birth cohort study. Intelligence, $37,567-572$. 
Rosenbaum JE, Kariya T, Settersen R and Maier T. (1990) Market and network theories of the transition from high school to work: their application to industrialized societies. Annual Review of Sociology, 16, 263-299

Ross CE and Mirowsky J. (1999) Refining the association between education and health: the effects of quantity, credential and selectivity. Demography, 36, 445-460.

Rutter M. (1985) Family and school influences on cognitive development. Journal of Child Psychology and Psychiatry, 26, 683-704.

Snow RE and Yalow E. (1982) Education and intelligence. In R. J. Sternberg ed. Handbook of human intelligence. Cambridge University Press, Cambridge.

Snowdon DA, Kemper SJ, Mortimer JA, Greiner LH, Wekstein DR and Markesbery WR. (1996) Linguistic ability in early life and cognitive function and Alzheimer's disease in late life. Findings from the Nun Study. Journal of the American Medical Association, 275, 528-32.

Wadsworth MEJ, Kuh D, Richards M and Hardy R. (2006) Cohort profile: the 1946 National Birth Cohort (MRC National Survey of Health and Development) International Journal of Epidemiology, 35, 49-54.

Whalley $\sqcup$ and Deary IJ (2001) Longitudinal cohort study of childhood IQ and survival up to age 76 . British Medical Journal 322, 1-5.

Whalley $\sqcup$, Dick FD and McNeill G. (2006) A life-course approach to the aetiology of late-onset dementias. Lancet Neurology, 5, 87-9.

\section{Endnotes}

'For a discussion of this term see Richards and Deary, this issue. 


\title{
Cognitive capital: the case for a construct
}

\author{
John Bynner \\ Institute of Education, London \\ Michael Wadsworth \\ Honorary Senior Scientist, MRC Unit for Lifelong Health and Ageing \\ J.Bynner@ioe.ac.uk
}

This Special Issue confirms the value of working across birth cohorts in the investigation of a key theoretical construct in child and adult development. From what was a very compressed analysis programme to support a seminar series,' the papers presented here are not only highly informative and challenging in their own terms, but provide the foundations of continuing research. We start with terminology then move to research findings and the methodological issues they raise. Conclusions follow and next research steps.

\section{Concepts and measures}

The terms 'cognitive function', 'cognition', 'intelligence', 'cognitive ability', 'cognitive capital', "cognitive capability' and 'cognitive reserve' are distinctive, but as is clear from their use in the papers in this Special Issue, they overlap. Moreover with the exception of Richards and Deary's introductory paper on cognitive capital in the British birth cohorts (this issue) and Richards, Stephen and Mishra's paper (this issue) on health returns to cognitive capital, none make any specific reference to cognitive capital as such. They are, however, implicitly working with the idea in the analyses they report. The seminar series, of which the papers formed a part, served a valuable purpose in highlighting some of the ambiguities in conceptualisation and terminology common in this area (Lerner 2002). The seminars also demonstrated the value of longitudinal data collected from birth cohorts starting at different times, in helping to illuminate the defining features of cognitive capital and its uses.
The key term where problems arise is that of cognitive ability, almost synonymous with, but still distinct from, intelligence. The former has The connotations of a personal attribute identified with performance, particularly on cognitive tests. Traditionally, exploratory factor analysis, and more recently, structural equation modelling, have been used to identify and operationalise the deeper ('latent') construct of Intelligence - also referred to as ' $G$ '. There is, as Richards and Deary make clear, a long tradition in psychology stemming back to the work of Galton (1869) and Spearman (1927) that seeks a biological basis for such a variable, either in single or multiple forms. This is less the case for cognitive ability, cognitive capability and especially cognitive capital and its associated outcomes in examination performance and qualifications, where the focus moves along the continuum from physiology to the learned attributes through which cognitive development is manifest. At this stage, cognitive capital can be usefully conceptualised as an accumulating asset derived from those aspects of cognitive functioning concerned with such developing faculties as memory, attention, perception, problem solving and mental imagery which can be drawn upon to create, and take advantage of, opportunities to sustain wellbeing in response to environmental challenge and stress (Henry 2004).

Notably, Schoon (this issue) operationalises the latent variable ' $G$ ' by means of two measures of verbal and non-verbal ability collected at age 10/11 in the 1946 cohort study, a single measure comprising these two components, in the 1958 study, and selected 
British Ability Scales in the 1970 study. Her identification and measure of ' $G$ ', is validated by structural equation modelling. The measurement of intelligence is sometimes achieved in this way, or directly from one test of reasoning such as Raven's' Progressive Matrices or the Stanford-Binet Intelligence test, or again, in line with Schoon's approach, for the 1970 cohort study, by assessment from a set of skills or abilities such as the British Ability Scales from which 'general ability' (G) or intelligence (IQ) can be derived.

The biological basis of $I Q$ is where controversy has raged, principally about the extent of its heritability or genetic origins. Richards and Deary (this issue) refer to 30 per cent of the variance that can be accounted for genetically from ability tests, free of the learning involved in the acquisition of educational skills of the reading and maths kind. They also point to a cohort shift revealing much less stability in performance on cognitive tests than was originally thought. Moreover, survey evidence across the across the world suggests that average levels of IQ test performance are rising (Arbuckle et al 1998; Emanuelson and Svenson 1990; Wadsworth 1991; Flynn 1987, 1999) pointing to the impact of education in stimulating cognitive development.

It is notable that the expectations of Galton and his followers, that genetically based $G$ would be manifested in measures of psychophysical attributes such as reaction time and visual acuity, correlated with each other and with educational success, failed to be borne out. It was not until cognitive skills of central important in education such as verbal reasoning, were used at the beginning of the $19^{\text {th }}$ century in France in the design of the Binet-Simon intelligence test, and validated by educational performance as assessed by teachers, that the expected correlations were established (Richardson and Bynner 1984).

Nevertheless when it comes to practical value and use in education in particular, teachers will typically tend to hold to the idea that ability, as measured by tests, in some way defines a genetic endowment effect which sets limits on what a child is capable of doing educationally, and this in turn tends to downplay the extent to which modifications are possible (c.f. Caspi et al 1996). We might say that the traditionally divided English school system based on levels of ability - e.g. Grammar, Technical and Secondary Modern was founded on such an understanding of the limitations on cognitive development.

In contrast, the cognitive capital conception stresses the importance of supplying continuing open learning opportunities to enhance ability throughout life. This is, of course, given the right learning conditions and the individual motivation to take advantage of them with the help of an effective teacher and strong family support (Douglas 1964; Werner 1989; Pilling 1990). Such effectiveness is hampered by the material conditions of children's lives. Sutherland shows in her paper 'Setting the Scene' (this issue) how these improved radically as wartime receded, and how government investment to match employer demands expanded education opportunities on a massive scale. Partly in response to the changing labour market and the take up of education in response, the class structure also shifted, with the declining manual working class jobs giving way to the expanding white collar and professional jobs that formed the middle class.

The British birth cohort studies starting in 1946 reflected these changes. For example, pre-school educational provision was meagre in the early post-war years, parental education was poor and nutrition was controlled by food rationing. Opportunities in further and higher education, and consequently in occupation and earnings, were limited (also see Blane; Wadsworth, this issue). By the 1970s, when the third study began, all these influential circumstances had changed, as reported in "Changing Britain, Changing Lives", which compares the members of the first three birth cohorts' situations in their early 30s (Ferri, Bynner and Wadsworth 2003). In the most recent studies - the Avon Longitudinal Study of Parents and Children (ALSPAC), begun in 19911992, and the Millennium birth cohort study begun in 2000-2001 - the shifts have continued, though not on quite the same scale or in quite the same form as in the earlier studies.

Cognitive capital in line with other forms of non-monetary capital - human capital, social 
capital, emotional capital - is thus an asset to be acquired rather than a fixed attribute embedded in the human organism at conception. Describing such an asset, arising from cognitive functioning, as 'capital' has important and illuminating connotations missing from the psychologists' alternative, ' $G$ '.

As a form of 'capital', cognitive capital meets the requirements of that term (Schuller, Bynner and Feinstein 2004). It is invested, e.g. in educational attainment through the efforts, initially, of parents and subsequently by children themselves. It is also transferable from teacher to learner and contributes to stocks that have value such as qualifications in the labour market. It is also fungible, that is to say one form of cognitive capital can be transformed into another, e.g. cognitive into human or social capital. It is distributed unequally in the general population and it generates educational returns in terms of educability, employability, earnings, health and citizenship. This is not to say that there is no biological component in the attributes involved in accumulating it, simply that the emphasis on capital growth and deployment of capital to produce rewards may be seen as offering a more tangible construct in life course terms, than notions of "fixed" ability and "intelligence".

The idea of ability separable and prior to attainment appeals to many researchers, of which economists are a notable example, because it offers the possibility of an exogenous variable, i.e. rooted in genetic endowment, that can be conditioned out of the relationship between say, exposure to different curricula and outcomes in terms of earnings. Such an assumption is implicit in Schoon, Schoon and Duckworth, Schoon and colleagues' and Richards, Stephen and Mishra's papers (this issue). Economists Gregg and Macmillan (this issue) are in this case the exception in using early measures of cognitive ability in the more recent child cohorts as the best approximation to educational attainment as revealed by qualifications. The attraction of Schoon's use of structural equation modelling (this issue) is that it not only controls for, but uses for explanatory purposes, the endogeneity that economists particularly want to remove.
Richards, Stephen and Mishra deploy similar reasoning from previous research, based on the earliest cohorts and their own research, using 1946 cohort study data, to identify the importance of educational achievement as a predictor of good health and resistance to cognitive and physical decline in old age.

The seminar series started with concepts and usage in education, then moved sequentially through the different stages of life, concluding finally with overall appraisal and next steps. The different papers add significantly to our understanding of the changing nature of cognitive capital both with age and across time. What does the stage by stage analysis tell us?

\section{Early years}

Schoon and colleagues (this issue) use the Millennium Cohort Study, with data collected up to age 3 , to show that the experience of maternal stress in the first two years of life disrupts good parent/child relations. These are central to the foundations of cognitive development as reflected in 'school readiness'. The relationship between economic conditions and cognitive outcomes has been long established and continues (e.g. Feinstein 2004). It may in part be by maternal stress resulting from original hardship. Prolonged experience of stressful conditions in childhood can disrupt physical growth (Widdowson 1951; Montgomery et al 1997). The important contribution here from Schoon et al is to show that, taking account of economic conditions, parental stress adds to, rather than removes, the problems infants have in acquiring cognitive skills such as word recognition and number concepts. Economic hardship does not account wholly for the critical effect of parental stress, which itself is influenced by poverty; rather there is a direct and indirect connection between economic conditions and children's cognitive outcomes. Notably, the pathways are slightly different for behavioural adjustment outcomes where the relationship with maternal stress is stronger, than with cognitive development. 


\section{From childhood to adolescence}

In Duckworth and Schoon's paper (this issue) on the role of cognitive skills and selfregulation in educational progress through primary school, the focus shifts from the parental effect on children's cognitive growth, as reflected in maternal stress, to the child's developing non-cognitive attributes. Their analysis of the rich ALSPAC data, collected annually from birth to fourteen, shows the important role of 'inattention' and 'external locus of control', less so 'poor self-esteem', in impeding the acquisition of cognitive skills. They also find a weakening of the effects of family circumstances by the end of primary school in some groups. It seems that family circumstances are critically important at the earliest stages of life in predicting cognitive performance later on. Such an effect becomes less apparent with age, as the whole psychological make-up of the individual, including cognitive function, and the impact of the wider social environment on that make-up, begin to take more permanent shape. In cognitive capital terms, the research also suggests that educational attainment - more typically described in the early years as educational ability - gains from a combination of factors of which the cognitive component is only one of many that enable individual children to 'buck the trend'. In other words non-cognitive factors, of which attention is the prime example, are revealed as increasingly important in educational attainment, not least because these attributes chime in with the 'hidden school curriculum' concerned with personal and social development.

\section{Adolescence to adulthood}

In the following paper (Schoon, this issue) the focus shifts again, this time to the impact of the social and policy context on the whole educational trajectory up to adulthood (age 26) via the examination of the accumulation of cognitive capital across the 1946, 1958 and 1970 birth cohorts. The notable finding here, in line with earlier structural equation modelling of 1958 and 1970 cohort data (Bynner 1998), is that from the earlier to the later cohorts there is a declining effect of family social class on cognitive development, as a range of other factors, non-cognitive and social, play an increasing part in determining the long-term outcome. Importantly, an improvement in educational participation and a reducing gender gap in attainment are also shown.

Schoon's analysis reveals very well the challenges to be met in this kind of crosscohort comparison because of the changing forms of measurement, both within cohorts to reflect age differences, but particularly across them. Strong assumptions are needed to be sure that we are in fact comparing like with like, which the latent variable approach through structural equation modelling that she employs, can resolve only to a limited extent. The paper displays excellent applications of validation approaches in assuring us that comparisons are legitimate. But as with every other use of evidence of this kind the analysis cannot stand entirely alone. It needs to be continually reinforced through triangulation with evidence from other sources and the evolving policy framework as discussed in Sutherland's paper (this issue), where reducing educational inequalities is a dominant theme. The more cognitive capital becomes detached from social class, for example, the more we can become convinced that policy has moved in the direction of enhancing social mobility and the more important it becomes at the same time to reduce educational inequality. Policy makers and practitioners need to be constantly aware that other attributes are also playing a part in the production of such mobility and inequality, and are also critically important in determining their outcomes.

\section{Income and Qualifications}

The most ambitious cross-cohort analysis is that from Gregg and Macmillan (this issue) in their investigation of the impact of family income on cognitive ability and educational attainment. Educational attainment is assessed through standard educational attainment tests for the most recent cohorts, together with English public examinations - GCE, O Levels, A Levels and university degrees for the earlier ones. They use not only the 1946, 1958 and 1970 birth cohorts for the investigation, but also the British Household Panel Study - Waves 1, 2, 3 for which ability tests are used as surrogates for educational attainment tests and the Longitudinal Study of Young People in 
England (LSYPE), where such tests are also used alongside qualifications. They show that equality of opportunity and outcomes in educational attainment increased across successive cohorts. They also demonstrate again the weakening relationship of family income to achievement across successive cohorts and when earlier socio-economic circumstances and educational performance (and cognitive ability) data are taken into account.

Validation of the measures used is another important feature of their paper, with comprehensive robustness checks applied across cohorts for the income measures used and assessment of biases due to sample attrition in the longitudinal surveys. The latter shows remarkably good maintenance of representativeness of the samples involved.

\section{Beginnings of cognitive decline}

Finally we move to mid-life functioning and the risk factors for the diseases of old age where Richards, Stephen and Mishra (this issue) using the 1946 cohort study, whose members are now in their mid-60s, investigate the relationship between cognitive capital and health outcomes. They make the useful distinction between on the one hand, the protective value of early cognitive functioning in relation to degenerative diseases of the nervous system such as Alzheimer's where the physiological components help to build 'cognitive reserve' and on the other, cognitive capital, as assessed by ability tests, which is linked more closely to such health outcomes as cardiovascular disease risk. Their main focus is on the latter, demonstrating that cognitive ability relates specifically to a range of physical conditions predicting risk of cardiovascular disease: smoking, physical exercise, unhealthy dietary choice, obesity, hypertension and noninsulin dependent diabetes. They also show that the long-term effect of cognitive capital, as measured by cognitive ability (IQ) tests, in moderating these risk factors is mediated by educational achievement.

\section{Conclusion}

The analyses answer some questions about the significance of cognitive capital in life course construction but leave many issues still to be resolved. Elucidating the role of biological (including genetic) factors in cognitive functioning and development continues to be a challenge, as does the impact of changing policy frameworks on their realisation through the growth of cognitive capital as a factor in achievement in all spheres of life. The development of further methods for assuring equivalence and robustness of the measures used, and for assessing and compensating for, by means of weighting and such methods as multiple imputation attrition bias, are other areas where significant research advance is needed. Appreciating fully the limitations of the cohort study data in cross-cohort analysis, and how to optimise their potential for work of this kind, requires a much more extended period of screening, testing and new variable construction than was possible for the research reported on this issue. The analyses were all completed in a relatively short period of time to meet the demands of a seminar timetable; hence the necessary test evaluation and variable development and data adjustment prior to analysis could be undertaken only to a limited extent.

Such work in future will inform not only existing analyses but particularly those to come, using the new data due to be collected in the earlier studies and especially in the relatively new studies, such as the Millennium cohort study and the prospective new birth cohort study due to begin in 2012. This latter study is expected to embrace a range of additional dimensions for understanding early cognitive functioning, its conversion into cognitive capital and its realisation through later beneficial outcomes. These dimensions include the relational factors in families that enhance or impede the development of such functions and also in the community via social settings such as the peer group. The relational inputs into child development raise further questions about the ecological impact of the local physical and social environment, which requires the development of a multi-level framework for analysis - from local education authority to the school, the community and the family.

The papers reinforce the case for cognitive capital as embracing those attributes associated with cognitive functioning, which are central to cognitive capacity and adaptive capability in later life. Such functioning is observable early on in life and the faculties it embraces - including, memory, attention, problem solving and mental imagery as 
assessed by tests - continue to develop through adolescence and adulthood, before levelling-off and starting to decline in old age. Their significance in educational performance extends further to life chances in relation to occupation and income, health and wellbeing, and functioning more generally, during the working years. The demonstrated protective value of cognitive capital through the medium of cognitive reserve also makes the case for investment in continuing adult learning and effective health education through to old age, as a form of resistance to cognitive decline (Richards and Deary 2005).

On a more technical front, the papers also show that the tasks of the kind deployed by psychologists in diagnostic ability tests, also tapping into intelligence, are little different in most respects from elements of the standard attainment tests, which measure educational outcomes at various educational stages. Viewing these test performances in terms of accumulating cognitive capital, identifies them more closely with 'educational progress' and the foundations of educational capability - that is to say the educational competences needed to achieve personal and community goals (Sen 1992). In contrast, traditional conceptions of intelligence, as measured by ability tests, have tended to see it as rooted in the relatively fixed biological nature of the individual, comparable more to height than an accumulating capital resource. In heurist and practical terms, there is much to be said for a term that reflects more fully the dynamics of life course development, and the exercise of human agency in a social context.

The papers also show the potential of the valuable national resource of the birth cohort and other large-scale longitudinal studies, for both policy and academic research. Their value lies not only in their wide-ranging data over many years of life, but also in their location in different historical periods (Wadsworth and Bynner, in press). This latter characteristic makes it possible to allow not only for policy change, but also for the changing effects of aspirations and expectations among children and by parents and society for children, from the pre-school years onwards.
The papers suggest the need for a review of longitudinal data resources in two areas in particular: the aim would be to discover new resources and synthesize findings so that researchers in this cross-disciplinary area can better understand how to design innovative research. First, is a review of childhood studies that have the capacity to support the investigation of influences on the pre-school development of cognitive capital, including physical growth, and of such self regulation skills as attention, patience, persistence, and impulsivity and their relationship with the family's socio-economic and material circumstances. The second area suggested for review is of studies that yield data comparable with the data used in the papers in this issue, but which have been undertaken in other cultures, with different expectations, aspirations and policies for children. The Scandinavian countries and the US and Canada and New Zealand are, in the short- term, the most likely sources. The expansion of birth cohort studies across the world since the millennium points in time to much wider intercultural research potential.

The inter-cohort analyses presented here are a stimulus for further work. Whilst the direction of new work concerning the equity of changing opportunities is evident, some new directions in the study of outcomes might be appropriate. The nature and effects of parenting by members of the birth cohorts, and in particular their aspirations for their children and their educational choices, can be studied intergenerationally in the 1946, 1958 and 1970 cohorts, using existing data collected on the next generation. In addition, the range of adult outcomes studied could be expanded in three types of area.

First, new studies, comparing across cohorts the nature of adult life for individuals, should be concerned with perceived quality of life outcomes, such as health and well-being and fulfilment in relation to life course goals and how these change with age. A second area of outcomes that could usefully be investigated includes indicators of occupational skills - that is to say, the ways in which high skill levels, intellectual, creative and practical, build upon 
the cognitive capital acquired earlier. Research would also include important questions about the role in the acquisition of these skills of biological aspects of early cognitive functioning and development. A third area of outcome indicators concerns the changing skills requirements of the labour market in relation to the skills acquired by members of the cohorts. The question to be asked is how far the attained skill levels matched labour market needs at specific times, and the role cognitive capital played in facilitating such a match.

The suggested programme is challenging but likely to be rewarding because of the combination of new conceptualisation with ideally targeted research resources for undertaking it. The authors of the papers in this Special Issue are to be commended for their contribution to signposting the way forward.

\section{References}

Arbuckle TA, Maag U, Pushkar D, and Chaikelson JS. (1998) Individual differences in trajectory of intellectual development over 45 years of adulthood. Psychology and Aging, 13, 663-75.

Bynner J. (1998) Education and family components of identity in the transition from school to work. International Journal of Behavioural Development, 22, 29-53.

Caspi A, Harkeness AR, Moffitt TE and Silver PA. (1996) Intellectual performance: continuity and change, in PA Silver and WR Stanton (eds.) Child to Adult. pp 59-74, Oxford University Press, Oxford.

Douglas JWB. (1964) The Home and the School, MacGibbon Kee, London.

Duckworth K and Schoon I. (2010) Progress and attainment during primary school: the roles of literacy, numeracy and self-regulation. Longitudinal and Life Course Studies 1, 223-240.

Emanuelson I and Svensson A. (1990) Changes in Intelligence over a Quarter of a Century. Scandinavian Journal of Educational Research, 34, 171-187.

Feinstein L. (2004) Mobility in children's cognitive development during school life. Oxford Review of Economic Policy, 20, 213-229.

Ferri E, Bynner J, and Wadsworth M. (eds) (2003) Changing Britain, changing lives: three generations at the end of the century. Institute of Education Press, London.

Flynn JR. (1987) Massive IQ gains in 14 nations: what IQ tests really measure. Psychological Bulletin, 95, 29-51.

Flynn JR. (1999) Searching for justice: the discovery of IQ gains over time. American Psychologist, 54. 5-20.

Galton F. (1869) Hereditary Genius: an enquiry into its laws and consequences. Macmillan, London.

Gregg P and Macmillan L. (2010) Family income, education and cognitive ability in the next generation: exploring income gradients in education and test scores for current cohorts of youth. Longitudinal and Life Course Studies 1, 259-280.

Henry P. (2004) Hope, hopelessness, and coping: a framework for class-distinctive cognitive capital. Psychology and Marketing, 21, 375-403.Lerner RM (2002) Concepts and Theories of Human Development. (Third edition). Lawrence Erlbaum, New Jersey.

Lerner R. ( 2002) Concepts and theories of Human Development ( $3^{\text {rd }}$ Edition). Lawrence Erlbaum Associates, Mahwah New Jersey.

Montgomery SM, Bartley MJ and Wilkinson RG. (1997) Family conflict and slow growth. Archives of Disease in Childhood, 77, 326-330.

Pilling D. (1990) Escape from Disadvantage. The Falmer Press, London.

Richards $M$ and Deary IJ. (2005) A life course approach to cognitive reserve: a model for cognitive aging and development? Annals of Neurology, 58, 617-22.

Richards M and Deary IJ. (2010) Cognitive capital in the British birth cohorts: an introduction. Longitudinal and Life Course Studies, 1, 197-200.

Richards M, Stephen A and Mishra G. (2010) Health returns to cognitive capital in the British 1946 birth cohort.

Richardson K and Bynner JM. (1984) Intelligence: Past and future. International Journal of Psychology, 19, 499-526.

Schoon I. (2010) Childhood cognitive ability and adult academic attainment: evidence from three British cohort studies. Longitudinal and Life Course Studies 1, 241-258.

Schoon I, Hope S, Ross A and Duckworth K. (2010) Family hardship and children's development: the early years. Longitudinal and Life Course Studies 1, 209-222. 
Schuller T, Bynner J and Feinstein L. (2004) Capitals and Capabilities, Research Centre for the Wider Benefits of Learning. Discussion Paper No1 http://www.learningbenefits.net/

Sen A. (1992) Inequality Re-examined. Clarendon Press, Oxford.

Spearman, C. (1927) The Abilities of Man. Macmillan, London.

Sutherland G. (2010) Setting the scene. Longitudinal and Life Course Studies 1, 201-208.

Wadsworth MEJ. (1991) The Imprint of Time; childhood, history, and adult life. Clarendon Press, Oxford.

Wadsworth MEJ, and Bynner J. (in press) A companion to life course studies: the social and historical context of the British birth cohort studies. Routledge, London.

Werner EE. (1989) Vulnerability and resiliency: a longitudinal perspective. In M

Brambring, F Lösel and H Skowronek (eds.) Children at Risk: Assessment, Longitudinal Research and Intervention. Walter de Gruyter, Berlin.

Widdowson EM. (1951) Mental contentment and physical growth. Lancet, I, 1316-1318.

\section{Endnotes}

i Supported by the Nuffield Foundation 


\title{
Historical note: early years of the 1946 British birth cohort study
}

\section{David Blane}

Imperial College London and ESRC International Centre for Life Course Studies in Society and Health.

\author{
d.blane@imperial.ac.uk
}

The article by Michael Wadsworth in the previous issue of this journal (Wadsworth 2010) prompted thoughts about the importance to life course studies of social history. Wadsworth demonstrated this relevance in his pioneering volume The Imprint of Time (Wadsworth 1991). The present text adds a little further information about the social history of the parents of the 1946 cohort and the 1946 cohort's early years. The social history of a birth cohort's parents is a relevant, if somewhat neglected topic, because it shapes the ideas and values which surround the cohort during its early years of dependency. At the time the 1946 cohort was born, over 70 per cent of the male population was employed in manual occupations, with them and their families assigned to one of the manual social classes. The present historical note mentions some possibly relevant features of their experience.

The recruits to the 1946 British birth cohort study mostly were conceived during July 1945 , the month in which Attlee's post-war Labour Government was elected, and gestated by mothers who had endured nearly six full years of war. The experience of women during the 1939-1945 war shaped the mental and physical health which the mothers brought to conception and gestation, while the ideas with which they raised their young children were coloured also by their socialisation in the pre-war world and the reality of post-war austerity. Each of these phases presents a complex picture of benefits and hardships, with a woman's likelihood of experiencing one rather than the other being linked to their social class. Working class mothers were most likely to have suffered hardship at one or more points: pre-war; wartime; post-war austerity.

The older mothers of the 1946 cohort had fathers and brothers killed in World War I or crippled by gas or amputation; and often carried rickets from the failure to add vitamin $D$ to the wartime whale oil margarine or heart valve defects from childhood rheumatic fever. All knew of neighbours and kin invalided or dead by respiratory tuberculosis. The ubiquitous out-door toilet ensured that bedrooms smelt of urine from the chamber pot under the bed; and insect infestation in the fabric of poor terraced housing encouraged their inhabitants to sleep in the street during the summer months. High unemployment due to the mass closure of heavy industry in the north and west of Britain was, in time, counter-balanced by new light industry in the midlands and south-east. Routes out of the working class were offered by the merchant marine, police, nursing and teaching, where women had to resign on marriage. Suburban homes, bought on mortgage, were strip-built along Metroland, allowing more space in the centre of cities. The cinema, cigarettes and lipstick brought a new glamour to life. Cycling and motor-bikes allowed escape from locality; truck driving along the developing national road network was an adventure of navigation and machine repair; and crystal wireless brought the international into everyday life. The cruelties of the Poor Law (means testing; break-up of families on entry to Work House; the able-bodied forced to tramp every day to the next Work House) ensured a terror of relying on welfare (Spring Rice 1939; Greenwood 1939; Stevenson 1984).

Total war brought a best-ever approximation to full employment, producing women's wages which enabled the purchase of rationed food, supplemented by the distribution of clothing coupons which could be sold to the more affluent via their domestic servants and, for those with means, food off ration from restaurants and the black market. Growing vegetables and keeping chickens became popular. Family life was disrupted by the evacuation of children, conscription of men, bombardment by aeroplane or prototype intercontinental ballistic missile and, particularly during the Atlantic war and after D-Day, the dreaded killed in action telegram. This drab and rather miserable 
life of long hours of work, sleeping in air-raid shelters, bland diet and constant anxiety, which lasted as long as a person's adolescence, was enlivened by the modest pleasures of friends, wireless, cinema and music (Calder 1969; Kennedy 1989; Titmuss 1950).

The end of the European war in May 1945 and the Pacific war in August 1945 brought transient celebration, an ominous demonstration at Nagasaki and Hiroshima of the threat that would dog the adolescence and early adulthood of the 1946 birth cohort and the onset of a period of post-war austerity which in some respects was harsher than the war-time years.

Within this general context, three aspects of life are examined next in a little more detail.

\section{Health services}

The quality of the antenatal care available to the mothers of the 1946 birth cohort, indeed whether they received any at all, was influenced by their ability to pay, which often was lacking, and by the skewed distribution of General Practitioners: prewar there had been proportionately seven times as many general practitioners in affluent South Kensington as in industrial South Shields (Titmuss $1950,71)$. The condition of the hospitals in which they gave birth varied from terrible to not particularly good. A series of surveys by the Ministry of Health in 1938, in preparation for the war, found in the words of Richard Titmuss: large old-fashioned wards, out-of-date kitchens, poor and insufficient equipment, inadequate or non-existing laboratories, ugly prison-like buildings and old, dilapidated structures (Titmuss 1950, 69-70). Typical was South Wales, where only three out of 141 hospitals had staffed and equipped laboratories (Titmuss 1950, 70). Specialist doctors were thin on the ground; for example, there were no paediatricians in the eastern counties of England (Titmuss 1950, 71). War-time planning and investment improved the situation by tackling the regional maldistribution of medical specialists, via the Emergency Medical Service, and by up-grading the medical infrastructure with some 80,000 new hospital beds in hutted wards, nearly 1,000 new operating theatres, equipped with as many new surgical instruments as had been ordered in the previous 30 years and X-ray machines and pathology laboratories (Titmuss 1950, 83). The post-war National Health Service (NHS) built on these improvements, but came too late for the birth and infancy of the 1946 cohort, who were well into adulthood before the war-time hutted wards joined as relics of the past, the TB sanatoriums and 2,000-plus bedded psychiatric asylums of their youth (DHSS 1975).

In a remarkably prescient discussion of why, despite many hardships, civilian death rates did not deteriorate during the war, and the stillbirth and infant mortality rates in particular improved during 1942-46, Richard Titmuss identified a number of important contextual and life course influences (Titmuss 1950, 537-538). The most relevant aspects of the wartime experience were: full employment, which mitigated food restriction by poverty; policy initiatives such as food rationing, national milk scheme, raising the extraction rate of flour, British restaurants and works canteens; thirdly, good fortune in avoiding epidemic influenza and respiratory disease and typhoid caused by, respectively, crowded bomb shelters and bombdamaged sewers. The life course argument rested on reasoning: It was not an accident that with each succeeding year of the Second World War there was an increasing number of mothers bearing children who had themselves been born and bred in more favourable circumstances than previous generations of mothers (Titmuss 1950, 535), which Titmuss attributed to the secular trends of rising living standards and decline in the number of children per family. Many of these influences continued into the early life of the 1946 British birth cohort.

\section{Social conditions}

By 1945 over two-thirds of national resources were directly employed on work for the Government (Robinson 1951), orchestrated by a civil service which had quadrupled in size and recruited almost every economist and statistician in the land (Hopkins 1951). From their point of view, the nutritional initiatives lauded by Titmuss were meshed with Anglo-American supply agreements, agricultural price controls and war agricultural executive committees, with input from a Scientific Food Policy Committee which advised a Basal Diet consisting largely of wholemeal bread and potatoes, giving a daily adult ration of 2,800 calories (Nash 1951).

Two months before the members of the 1946 birth cohort were conceived, food rations were cut. In ounces per person per week, sugar (8oz), sweets 
(4oz), cheese (2oz), butter (2oz) and margarine $(4 \mathrm{oz})$ remained unchanged from wartime levels, as did milk (2.5 pints per person per week) and eggs (1 per person per fortnight), but cooking fat was cut by $50 \%$ (to 1 oz per person per week), bacon by $25 \%$ (to $30 z$ per person per week) and points from 24 to 20 per person per month: 4 points $=$ tin baked beans; 17 points $=$ small tin spam (Waller 2004).

Disappointment that diet worsened with the end of war, rather than improving as expected, sudden intolerance of endless queuing, coal shortages during the harsh winter of 1945-46 and widespread bomb damage to houses, combined to ensure that the 1946 cohort were not delivered into easy conditions. The wartime diary of George Beardmore, a BBC staff member, for 3 June 1945 (around conception of 1946 cohort) records: Food is scarce. Most days I go to the British Restaurant for a mid-day meal. I suffer from stretches of lassitude, mostly in the evening when I usually like to go gardening. I put it down to deficiency in this or that protein or vitamin (Beardmore 1986, 195); and for 3 March 1946 (around birth of 1946 cohort): Two wretched families have moved into a requisitioned mansion nearby... Have twice visited... A scene of squalor and misery rare even in these days. A bus conductor, two women and three schoolchildren, driven desperate for somewhere to live, camp out in a large dilapidated room without light, water and (yesterday at least) fuel for a fire. Sullen, dirty faces swollen with colds (Beardmore 1986, 200).

The austerity of the 1946 cohort's early childhood years derived from the poor state of Britain's finances at the end of the war: large foreign debts; visible exports at $40 \%$ of pre-war levels; invisible exports, like shipping, much reduced; civilian industry run down after six years of war; the end of Lend-Lease (Calder 1969). Slowly families re-assembled, with demobilisation and the return of evacuated children, often meeting again as virtual strangers. Food rationing and the housing shortage continued into the next decade, with the urban working class particularly affected, and some nutritional categories, cheese, eggs and vegetables, remaining at sub-wartime levels throughout 194649 (Ministry of Food 1951). Many of those returning home were physically or mentally scarred; rehabilitation, prosthetics and plastic surgery for the former were rudimentary, while the latter was largely undiagnosed and untreated. There was a feeling among those returning that the war had stolen their youth (Grafton 1981) and some women among those who had remained were reluctant to resign their paid employment (Sheridan 1990). Improvements came slowly: by the time of the next decennial census, in 1951 when the 1946 cohort were entering primary school, nearly half of all households lacked sole use of a fixed bath; one-infive lacked piped water; $85 \%$ left school at the minimum leaving age of 15 years; and 2.6\% attended university (Carr-Saunders, Caradog Jones and Moser 1958).

\section{Men}

What of the fathers of the members of the 1946 British birth cohort study? Three things stand out from contemporary social studies as potentially relevant (Zweig 1949; Rowntree and Lavers 1951; Zweig 1952). In the main, fathers were little involved in the raising of their children; men's social attitudes were little changed by the wartime experience of we're all in this together; the marked upward social mobility of the post-war generation, from working class to middle class, was not fuelled by their fathers' ambition.

Most men of working age were in paid employment in manual occupations, working 50 hours or more per week, depending on overtime, spread over five-and-a-half or six days; plus travelling from home to work, and back, by bicycle, bus or train for anything up to 90 minutes each way (Zweig 1949; Zweig 1952). Pleasures mostly were outside the home, perhaps driven by residential crowding: tobacco and alcohol in the pub; gambling on greyhounds, horses and football pools; cinema, dancing and sometimes theatre; low grade deviancy, street betting, petty dishonesty, sexual promiscuity (Rowntree and Lavers 1951), with comparatively little involvement in the practice of religion, politics, civic society or adult education; reading and wireless were the main home pleasures (Zweig 1952). These weekly routines, combined with little or no paid holiday, predisposed to limited contact between fathers and offspring.

Ferdynand Zweig, professor of political economy at Cracow University, given wartime refuge by University of Oxford, was puzzled by the attitudes of British workers towards their employers and the wider social order, which he regarded as conservative and constrained by long institutional memories of past grievances and abuses - cotton spinners referring to their strike of 50 years earlier, 
for example. Zweig seems to have assumed that social attitudes would change as a result of full employment, nationalisation and the welfare state, and expected that the post-war economic crisis would produce the same national unity as the war had done. He was a good enough social scientist to recognise that what he found contradicted his assumptions, but failed to consider explanations other than 'long institutional memories'. Some historians (Calder 1969; Grafton 1981; Sheridan 1990) have documented the class-based nature of World War II in Britain; to the extent they are correct, the continuities in social reality from the 1930s through the 1939-45 war to the late 1940s mean that Zweig's findings do not require explanation - the continuity in social attitudes was based on continuity in the social structure.

Zweig (1952) found a working class with fine internal stratification by prestige and hourly rates of pay:

- Casual labourers, often in poor physical or mental health.

- Light labourers, often reserved for the elderly.

- General labourers, loading, unloading, mixing cement.

- Heavy labourers or navvies.

- Craftmen's labourers, a semi-skilled mate.

- Handymen, performing small routine jobs under a craftsman's supervision.

- Semi-skilled men, who increased proportionately with mechanisation.

- Craftsmen, who had completed an apprenticeship of five to seven years.

- Leading hands - craftsmen who set standards in a workshop.

- Sub-foremen and foremen, midway between junior management and workers.

Workers' ambitions for themselves and their children were confined to movement between these strata, with little consideration of movement into the middle class of white-collar workers, via educational qualifications (Zweig 1949; Zweig 1952).

\section{Ruminations}

The preceding brief comments raise three interesting questions. The members of the 1946 British birth cohort were conceived, gestated, delivered and raised through infancy and early childhood in pretty tough conditions, yet they belong to a generation whose current life expectancy at middle age is increasing too fast for the pension system to cope. Has recent research interest in early life been over-done? Perhaps more attention should be given to continuities over the life course such as, for the 1946 cohort, never conscripted to fight a war, working life spent in a full employment economy, steady improvement in the material conditions of life? Second, recent interest in waning rates of social mobility have concentrated on supply side phenomena like parental aspirations and educational opportunity, yet the 1946 cohort achieved historically high rates of social mobility despite low parental aspirations and low rates of further and higher education. Perhaps more weight should be given to demand side phenomena such as, in the case of the 1946 cohort, the creation and expansion of the nationalised industries and the welfare state? Finally, the above summary which gives due weight to working class experience, is somewhat at odds with the structure of the 1946 cohort, with its onein-four sampling of the working class. Given selective attrition out of this 1:4 sample by social deviance and disadvantage, how representative are the surviving cohort members who were born into the working class; how adequate are the standard weighting procedures; what are the size and direction of the biases which may have resulted?

\section{References}

Beardmore G. (1986) Civilians at war: journals 1938-1946. Oxford University Press, Oxford.

Calder A. (1969) The People's War: Britain 1939-45. Jonathan Cape, London.

Carr-Saunders A, Caradog Jones D and Moser C. (1958) A Survey of Social Conditions in England and Wales. Clarendon Press, Oxford.

Department of Health and Social Security. (1975) Health and Personal Social Service Statistics for England.

Table 4.1. HMSO, London.

Grafton P. (1981) You, You \& You: people out of step with World War II. Section 24. Pluto, London.

Greenwood W. (1939) How the Other Man Lives. Labour Book Service, London. 


\section{NOTES, COMMENT AND DEBATE}

Hopkins R. (1951) Introductory note. In: D Chester, ed. Lessons of the British War Economy. Pp 1-4. University Press, Cambridge.

Kennedy L. (1989) War Papers. Fontana, London.

Ministry of Food. (1951) National Food Survey: The Urban Working Class Household Diet 1940-1949. HMSO, London.

Nash E. (1951) Wartime control of food and agricultural prices. In: D Chester, ed. Lessons of the British War Economy. Pp 200-238. Cambridge, University Press, Cambridge.

Robinson E. (1951) The overall allocation of resources. In: D Chester ed. Lessons of the British War Economy. Pp 34-57. University Press, Cambridge.

Rowntree S and Lavers G. (1951) English Life and Leisure. Longmans, London.

Sheridan D, ed. (1990) Wartime Women: a Mass-Observation anthology of the experiences of women at war. Chapter 20. Heinemann, London.

Spring Rice M. (1939) Working Class Wives. Penguin Books, London.

Stevenson J. (1984) British Society 1914-45. Allen Lane, London.

Titmuss R. (1950) Problems of Social Policy: History of the Second World War; United Kingdom Civil Series. Longmans Green, London.

Wadsworth MEJ. (2010) The origins and innovatory nature of the 1946 British national birth cohort study. Longitudinal and Life Course Studies 1, 121-136.

Wadsworth MEJ. (1991) The Imprint of Time, Clarendon Press, Oxford.

Zweig F. (1949) Labour Life and Poverty. Gollancz, London.

Zweig F. (1952) The British Worker. Penguin, London. 


\title{
Response to: 'Historical note: the early years of the 1946 British birth cohort study'
}

\author{
Michael Wadsworth \\ Honorary Senior Scientist, MRC Unit for Lifelong Health and Ageing \\ mejw@btinternet.com
}

My purpose in writing 'The origins and innovatory nature of the 1946 British birth cohort study' (Longitudinal and Life Course Studies 2010 1, 121-136) was to show how the methods used in the first British birth cohort study derived from the research questions current when it began and the methods then used to address them. Those, in turn, affected the design of later British birth cohort studies. David Blane's comments and contributions are valuable because they raise important questions about the research value of information about the social context, which in a longitudinal study can be an historical social context.

Context is of value in focussing and guiding the aims of analysis. The value of social historical knowledge of context is illustrated by the findings of a marked gradient in socio-economic differences in perinatal risk in the second (1958) British birth cohort study, almost the same as had been found in the 1946 study, despite 10 years of the National Health Service. In commenting on those findings Illsley and Kincaid (1963) were particularly concerned with the association of raised perinatal risk with short maternal height. They commented that the mothers of 1958 were born in the less prosperous days of the 1920s and 1930s and if it could be demonstrated that their early experience had left an enduring imprint on their health, this might account in large part for present-day failure to achieve equality of obstetric performance.' In a second example of the importance of social context, Forsdahl (1977) speculated that early poverty might bring about 'a life-long vulnerability' to poor health that could be triggered by new adult exposure to risk, such that 'great poverty in childhood and adolescence followed by prosperity is a risk for arteriosclerotic heart disease.' Barker (1998), Kuh and Ben Shlomo (2004) and others using birth cohort study data, took that idea much further, particularly since it was exactly the experience of the early post-war cohorts. Schooling and Leung (2010) add another perspective by considering populations undergoing economic transition in developing countries. They note that improved living conditions act during the period of physical growth to make those in the first generation who have that experience, more vulnerable to diabetes, which will be most prevalent in the poorest. They hypothesise that the social gradient in diabetes will change once 'most people in the population have several generations of economic development behind them' because of environmentally driven changes in gene expression.

These examples of the value of context depend essentially on having enough detail about the lives of sample populations so that differences between individuals can be used to make a graded scale of exposure to risk. Maternity in Great Britain (Joint Committee 1948), the first book from the 1946 study, and itself a documenting of social history, shows the range of housing and health care experienced in 1946. Blane concentrates on the difficulties of life in the early post-war years and conflates material hardship with other sources of difficulty. There are arguments for conflation, because poor material circumstances are often associated with chronic stress, and it is true that material circumstances of the post-war period were very much worse than those of today. However, partly as a result of rationed diet, there was very little childhood obesity, but the value (but not the dullness) of that diet compared with more recent diets has been shown (Prynne et al 1999). There was in fact even in the earliest post-war years a broad range of socio-economic conditions, and more importantly, probably a great difference in the prevalence and socio-economic distribution of well-being and feelings of stress in comparison with today. The post-war years, despite the austerity, were also times of forward-looking optimism 
(Kynaston 2007). This is an essential point because of the importance of well-being in childhood, and because the 'physiological, cognitive and psychosocial components of capital, well-being and resilience are intertwined over the life course' (Hatch et al 2007).

Blane's arguments for studying early life in the context of what happens later on in life should be welcomed, and as the examples above, and others from the birth cohort studies show, that is currently happening extensively in health studies. His second point about social mobility is also valuable and should take into account the post-war structural social mobility experienced by the parents of the 1946 cohort. In that study, upward social mobility of parents was associated with increased aspirations for and increased educational attainment by their children (Douglas, Ross and Simpson 1968). On his third point, the 1946 study sampled 1 in 4 of the working class because that was proportionally the largest class, and followingup all the 16,695 births from the birth week would have been too expensive and too difficult, given the current data handling technology. His questions on this point are important.

The importance of socio-economic context in research using the five British large-scale birth cohort studies is extensively discussed in Wadsworth and Bynner (forthcoming).

\section{References}

Barker DJP. (1998) Mothers and Babies and Health in Later Life. $\left(2^{\text {nd }}\right.$ edition) Churchill Livingstone, Edinburgh. Douglas JWB, Ross JM and Simpson HR. (1968) All our Future. Peter Davies, London.

Forsdahl A. (1977) Are poor living conditions in childhood and adolescence an important risk for arteriosclerotic heart disease? British Journal of Preventive and Social Medicine 31, 91-95.

Hatch S, Huppert FA, Abbott R, Croudace T, Ploubidis G, Wadsworth M, Richards M and Kuh D. (2007) A life course approach to well-being. In J Haworth and G Hart (eds.) Well-being: Individual, Community and Social Perspectives. Pp. 187-205, Palgrave Macmillan, Basingstoke.

Kuh D and Ben Shlomo Y. (2004) (2 $2^{\text {nd }}$ edition) (eds.) A Life Course Approach to Chronic Disease Epidemiology. Oxford University Press, Oxford.

Kynaston D. (2007) Austerity Britain 1945-1951. Bloomsbury, London

Ilsley R and Kincaid JC. (1963) Social correlates of perinatal mortality. In NR Butler and DG Bonham (eds.) Perinatal Mortality. Pp 270-286. Livingstone, Edinburgh.

Joint Committee (1948) Maternity in Great Britain. Oxford University Press, Oxford.

Prynne CJ, Paul AA, Price GM, Day KC, Hilder WS and Wadsworth MEJ (1999) Food and nutrient intake of a national sample of four-year-old children in 1950: comparison with the 1990s. Public Health Nutrition, 2, 537-547.

Schooling CM and Leung GM. (2010) A socio-biological explanation for social disparities in non communicable diseases: the product of history? Journal of Epidemiology and Community Health, online first, June $1^{\text {st }} 2010$.

Wadsworth MEJ and Bynner J. (eds.) (forthcoming) A Companion to Life Course Studies: the social and historical context of the British birth cohort studies. Routledge, London. 


\section{NEWS, EVENTS AND RESOURCES}

\section{News}

Society for Longitudinal and Life course Studies (SLLS) conference

As reported in the last Issue of the journal, SLLS will become formally established at the Society's inaugural conference, to be held on September 22-24 in Clare College Cambridge, England. To support the conference, Longview, the think tank that initiated the establishment of the Society, joined forces with the European Science Foundation-sponsored EUCCONET (European Child Cohort Network) through which conference costs for many participants are being met. The response to the call for papers to the conference was excellent, with 180 abstracts for symposia, individual papers and posters received. We look forward to a successful meeting which will contribute further to the development of international longitudinal and life course research, providing a forum for collaboration, communication and debate. Future conferences are planned annually with different host countries each time. For further information go to:

wuw.longstudies.longviewuk.com/pages/conference.shtml

\section{Life course changes}

Two members of the LLCS Editorial Board have been appointed to key posts of much significance for longitudinal and life course researchers.
Paul Boyle, currently at St Andrews University, where he is professor of Human Geography, will be taking up, this September, the post of Chief Executive of the UK Economic and Social Research Council (ESRC) the main funder of UK social science research and longitudinal research resources. As Director of the ESRC-funded Longitudinal Studies Centre - Scotland, and the founder of the census-based Scottish Longitudinal Study, much of his career has been in longitudinal research, including writing a major report for ESRC on administrative data linkage. He is also an elected member of the recently established SLLS Executive Committee.

Karl Ulrich Mayer, previously professor of Sociology at Yale University, and emeritus professor at the Max Planck Institute for Human Development in Berlin is taking up, in the autumn of this year, the role of President of the Leibniz Institute for the Social Sciences - GESIS - in Berlin. This is the premier institute in Germany for supplying infrastructure services to the social sciences and conducting research. We are fortunate to have professor Mayer as our first keynote speaker at the SLLS conference in September.

\section{Events 2010}

ESHMS - (European Society of Health and Medical Sociology) $13^{\text {th }}$ Annual Congress, Ghent, Belgium, 26th28th August. Theme: 'Health and Well-Being in Radically Changing Societies'. http://www.eshms.org/Eshmsnews-2010-10-10\%20Ghent\%20Belgium.htm

ALSPAC - (Avon Longitudinal Survey of Parents and Children) Workshop. 'Longitudinal Data Analysis: Multilevel Modelling and Structural Equation Modelling Approaches'. 20-21 September. Bristol University, UK http://www.bristol.ac.uk/alspac-social-sciences/workshops/longitudinaldataanalysis.html

SLLS - (Society for Longitudinal and Life course Studies) Inaugural Conference and General Meeting, Clare College, Cambridge, UK, 22-24 September.

http://www.longstudies.longviewuk.com/pages/conference.shtml

CELSE 2010 - (Conference of Epidemiological Longitudinal Studies in Europe) Paphos, Cyprus, 13th-15th October. http://www.celse.eu/

LHRS Meeting - (Life History Research Society) $14^{\text {th }}-17^{\text {th }}$ October, Montreal, Canada http://crdh.concordia.ca/LifeHistory/ 


\section{NEWS, EVENTS AND RESOURCES}

\section{Events 2011}

SRCD - (Society for Research in Child Development) Biennial Meeting March 31 $^{\text {st }}-$ April $^{\text {nd }}$, Montreal, Canada. http://www.srcd.org

Volunteer Reviewer website http://www.srcd.org/submissions2011/volunteers.

SLLS - (Society for Longitudinal and Life Course Studies) Summer School, July $4^{\text {th }}-8^{\text {th }}$, University of Antwerp, Belgium, particularly for research post-graduates and post-doctoral fellows. Other sponsors include the European Association of Population Studies and CELLO (Centrum voor Longitudinaal en Levensloop Onderzoek - Research Centre for Longitudinal and Life Course Studies), University of Antwerp. Registration opens on 1 Sept 2010 at www.ua.ac.be/cello/summerschool.

\section{Resources}

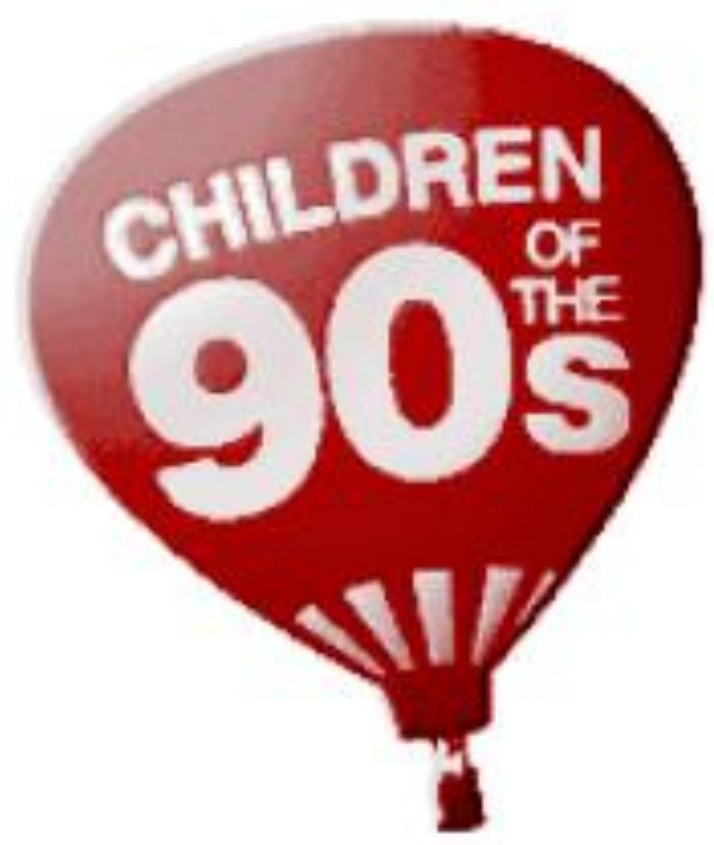

Avon Longitudinal Study of Parents And Children: the Social Science Edge

Eleanor Walsh, Social Scientist, University of Bristol

Now in its $20^{\text {th }}$ year of data collection, ALSPAC has become renowned in health and medical research circles. More recently however, ALSPAC has been recognised as a valuable resource for social science researchers. Geographers, criminologists, sociologists, economists, psychologists and statisticians alike are all using the ALSPAC data resource both within their own disciplines as well as in multidisciplinary research teams.

Not only does the ALSPAC data provide a retrospective look at health, environment and socio-economic factors in the Avon area since the 1990s, researchers are becoming interested in the potential impact of more recent changes in the UK. The impact of the economy on parents and children's employment and education, advances in technology and the "obesity epidemic", are particularly relevant today.

\section{Using ALSPAC data}

Researchers have gained insight into the data that is included in ALSPAC through the information held on the ALSPAC and ALSPAC social sciences websites. Access to the ALSPAC data has become increasingly popular. And the relative ease of the application and approval process has meant that

the number of collaborators has grown dramatically in the last few years. There really are infinite options with the ALSPAC data with many areas of potential research yet untapped. This is not unsurprising given that the ALSPAC data comprises (next page): 


\section{NEWS, EVENTS AND RESOURCES}

\begin{tabular}{|c|c|}
\hline \multicolumn{2}{|c|}{ Self Completion Postal Questionnaires (500000+ received) } \\
\hline \multirow{11}{*}{$\begin{array}{l}\text { Self-report measures of } \\
\text { physical activity } \\
\text { lifestyle } \\
\text { education } \\
\text { occupation } \\
\text { social environment } \\
\text { life events } \\
\text { health } \\
\text { depression \& anxiety } \\
\text { diet }\end{array}$} & Carers - about themselves \\
\hline & \\
\hline & Children - about themselves \\
\hline & \\
\hline & Carers - about their children \\
\hline & \\
\hline & Partners-about themselves \\
\hline & \\
\hline & Puberty - carers \& children \\
\hline & \\
\hline & Teachers \& Schools - about the children \\
\hline Hands on Assessments & ages $7-17$ \\
\hline $\begin{array}{l}\text { Biological Samples } \\
\text { (1 million collected) }\end{array}$ & DNA from over 10,000 young people \\
\hline Direct linkage to Administrative data & School and educational data \\
\hline Linked Datasets & $\begin{array}{l}\text { GIS and other geographic based data, growth } \\
\text { and development trajectories }\end{array}$ \\
\hline \multicolumn{2}{|l|}{ Environmental monitoring } \\
\hline Sub Studies & $\begin{array}{l}\text { GIS techniques to look at environmental } \\
\text { exposure }\end{array}$ \\
\hline
\end{tabular}

- For more information on what the ALSPAC database has to offer, visit www.bristol.ac.uk/alspac.

- To find out how you become an ALSPAC collaborator and use the data available, visit www.bristol.ac.uk/alspac-social-sciences

\section{ALSPAC Social Science User Group}

Many of these researchers are part of the ALSPAC Social Science User Group. This has been set up as part of an Economic and Social Research Council-funded grant. The development of the Social Science User Group aims to raise awareness of the ALSPAC database within the social science community and to encourage and support its usage by researchers. This is currently has over 300 members across the UK and internationally. The broad spectrum of social science research means that there are a wide range of researchers included in this group. Of course, with the inherent overlap between these disciplines, there is a breadth and depth of research interests involved. This user group is entirely collaborative, with those using ALSPAC data being invited to contribute to the project newsletter as a dissemination output for their ALSPAC-based research. For more information about signing up to the mailing list visit: www.bristol.ac.uk/alspac-social-sciences. 